UC-NRLF

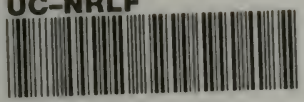

ㄷ $37 \quad 056$

THE A B C OF

PHOTO-MICROGRAPHY

By W. H. Walmstey 


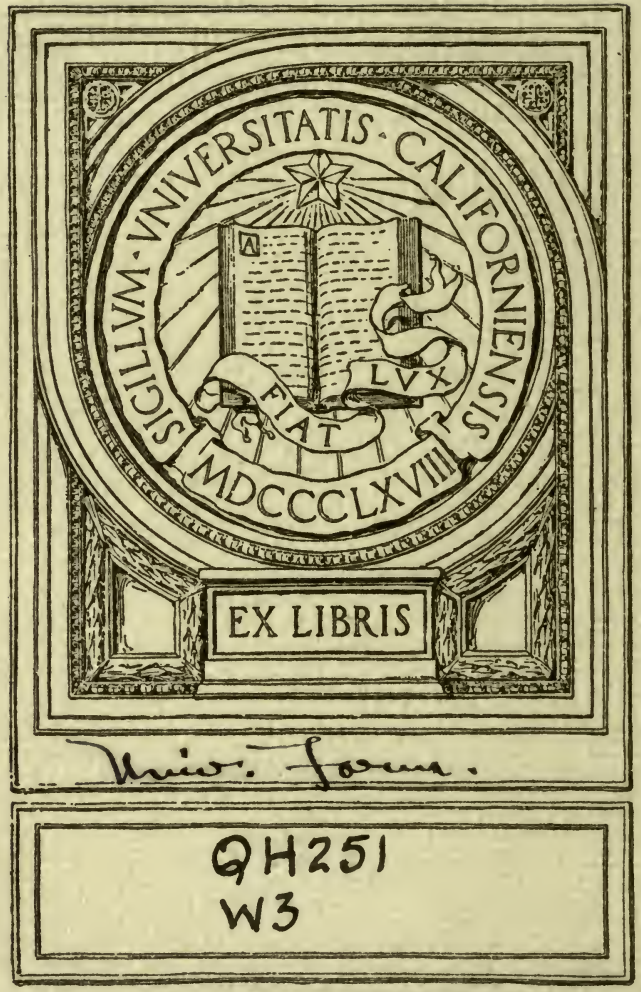

$$
\text { TTRTAT? }
$$

UNIVERSITY F CALIFORNLA

$$
\text { DAVIS }
$$



Digitized by the Internet Archive in 2007 with funding from Microsoft Corporation 





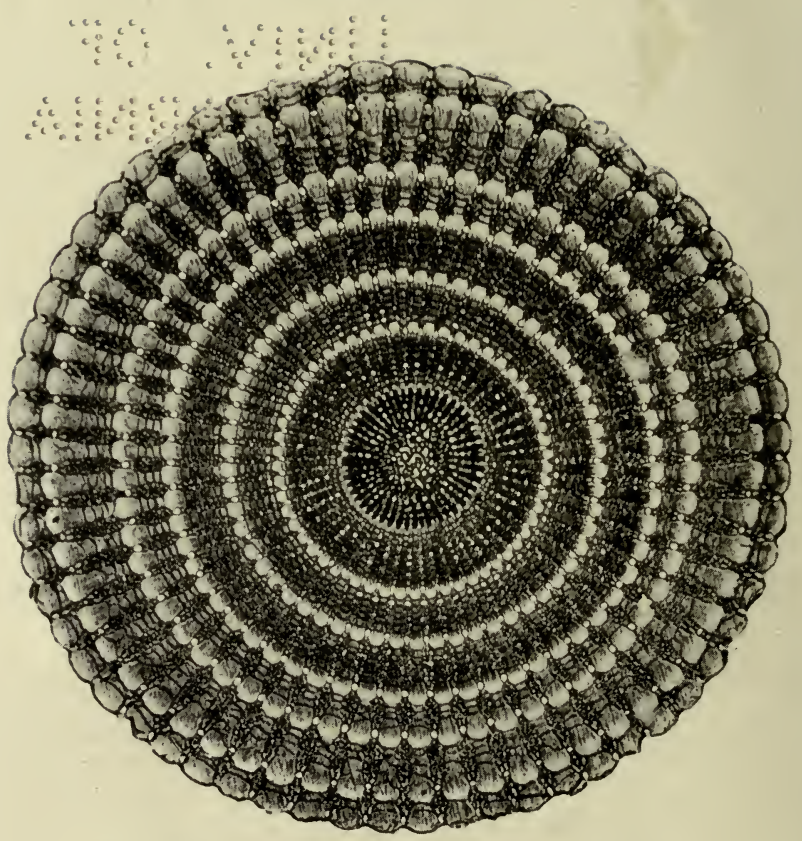

Trans. Section of Echinus Spine. Echinometra lucunter +30 


\title{
THE A B C OF PHOTO-MICROGRAPHY
}

A 放rartiral 弥andinank

far Trgituter

\author{
BY \\ W. H. WALMSLEY, F.R.M.S., F.A.A.A.S. \\ CHARTER MEMBER AMERICAN MICROSCOPICAL SOCIETY, ETC.
}

2iviu Tark

TENNANT AND WARD

1902 


\section{Copyright, 1902 \\ By Tennant $\Xi^{\circ}$ Ward, New York \\ All rights reserved}

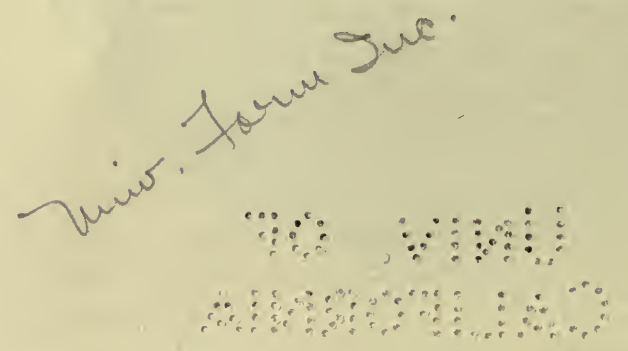

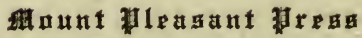

J. HORACE MCFARLAND COMPANY HARRISBURG, PENNSYLVANIA 


\section{PREFACE}

THE only apology I can offer for the being of this little work is a dual one, smacking somewhat of egoism. It had appeared for a long time - to me - that it was needed, and further that I could fill the need. Acting under this belief, or possibly delusion, it has been written; whether successful as to the second proposition, its readers must determine for themselves. There can be no two opinions, however, regarding the first, for it is a matter of fact, that in all the world of books-so far as my researches have extended - there is not one through which a person totally unacquainted with the practical requirements of Photo-Micrography can learn them. There are some fairly elaborate works on the subject, but one and all, assuming their readers to be fully acquainted with the alphabet, as it were, of the science or art, start them at the outset in reading lessons ere they have learned to spell. The result is, that by hard work, much perseverance and many failures alone, can they hope to make acquaintances with the little things of vital importance to be done, or left undone which the books have signally failed to teach.

With keen recollections of my own early struggles and failures, $I$ have in these pages sought to aid the novice, by an earnest endeavor to teach him the A B C of the matter and explain clearly as possible the simple but indispensable methods and manipulations, by which alone he can hope to arrive at any measurable success. The book has 
not been written for advanced scholars, but is simply intended for kindergarten use, as it were. In furtherance of this design, care has been given to explain many things so simple that they would seem to be self-evident to those already familiar with the requirements of Photo-Micrography, but which, alas, are often insurmountable obstacles to the beginner; a feature quite ignored in all the works on the subject which have come under my notice. With this explanation of its scope and purposes, the little work is put forth accompanied by the earnest hope that it may prove to be a useful aid to many an earnest gleaner in the ever-broadening field of Photo-Micrography.

My earnest thanks are due, and herewith expressed, to the many kind friends who have aided my efforts in the "long ago" by precept and practice. Among them I would especially name my old-time friend, Dr. A. Clifford Mercer, of Syracuse, New York, and Dr. Wm. M. Gray, of the Army Medical Museum, Washington, D. C., each of whom has so largely contributed to the advancement of Photo-Micrography, to its present important condition of comparative perfection. My thanks are also due, in like measure, to the publishers, whose liberality, experience and good taste have done so much toward presenting the little volume in its present attractive form. And, I may add in conclusion, that should it meet with the hoped-for approval at the hands of my readers, it will probably be followed by a much fuller and more elaborate treatise on the same subject, which has been in course of preparation for several years.

Philadelphia, Pa.. Fuly 4, 1902. 


\section{CONTENTS}

CHAPTER

I. Introductory - . . . . . . . . . I

II. The Microscope and Optical Apparatus . 8

III. The Camera and Photographic Appliances - 18

IV. The Radiant and Illumination . . . . . 42

V. Negative Making . . . . . . . . 49

VI. Printing Methods - Lantern Slides . . . 98

VII. General Notes . . . . . . . . II9

Description of Plates . . . . . . 145

Index . . . . . . . . . . . . . 149 



\section{ILLUSTRATIONS}

NUMBER

PLATX

Transverse Section of Echinus Spine

- Frontispiece .

I. Student Microscope and Portable Camera. .

2. Adjustable Camera. Upright to Horizontal

3. Walmsley's Enlarging and Reducing PhotoMicrographic Camera . . . . . . .

4. Walmsley's Camera and Microscope, without Ocular. . . . . . . . . . .

5. Walmsley's Camera arranged for Focusing with Microscope . . . . . . •

6. Walmsley's Camera and Microscope arranged for High Powers. . . . . . . .

7. Carcinoma of Mammary Gland . . . .

8. Suctorial Tubes, Tongue of Blow-Fly . .

III

9. Aulacodiscus Oreganus. Diatom

10. Voluntary Muscle. Man . . . . . .

IV

II. Karyokinetic Figure in Leucocyte . . . .

12. Pleurosigma angulatum. Diatom . . . .

II

13. Grouped Anchors and Plates of Synapta . .?

14. Heliopelta euleri. Diatom . . . . . .

VI

15. Diatoms from Cuxhaven . . . . . . . \} VII

16. Cluster Cups; Ecidium . . . . . . . \} VII 


\section{viii}

\section{ILLUSTRATIONS}

NUMBER

17. Starch of Canna Root. Tous le Mois

18. Crystals of Amygdalin .

19. Bacillus tuberculosis in Sputum

20. Bacillus anthracis

21. Streptococcus Pyogenes

22. Bacillus Trommel-Schlägel

23. Corisa undulata

24. Transverse Section, Stem of Serjania

25. Mosquito. Anophele (Female)

26. Human Scalp. Flat Section . . . . . . . XII

27. Lantern Slide, Front. Compound Ovary. . 28. Lantern Slide, Back. Compound Eyes of XIII Beetle 


\section{CHAPTER I}

\section{INTRODUCTORY}

The distinction between a Photo-Micrograph and a Micro-Photograph would seem to have been settled a good many years ago,-fully a quarter of a century, at least, - yet we continually hear the latter name applied indiscriminately to either; an illustration of persistence, it having preceded the former by other long years. As defined by Worcester, however, a Micro-Photograph "is a minute photograph of any subject, so small that its form or details are invisible to the unaided eye, requiring the use of a microscope to see them." A practical illustration of these may be found in the so-called "charms," many of them shaped like a miniature opera-glass, containing a Stanhope lens, to the flat end of which is attached a minute photograph. On holding it to the light and looking into the other end an enlarged picture is seen. The subjects are almost innumerable in variety and interest. They are all made in Paris, I believe. Formerly they were also to be had mounted on a 
slip of microscopic glass, and were used under the microscope; being very favorite objects; and always formed a portion of an amateur's collection of slides. Their manufacture was carried to great perfection in those days. I have one made by Langenheim (a noted Philadelphia photographer), of the Lord's prayer, which is so minute as to be invisible to the naked eye. It requires a magnification of nearly roo diameters to be clearly read, under which, each letter is sharply cut as though done by the stroke of a pen, no granulation of the silver being perceptible. It is a marvelous piece of work, and probably could not be duplicated at the present day. But to return. By the same authority a Pboto-Micrograph is said to be "an enlarged photograph of a microscopic object produced by throwing its image through a suitable combination of microscope and camera." It is the latter class that forms the subject matter of this little volume, and by this means the negatives were made from which the reproductions that illustrate it were produced. My friend, Dr. A. Clifford Mercer, has given probably the most concise definitions of the two terms. He says "a micro-photograph is a microscopic photograph of a macroscopic object. A photo-micrograph 
is a macroscopic photograph of a microscopic object." Macroscopic denotes an object of minute proportions, but visible to the naked eye, or by means of a pocket lens, and does not require the use of a microscope. An enlarged drawing of such an object to the extent of a few diameters is termed a macrograph: if made by the aid of cameras, why not a pboto-macrograph? There is an endless number of such objects, which may be enlarged by the aid of a suitable camera and photographic lens from one to about ten diameters - the limit of a pocket lens of one-inch focus. I have ventured to coin the word photomacrograph in this connection, and descriptions of the method of making them, together with illustrations, will be found in Chapter V, under Negative Making.

It may not be generally known that photomicrographs were made long before $\mathrm{Da}$ guerre's discovery of photography itself, in fact, about one hundred years ago. In 1802 Thomas Wedgwood and Humphry Davyafterwards the celebrated Sir Humphry-made a number of photo-micrographs, or macrographs, by throwing enlarged images of small objects through a solar microscope upon surfaces of paper or white leather sensitized with 
a solution of silver nitrate, which soon faded from not being fixed. There is no record of any further advances in this direction until 1837, when the Rev. J. B. Reade obtained a series of very satisfactory photo-micrographs of insect and vegetable preparations on paper sensitized with an infusion of galls, table salt and silver nitrate. These prints proved to be permanent and of such excellent quality that a ready sale was found for them. The optical work was done with the solar microscope. After Daguerre's discovery of the photographic process to which his name was given, most excellent pictures of microscopic objects were made by it, the oxyhydrogen light being used as the radiant for the first time of which we have any record. A little later Dr. Donnè, of Paris, issued a work on microscopical anatomy, illustrated by photo-micrographs, taken on daguerreotype plates and chemically etched so that they could be printed from in ink. Their excellence was marked, and they were probably the first photo-micrographs ever published as book illustrations.

From that time - more than a half century ago - there has been continual progress in the art, until it has reached an excellence undreamed of, and is universally in use the world 
over by advanced workers in most branches of science. It received its first, and probably greatest advance, through the labors of our own Dr. J. J. Woodward, of the Army Medical Museum in Washington, whose fame was and is world-wide. His work in some directions has never been excelled, although it antedated homogeneous and apochromatic objectives, gelatine dry plates and other appliances now so common and thought to be indispensable for high-class work. Dr. Maddox, of England, recently deceased, gave throughout a notable career of more than half a century, a wonderful amount of help to all workers in photo-micrography. By the aid of the halftone engraving process, faithful and beautiful reproductions are furnished at a nominal cost, and it may be confidently predicted that hereafter no work dealing with any subject requiring the aid of a microscope will be published without being copiously illustrated by photomicrographs, reproduced through the half-tone processes; most likely in trichrometry.

For many years I have been fully convinced of the importance of photo-micrography in educational interests, "and the trend of thought and action in that direction seems to more than justify my opinions. In some of the 
high schools of New York city they are used to the extent of several thousand prints; mostly thus far in illustrating animal histology. Professor Peabody employs them in his classes for comparison by the students with the same subjects under the microscope, finding them to be of the greatest service. He has lately published an interesting sketch of this work. As lantern slides for use on the screen before large classes, their importance has long since been fully established. It is useless for me to urge a point already conceded by many who wholly ignored it less than a decade ago, and it therefore only remains to say a few words as to the scope of this little book and the reasons for its being.

The latter are my firm conviction that every student should, in these days of universal amateur photography, be able to do good photomicrography as well as to push the button of a kodak, and the knowledge that no work on the subject which would teach him the A B C of it is at present in existence. Whether I have succeeded in writing such, time must make manifest. The work is wholly original; there are neither paste nor scissors in its composition. Having carved what little I know of the subject out of actual experience, I have 
endeavored to impart the same to others in the simplest manner possible, and thus save them, perhaps, many an hour of work and experimenting, which I have gone through with unaided. The large standard works of Sternberg, Pringle, Spitta and others, are too learned, too scientific, for the beginner, and therefore of but little use to him. The smaller publications, - all English in so far as I know - are really of much less use, being merely a compilation of "say so's" without any practical value. I earnestly hope such may not be the case with the present little work. It has been written, after several years' labor upon a book of much wider scope on the same subject (yet unpublished), to fill a supposed want, which the latter cannot do. It is written in the first person as being more familiar with, I trust, my sympathetic circle of readers than is possible to the impersonal we. It is sent forth with the earnest hope that in its perusal may be found help for some earnest beginners in the fascinating and important art of photo-micrography. And it is possible that among those who "know it all" there may be a few who will gather a seed or two of further information from the many sown broadcast throughout its pages. 


\section{CHAPTER II}

The Microscope and Optical Apparatus

The primary essentials in photo-micrography are a microscope and a camera, or their equivalents. These may be combined in one instrument, as was actually done in a commercial way by the Atwood Camera-Microscope a number of years ago, but long since discarded "for good and sufficient reasons." There must be a lens to magnify the object and project its enlarged image - either direct or through an eye-piece - upon the sensitized plate, which in turn must be held in position to receive it by a camera or some contrivance answering the same purpose. Of these, the microscope is the more important, since with no camera, however complete in design and workmanship, can one make even a passable photo-micrograph, if the optical portions of his apparatus, - the lenses or objectives,- -are not properly corrected for the work. Almost every one may, at a pinch, construct something that will answer for a camera, but very 
few of us can make a microscope; hence this indispensable must be purchased, and should be selected with the greatest care. Its first cost may be whatever sum one chooses to invest in it: after that, with proper care, its cost for maintenance is nothing. The camera, on the other hand, must be continually supplied with food in the shape of sensitive plates. Between the two, however, the earnest and diligent worker will receive the reward of his labors in the shape of more or less perfect negatives, as his skill or lack of it can produce.

Microscopes specially designed for photomicrography, of superb workmanship and combining every improvement and device calculated to fit them for the highest grade of work, may be had - for a price. But it is not with these we have to deal in this little book. Following upon the lines indicated by its title, I can do no more than simply refer to them as being procurable if wanted; every-day instruments for busy workers must furnish the materials for my illustrations of the beginnings of practical photo-micrography. The optical requirements for microscopical research and study in our leading colleges and schools are now so thoroughly understood, and there 
is such a unanimity of opinion on the subject among teachers generally, that the microscope and outfit furnished the students are practically the same in design, quality and cost, though supplied by many different makers in America and Europe.

The "Continental" form of stand almost universally in use had its birth in Germany, but so eminently is it adapted to the daily work of the student that it has practically superseded all others everywhere. The usual outfit consists of stand with two objectives, $\frac{2}{3}$ " and $\frac{1}{6}$ "; two eyepieces or oculars of the Huyghenian form, and an Abbè chromatic substage condenser. To these an excellent $\frac{1}{1} \frac{1}{2}$ oil immersion objective is added for bacteriological and high power work, at a marvelously low price for such a lens. The instruments by Zeiss and Leitz, of Germany, and the Bausch $\&$ Lomb Company in the United States are too well known to need more than mentioning here. All of these eminent makers furnish outfits as above, practically the same in design, workmanship, optical qualities and cost. Each has some special feature of its own, as well as special admirers, but it may be safely said that one cannot go amiss in selecting either of these makes for photo-micrographic work. Not so 
universally known as the foregoing are the student's microscopes and outfits of the Spencer Lens Company, Buffalo, New York, but which are destined to at least rival the best of them in popularity as they become more generally known. The name of Spencer indeed antedates all of these. The first American lenses (made by the founder of the present house) bore an extended reputation early in the second half of the last century. Having been furnished, through the courtesy of its makers, with an opportunity to examine and practically test one of these instruments, I can do no less than give expression to the great satisfaction afforded me thereby. In design and general appearance it closely resembles the other microscopes of its class already mentioned. The workmanship throughout is first-class; the fine adjustment in particular being extremely delicate in action with great solidity of construction. The compound body is of greater diameter than other stands of its class, thus allowing a larger cone of light to pass than is possible with the narrow German tubes, - a decided advantage in photo-micrography, and particularly so when the objective is used alone for projection without an eyepiece. The draw-tube is then to be re- 
moved and the wide body being carefully blackened on the inside is ready at once for use in this manner. Other makers might well adopt the simple plan of blackening the inside of the tubes, but do not, as a rule, seem to have thought of it. The aplanatic eyepieces are particularly well adapted to photographic work, being fully equal to the projection oculars of Zeiss for the same purpose. A mechanical stage having very smooth rectangular motions may be adapted in a moment, or removed as readily. The objectives are remarkably good, indeed the $\frac{1}{12}$ oil immersion is the best lens for photographing bacteria in tissues that I have ever used. The lower powers are equally excellent. The frontispiece and Figures 7 and 20 were made with them.

Larger and more elaborate microscope stands are, of course, to be had from all these makers (some of them specially designed for photo-micrography) up to the most perfect and costly instrument by Zeiss for that purpose, but it is not within the scope of this elementary book to do more than mention them. I may say, however, that aside from their greater and special conveniences no better work can be obtained with them from any given objective than is possible with the more 
simple and greatly cheaper stands already mentioned. If the possessor of these but put his heart into the work and make the best use of his tools, he can depend upon results which will compare favorably with any, no matter what microscope they may have been made with.

A Bulls-eye condensing lens mounted on stand, with universal movements, will be necessary for the illumination of opaque objects, and for throwing partially parallel rays upon the substage condenser. The latter should be achromatic and provided with either iris diaphragms or a series of stops. The usual form of cbromatic Abbè condenser, supplied with all of the microscopes I have named, is not suitable for photo-micrography, if the best work is expected; indeed, for critical lighting and resolution it is utterly useless. It can be made to answer fairly well with medium powers, but I would strongly advise that it be discarded altogether when purchasing a stand, and an achromatic form procured at the outset. A suitable lens for accurately focusing an object upon the screen is necessary. The most simple form is that known as a three-legged microscope, a double-convex lens mounted in a frame of that description, with 
I4 THE A B C OF PHOTO-MICROGRAPHY

a screw collar for adjusting its distance from the plane of focusing screen. This costs but fifty cents. A more elaborate and better form, commonly known as Darlot's focusingglass, consists of a compound lens, mounted in somewhat similar manner, with a clamping screw for fixing the focus when adjusted.

A much lower power than the $\frac{2}{3}$ " objective of these outfits is highly desirable, in fact necessary, for photographing many large objects, opaque subjects, etc. A most useful lens is a good 2 -inch properly corrected for photography. Unfortunately, the limited length of rack on all the students' microscopes forbids the focusing of an objective of so low a power unless it be in a very short mounting, which is not possible for a well-corrected doublet. A feature of the Spencer microscope will be found most useful and essential in this case. The lower end of draw-tube is fitted with the society screw, to which the objective may be attached and used within the compound body, thus enabling one to utilize the very lowest powers with a small and compact stand.

I have spoken of the $2^{\prime \prime}$ objective being corrected for photography. It is not perhaps generally known that the corrections of the 
very best objectives were not until within a few years at all suited to photographic purposes, there being a decided difference between their visual and actinic foci, for the former of which alone they were corrected. The consequence was that the details of an object showing sharp and clear upon the focusing-screen were found to be somewhat blurred in the negative. This applied only to the lower powers, under a $\frac{1}{4}$, the difference in the higher powers being so slight as to require little or no attention. It was then the practice, after obtaining a sharp visual focus on the screen, to withdraw the objective very slightly by means of the fine adjustment screw, about $\frac{1}{1000}$ " for the $\frac{4}{10}$ " or $\frac{1}{2}$; $\frac{1}{200}{ }^{\prime \prime}$ for a $\frac{2}{3}$; $\frac{1}{150}$ " for the $\mathrm{I}^{1}{ }^{\prime \prime}$ objectives. This was not very satisfactory at the best, and a great advance was made when Wenham advised that a double convex lens be fitted in place of the back-stop of the objective, one of 5 -inch focus for the $\frac{4}{10} "$ and $\left.\frac{2}{3}\right)^{\prime \prime}$, and one of 8-inch focus for the $\mathrm{I}_{2}{ }^{\prime \prime}$ or $2^{\prime \prime}$ objectives. I have used for many years a complete set of Beck's objectives from $3^{\prime \prime}$ to $\frac{4}{10}$ " thus fitted, with entire satisfaction, and mention these facts here for the benefit of any who may be in possession of these older lenses. They can readily have 
them corrected by any reliable optician. Fortunately, no such procedures are necessary with lenses of the present day. They are all corrected with the view of being required for photographic purposes, and their visual and chemical foci will be found practically coincident.

The optical appliances thus far named are absolutely essential for the prosecution of photo-micrography by transmitted light with transparent subjects, and by refiected light with those of an opaque nature. These comprise the great majority with which the student will have to deal, but there are many others requiring particular illumination to bring out certain details of structure which cannot be done without special optical apparatus; as the polarizer and paraboloid for dark field effects. These will be more fully detailed in the chapter devoted to illumination, but are mentioned here in order to bring them to notice under the head of optical appliances. Both should form a part of the photo-micrographic outfit of every serious worker.

At the moment of writing this concluding paragraph, I am informed by my friend, Prof. M. L. Seymour, of Los Angeles, California, that a very valuable optical accessory 
to the microscope, which he devised some months ago, has reached perfection, and is ready to be placed on the market. His note was accompanied by photographs and descriptions of the apparatus. It is too late for insertion in this book, but full description, with illustrations of work done by it, will be found in my larger work when issued. I can only say now that the arrangement is intended to permit the instantaneous photographing of living microscopic forms and growing cells whilst under observation. The magnified image is in clear view and at the desired time the simple pressing of a pneumatic bulb opens the shutter, exposes the plate and secures the picture. It is simple, practical and very valuable. 


\section{CHAPTER III}

The Camera and Photographic Appliances

A camera or its equivalent - some arrangement by which the sensitive plate may be held in proper position to receive the projected image from the microscope whilst securely protected from all extraneous light-is equally important with the microscope itself. It may be broadly stated at the outset that any camera, no matter what its size or shape, may be thus utilized provided it has a focusing screen; without this it is of no use for photo-micrographic purposes. At the same time it may also be said that the majority of "push the button" cameras are but little better than makeshifts for photo-micrography. As a rule their bellows are entirely too short for general usefulness and must be added to in some manner by the user. This is especially the case with American boxes, though the long extension forms which most makers have introduced recently, go a long way toward correcting this deficiency. I would earnestly 
advise every one about purchasing a camera for use in photo-micrography to provide himself with one specially intended for and adapted to that purpose. If for any reason this is not feasible and he is obliged to employ some other, let him make the best of the situation and adapt the box he may happen to have to the end in view, in the best manner he can contrive. A simple example of such an adaptation must suffice at this time.

Having a small camera with bellows extension of about ten inches and a student's microscope stand with joint for inclination of body, I desired to so adjust them quickly and cheaply as to render them suitable for practical work. It would have been very easy to place each upon the table.top, with a book beneath the camera of proper thickness to raise its center to the level of microscope eyepiece, and, by the exercise of great care, perchance secure a good negative with no further expenditure of time. But the whole affair would be so liable to disarrangement by the slightest inadvertent touch that it was not worth thinking about. A board some four feet in length by nine inches wide was therefore obtained and placed upon the table top. To one end of this the camera was firmly 
attached, with a second short board beneath it of proper thickness to raise it to the height of microscope. This in turn was placed in front of the camera so that its optical axis coincided with the center of ground-glass focusing screen, and securely clamped to the board or platform. The radiant-a Welsbach incandescent mantle, mounted on a low stand, so that it could be freely moved about, - was then placed some six inches from the substage condenser and a home-made stand with holder carrying a color-screen inserted between the two. A sheet-iron box, open at top and bottom, with glass front, was slipped over the burner in order to prevent the dissemination of superfluous light in the room. I thus had, after a few minutes' work, a really practical arrangement of microscope and camera capable of turning out quite excellent photo-micrographs under a considerable range of amplification. Reference to the illustration (Fig. I) will make the details of this arrangement quite clear. Modifications of it may, of course, be made to suit all circumstances, but the general ideas governing them are identical.

These comprise - presuming of course possession of the necessary microscope and camera - the arranging of them for working together 
in unison; absolute steadiness, when so employed, and the means for placing them in position accurately and without loss of time.

It will be vastly better, however, to obtain at the outset a camera specially devised for photomicrographic work, and to have it always in readiness for immediate use, since it frequently happens during microscopic examinations that objects are found which require to be photographed or drawn at once. With a camera always ready, the microscope may be very quickly attached and the record made. There are a number of such cameras in the market-some to be used with the microscope in vertical position only; others are adapted to the horizontal alone, whilst a third class combines the two in a single instrument. Of the latter, the best form I have seen is one by the Bausch \& Lomb Optical Company. Like all of their apparatus, it is very well made, is equally firm and steady in all positions, and sold at a fairly moderate price. The accompanying illustration (Fig. 2), showing it horizontally inclined, gives a good idea of its design.

Probably the best strictly vertical photomicrographic camera is that of Zeiss from the world-renowned works at Jena. A heavy tripod-bar carries a column in which a rod grad- 
uated in centimeters slides vertically, being held at any point by a set-screw. This rod carries a cone-shaped bellows by means of two sleeve collars, also controlled by set-screws at any desired extension, and its front is provided with a light-tight connection between the camera and microscope. As with all work emanating for the Zeiss establishment it is made in the best and most careful manner.

The upright camera by Leitz has had a fairly large sale in this country, principally in schools and colleges. It is well made, of course, and is good-of its kind; but its cost (\$40) seems excessive. The fact is that a horizontal camera has so many points in its favor that I cannot understand how any one could deliberately choose an upright type when purchasing, unless he were entirely ignorant of the work he was about undertaking. The single point of superiority possessed by the upright form is found when it becomes necessary to photograph objects moving freely in a fluid medium, such as yeast cells, etc. In these rare cases the object-slide, of course, lies flat and the camera must be held perpendicularly above it. A little ingenuity will always enable one to accomplish this in some manner, and since an occasion for so 
doing will not occur, perhaps, in a hundred or more exposures, it is not worth while to encumber one's self with an otherwise inferior form of camera in order to provide for the infrequent requirement. An excellent method is to attach the camera to a stout board fastened vertically to one end of a heavy table, placing the microscope beneath it on a lower support, large enough to carry a lamp as well. The light is to be reflected upward by the mirror, as is usual when using the microscope in upright position. Diffused daylight may be employed for this manner of working as well as that from a lamp or other artificial radiant.

Some twenty years ago, when no suitable camera for photo-micrography could be found at any dealer's, I devised a form which the Scovill Manufacturing Company, of New York, made for me in the most satisfactory manner, and which is to-day, after constant use in all these years, as good as when it left their shop-nay, better, in the smooth working of its various parts. A careful study of the illustration (Fig. 3) will serve to give a fair idea of its special features. The bellows are in two parts, with a central box serving the double purpose of a support to prevent them from sagging in the middle and carrying a 
lens for making photo-macrographs, lantern slides or enlargements on bromide paper. This central box and the rear portion of the camera, with the focusing screen, slide freely and independently upon V-shaped ways, and may be firmly fixed at any desired point-a necessary feature in making lantern slides or bromide enlargements, the front being immovably attached to the camera-bed. The distance from it to focusing screen with bellows fully extended is about three feet, whilst the addition of a second bellows (coneshaped), which receives the eyepiece of microscope, makes it possible to have the object on stage of microscope fully five feet from screen-sufficient for almost any practical amplification. This cone bellows may be removed by simply turning a button and replaced by an ordinary lens board when it is desired to use the camera for copying, and the entire front can be shifted several inches vertically or horizontally. The plate-holder is single, the plate being inserted at the back, as in the old style of wet holders. This form is in every way superior to any of the double holders, with the possible exception of the English book form, and is especially adapted to my method of backing plates-to be de- 


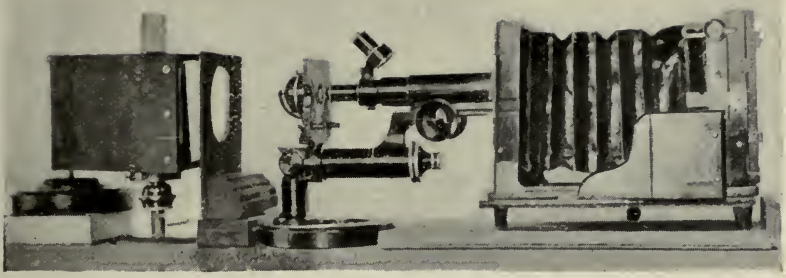

F1G. I

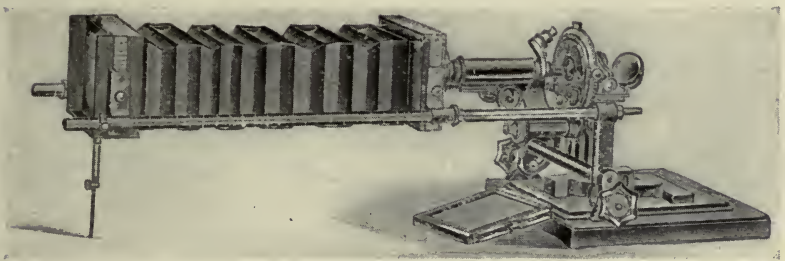

FIG. 2

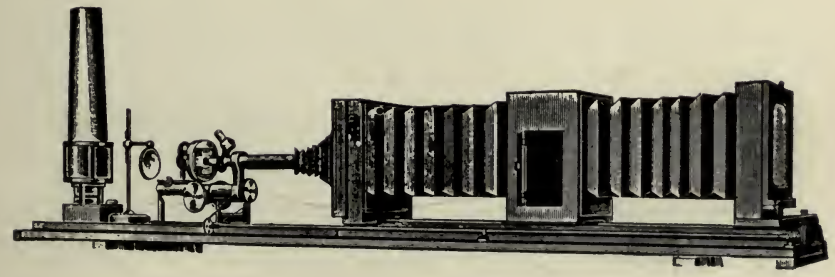

F1G. 3 


\section{PLATE II}

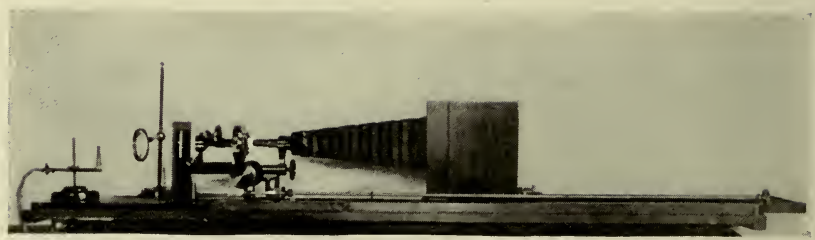

FIG. 4

E. R. \& C. camera and microscope arranged for use without eyepiece

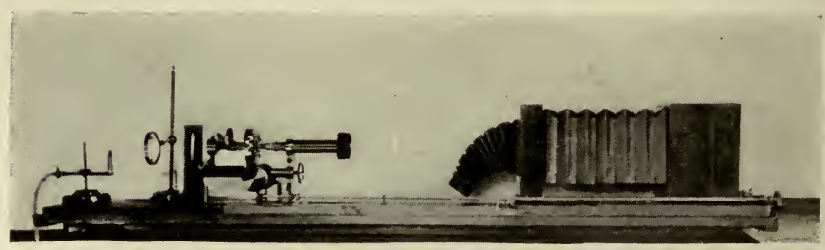

Fig. 5

E. R. \& C. camera, slid back from microscope for preliminary arrangement of light and object with latter

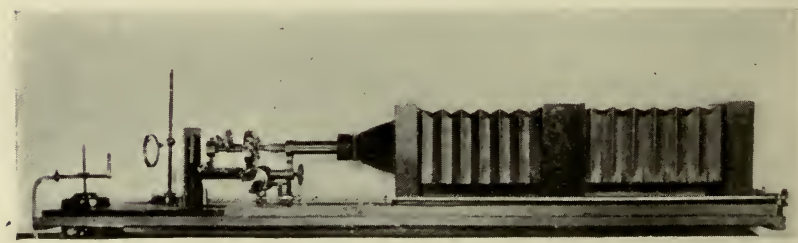

Fig. 6

E. R. \& C. camera and microscope arranged for high-power work 
scribed later on. It is fitted with kits for carrying various sizes of plates, which can be used upright or horizontal, as the subject may require. A metal rod with milled head and adjustable pulley-wheel attached to the base of camera frame furnishes means for manipulating the fine adjustment when it cannot be reached by hand.

This simple and most efficient camera was early placed upon the market by the Scovill \& Adams Company, under the somewhat lengthy but expressive title of "The Walmsley Enlarging, Reducing and Copying Photomicrographic Camera," and has met, I believe, with a steadily increasing demand. It is made in two sizes $\left(6 \frac{1 / 2}{1} \times 8^{1 / 2}\right.$ and $\left.4^{1 / 4} \times 5^{1 / 2}\right)$, each size carrying smaller plates, if desired. It is perfectly adapted to each of several different requirements. For simple negativemaking in connection with a microscope or for copying engravings, etc., with a photographic lens, its long bellows extension, simplicity and smoothness of working leave little or nothing to be desired. In making enlargements on bromide paper or lantern slides by reduction, it is equally useful, as will be detailed in the chapter devoted to those subjects. In still another direction its adaptability 
to a purpose will be found equally satisfactory. I refer to the photographing under very low amplifications (less than ten diameters), of macroscopic objects too large for the field of an ordinary microscope objective, - to which I have ventured to give the name of pboto-macrograpby, and to the pictures thus made, that of photo-macrographs. Full details of the process will be found in Chapter V on Negative Making. Illustrations of this camera in connection with my special microscope stand are given in Figures 4,5 and 6.

In the preceding chapter I have endeavored to give clearly and briefly as possible an idea of the optical apparatus necessary for the making of a photo-micrograph, which may be said to begin and end with the microscope, since each and every piece is but an accessory of this central instrument. Not so, however, do we find it in the photographic department of our pursuit, for no matter how indispensable the camera may be, there are other appliances equally so, but which have no connection with it, as the optical accessories have with the microscope. The first of these neces. sities is a dark-room in which the sensitized plates may be manipulated safely, from placing in the holders to the fully developed nega- 
tives. So universally is amateur photography practiced in these latter days, that I presume most of my readers are already acquainted with all the details of the purely photographic portion of our subject, and that any attempt at guidance in that direction may seem to them superfluous, if not presumptuous. None the less I deem it best to give a few hints culled from my own practical experiences of many years. So let us start with the darkroom.

This should be of a good size, well ventilated and comfortably warmed in winter. It sbould be provided with running water and sink of ample size for all manipulations so as to prevent any slop from spilling on the floor. Shelf room for trays, bottles and graduates should be provided within easy reach whilst a negative is being developed. It should be electrically lighted for comfort, convenience and freedom from vitiation of the air by combustion of even the most perfect lamp. All of these conveniences I enjoyed for several years, and speak from experience, when I emphatically advise every one who can to adopt them. But pleasant as they were, it is fortunate that they are not indispensable, else would my work in this direction have ceased. 
some years ago, since which time my darkroom has consisted of a none-too-roomy closet, lighted by a ruby lantern burning coal-oil, and every drop of water must be carried up and down a flight of stairs. Yet I venture to say the negatives made in that closet are at least equal to any I ever developed in the old perfectly appointed dark-room, and so accustomed have I become to the surroundings and extra work made necessary, that the aforetime conveniences are never missed. So take heart, all ye who cannot compass these, and make the best of your environments.

As a dark-room accessory, the ruby or developing lantern holds precedence. Make no mistake in selection at the start. It should be of ample size to avoid overheating, which volatilizes the oil and produces an offensive odor, as well as a dangerous poison, if breathed for any great length of time. There are many such affairs in the shops, more or less perfect, but I think there can be no two opinions as to the superiority of the Carbutt lantern, on account of its large size, ample ventilation and facilities afforded for manipulating the lamp. I purchased one of the first ever sold, almost twenty years ago, and it has been in more or less continuous use ever since. A sheet of 
ruby glass in front of which may be placed one or more thicknesses of post paper, affords a perfectly safe light for any plate, though none should ever be exposed close to the lantern, nor for a longer period than is absolutely necessary during development. This lantern has never emitted any unpleasant smell, and the secret of this is that it has never been permitted to get into a condition for so doing. "Eternal vigilance" alone has been the cause of its freedom from this too-frequent occurrence, but the same care would prevent the nuisance with any other lantern that is fit to use at all. The rules which I never neglect-are extremely simple. The lamp is kept at all times well filled with the best oil, carefully wiped dry, and the wick properly trimmed. The lantern and chimney are also carefully wiped both inside and out with a clean, dry cloth. The flame is kept at a moderate height to avoid danger of smoking, and the lantern door is opened at all permissible times for cooling the interior. As soon as work is done, the light is extinguished, and the lamp removed from the lantern, which is thrown completely open and thoroughly wiped out to remove any oil which may have been volatilized and con- 
densed upon its sides or top. If these precautions are taken you will never have any smell or trouble with the use of oil in the dark-room lamp.

The trays for developing may be of hard rubber (preferably), celluloid or agate-ware. Do not touch papier maché. It looks very nicely at first, but the sharp edges of glass plates soon cut through the varnish or enamel, and then the life of the tray is but brief. Porcelain is easily broken and heavy. Hard rubber is altogether the best. There should be at least three graduates, 2-oz., 4-oz. and $8-o z$. For the fixing bath I find on the whole a hard rubber or agate-ware tray of $8 \times 10$ size, fitted with cover, to be the most satisfactory. The acid fixing bath (formula for compounding which is given with most makes of plates) is undoubtedly the best, keeping clear and clean until exhausted. My own formula, as below, is recommended:

Sodæ hyposulphite . . . . . 16 ozs.

Sodæ sulphite . . . . . 4 ozs.

Chrome alum . . . . . . . $1 \mathrm{oz}$.

Sulphuric acid . . . . . . I drachm.

Water . . . . . 64 ozs.

As the alum dissolves very slowly, it should be powdered in a mortar, or a portion of the 
water heated, in which it may be dissolved and then poured into the rest of bath. The sulphuric acid must be added quite slowly. If you have no running water or drain, thus necessitating the use of a pail, do not attempt the employment of a wooden one. These soon become foul and leaky. Get one of the best quality of fiber pails; it will last for years, always giving satisfaction. They are light, never leak, and, if occasionally coated with asphalt on the inside, are always clean and pleasant to use. A couple of folding racks for drying plates, a few stirring rods and a scale for weighing, with some clean towels conveniently hung by loops, will complete the list of absolutely necessary dark-room appliances, excepting the developers.

A most important adjunct, truly, and one about which pages might be written did space permit. Since this is not, however, possible, I must be brief to some extent. As a general rule, I would advise every one who has had some experience in photography, including the development of his own plates, to use the particular developer with which he is already acquainted, in his photo-micrographic work - at least until he has mastered it sufficiently to permit experimentation with other agents, for 
I believe there is not a single reagent among the very many now obtainable which will not develop a properly exposed plate in a satisfactory manner if carefully used. Of course some are better than others, but all can be used. The developer should bring out all details to the very finest, and it should produce the fullest density required without choking or obliterating any of them. It should not produce chemical fog or stains under any circumstances, and should not be liable to any considerable loss of density in the fixing bath. Pyrogallol in the hands of an expert fulfils all of these requirements, but it is so sure to stain the hands that few amateurs care to use it in these days of cleaner developers. The combination of two or more reagents possessing different qualities has been found most satisfactory. I lay no claim to having been the first to so employ them, but I do claim that so doing, in my case, was the result of an original thought brought about accidentally. I was experimenting with eikonogen (then just introduced), finding it a very energetic developer and extremely rapid as compared with hydroquinon, which I had been using for some time with satisfaction, but it was impossible to obtain requisite density in the negative. I 
therefore poured it off from the plate in developing dish, supposedly into an empty graduate, but really into one containing hydroquinon prepared for use. This mixture was in turn flowed over the fully developed, but very thin, negative in dish, and not until the rapid darkening of the plate became noticeable was the mistake observed. The resultant negative proving to be one of the best I had ever made and the compound developer remaining clear, I continued to use it, and from that time to the present always with satisfactory results. In an article contributed to Anthony's International Annual for I89I I have given a rather full account of this "eiko-hydro" developer, with formulæ for compounding in two solutions or a single one. For years, however, I have used it in the powdered form, as this keeps indefinitely and is always ready for quickly making a solution of unvarying strength. The formula is as follows:

No. 1 .

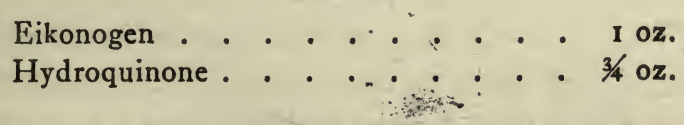

Mix very thoroughly and keep in a glass vessel with screw top. An empty jar of Higgins' Photo-Mounter will be found just the thing for this purpose. 
34 THE A B C OF PHOTO-MICROGRAPHY

NO. 2.

Sodium carbonate, dried and powdered . 2 ozs.

" sulphite, " " I oz.

Mix also very thoroughly and put into a similar jar. For developing a photo-micrographic negative a single solution is the most convenient and always reliable. For this purpose put about Io grains of No. I in 2 ounces of water and stir until completely dissolved, then add 20 grains of No. 2 and a few drops of a ro per cent solution bromide of potassium, again stirring thoroughly. To avoid the necessity of weighing the chemicals every time I use two small thimbles, soldered to short pieces of brass wire, one of which holds, when evenly filled, the exact amount of No. I powder; the other doing the same with No. 2. This developer acts slowly but regularly, and should be allowed to proceed until the back of the plate is fairly well darkened, as there is some loss of density in the fixing bath. The addition of a few grains of metol will give greater energy to the developer, but I have not found any other advantage in its employment. The used mixture should not be thrown away, but filtered into a bottle to be used as a restrainer instead of bromide with a freshly made solution. It may be used repeatedly. 
CAMERA AND PHOTOGRAPHIC APPLIANCES 35

Although the sensitized plates are necessarily developed in the dark-room, they are not properly appliances of that indispensable apartment. In fact they have no business there, save at the times of being placed in the holders and development. They should be stored in a dry, well-ventilated room, where no deleterious gases or fumes can possibly gain access to them. The too common practice of keeping plates in dark-rooms is a very frequent cause of fog and other deteriorations in them, and the avoidance of so doing cannot be too earnestly urged.

As to the plates themselves. It may be broadly stated that any of the numerous brands now in the market are capable of furnishing satisfactory photo-micrographic negatives if properly manipulated, though not equally so with all classes of subjects. Some of these require certain qualities not found in all plates for their best rendition. As a rule, very sensitive emulsions yield soft negatives; slower ones giving greater density, with inclination toward harshness. For the greater part of all microscopical objects, orthochromatic or isochromatic "color-correct" plates are infinitely superior to all others. Indeed so greatly are they better that for a long time 
I have used none others, - this after the experiences of many years with almost every sort that were made during that time. It is unfortunate that our American makers are so far behind their foreign rivals in this particular branch of plate-making. Here it is possible to procure those sensitized for yellow rays alone, whilst in Europe they are made for all portions of the spectrum. It is said that the Lumière Brothers, of Lyons, whose "colorcorrect" plates are of world-wide fame, is about to establish a branch of its works in this country, a consummation most devoutly to be wished. Of American plates the very well-known orthochromatics of Carbutt and isochromatics of Cramer are most excellent. During the past year I have used, exclusively, Forbes' orthochromatics, made in Rochester, New York (the home of photography in this country), finding them so uniformly good in every particular and so moderate in cost that there has been no temptation to change for any other brand. In stating this I would take occasion to say that I am in no manner interested in these plates beyond the desire of using the best and cheapest in my own work, and having found what I sought, feel like sharing this good fortune with my neighbors. 
They are furnished in two degrees of sensitiveness and cover all demands, from the lowest powers to the highest, equally well.

All plates used in photo-micrographic work should be backed. In fact the advantage of so doing is even more marked than in other branches of photography, where it is now considered indispensable. Here again our foreign cousins are better served than we. All English plate makers furnish them ready backed without extra cost. I believe-but cannot state positively-that Carbutt is the only American manufacturer who lists them, but at an increased cost, and the backing, though efficient, is so difficult to remove, and makes such a mess of the developer that the remedy becomes almost as bad as the disease. As a consequence each one of us must learn to back his own plates. A method of doing this, published in one of the annuals some years ago, is so simple, easy of application and perfect in results, that I take pleasure in reproducing it :

Put ro ounces of 95 per cent alcohol into a wide-mouth bottle with $1 / 2$ ounce of powdered white castile soap, for a stock solution. Shake the bottle occasionally until the soap is dissolved, which may take a week or longer. When half dissolved it is ready for use. Pour off 2 ounces and filter, to which add 10 grains each of Erythrosin and Aurin, 
which will be promptly dissolved. Paint backs of plates with this solution, using a flat camel's hair brush. It will be nearly colorless in a red light, and care should be taken not to expose the plate to unnecessary light, no matter how safe this is supposed to be. Wipe off the coating with a wad of wet cotton wool before development, and rinse the whole plate carefully in a tray of clean water.

An original method of backing plates, worked out some years ago, has given me such uniformly good results that I no longer hesitate to make it known. Others may possibly have used the same means; if so, I have not heard of it. The method is extremely simple. Procure some sheets of thin, dead, black paper, and have them cut into pieces slightly smaller than the plate. Do the same with an ordinary sheet of white blotting board. For use, dampen the blotter, and lay the black paper in a tray of water for a moment, taking care that it becomes wet through on both sides, leaving no air bells on the surface. All this may be done of course in full light, the balance in that of the dark-room. Taking a plate from its box, hold in the left hand, back upward, and not too near the lantern, no matter how safe its light is thought to be. Then, with the right hand, lift the wet paper from the tray, drain off superfluous 
moisture and lay on the plate, smoothing it out at the same time. Now place the dampened blotter on top, pressing it down all over, with the hand first and a soft dry towel as a finish, holding the plate all the while by its edges, between thumb and fingers, and not allowing the hand to come in contact with the film surface. If your plate holder opens at the back, as with the E. R. \& C. camera, or is of the English book form, it remains only to lay the plate in place and close the holder. If of any other pattern, you may experience some difficulty in employing this method of backing; and there are some to which it is quite inapplicable. Every one attempting it must ascertain that by trial. In all cases where it can be used, nothing is more satisfactory. It is not an absolutely perfect backing. With the utmost care there will probably be some little spots where a thin stratum of air between paper and glass prevent absolute optical contact. But in actual practice, I have found it quite equal to the most approved methods, in results. It is well to note, that the plate should be backed and placed in the holder, after all preliminary operations with microscope and camera are completed ready for the exposure, which must be made whilst the paper is still wet. 
40 THE A B C OF PHOTO-MICROGRAPHY

And now a ray of light comes from the far East, illuminating and making clear whatsoever dark places my black paper backing scheme may contain. In the British Journal Photographic Almanac for 1902, I have found a short article under the caption of "Ex Oriente Lux," contributed by Mr. George Ewing, of Calcutta, which makes the plan simply perfect, and almost impels me to purchase a Chicago self-acting kicking machine for personal use as a well-merited punishment for not having thought of it myself. However, I am quite ready to take a back seat and to give him thanks for a suggestion which has given me no end of satisfaction in its practical application during the past month or two. Instead of water he uses glycerine wherewith to coat the black paper - on one side only which not only furnishes an absolutely perfect backing, but will remain in perfect condition for many days after application to the plate. Well may he ask his "readers to drop for a moment caramel, burnt sienna, Indian ink, gum and gamboge and many other messy abominations and try a backing of thin black paper coated with glycerine and squeegeed into optical contact with the back of the plate" to which I will add that the dropping will not 
be for a moment only but for the altogether. So perfect is this backing in practice that I have exposed a plate thus protected directly facing several windows, outside of which the sun was shining brilliantly, for several minutes without the slightest trace of halation appearing in the negative on being developed. In preparing the paper for use I lay a sheet slightly smaller than the plate upon a clean table, pour a small quantity of glycerine in the middle and spread it evenly over the surface with a finger, using a liberal quantity, but not too much. Then place it on the back of plate and squeegee into optical contact. Strip off before development. The paper may be used repeatedly, adding a little fresh glycerine each time. Try this. You will use no other backing ever after. 


\section{CHAPTER IV}

\section{The Radiant and Illumination}

One of the most important primary questions confronting the beginner in photo-micrography is what form of radiant or illuminant, within his means, will be the best for practical use. If he be in a position to choose whatever he likes, then a considerable range of light sources is open to him. First and by far the best is that of direct sunlight, regulated and controlled by means of a heliostat. This is the purest and most actinic of all radiants, making possible the very shortest exposures and yielding negatives - all other conditions being favorable - of unsurpassed brilliance and perfection. In this country, blessed with so many days of sunshine, it is for the day worker a very certain and reliable radiant; in others-England, for example-sunny days are so rare as to practically debar it from use. It is not within the scope of the present work to do more than refer to its preëminent merit, and to advise those who possibly can employ its perfect rays to do so. Diffused daylight is 
also a good source of illumination, but so uncertain in its intensity at different hours of the day during the varying seasons as to render its employment somewhat difficult and unsatisfactory. Since, in common with direct sunlight, its use is confined to daytime, the night worker cannot employ either, but is obliged to look for some artificial source for his light.

Fortunately these are numerous enough to suit his circumstances or convenience, whatever they may be. First and most important, in fact rivaling the direct rays of the sun, is the electric arc light, the current for supplying which is now so universally available that few are debarred from use of it, should they so elect. Nor is the question of cost a very serious one any longer. A hand-feed lamp very good-may be purchased for a very moderate sum. The cost of installation is not large and that of maintenance equally inconsiderable. The light is steady, brilliant and highly actinic, permitting exposures approximating in briefness to those possible with sunlight. I would advise every one to whom it may be available to look carefully into this source of illumination when arranging for an outfit.

The rays of burning magnesium are proba- 
bly the most highly actinic of any artificial light, but the smoke and dust accompanying its combustion, together with the comparatively high cost of the material, preclude its general use where much work has to be done. Special means may be devised for disposing of the fumes and dust, but, on the whole, burning magnesium as a radiant is not likely to become very useful in continuous work.

The lime light seems to be the most common form of radiant in England for photomicrography. This is doubtless due to greater facilities for procuring the necessary oxygen and hydrogen gases afforded in that country, together with correspondingly lesser ones for obtaining the electric current than prevail in the United States. The light is highly actinic, very intense, and capable of doing rapid and excellent work, but its management is vastly more complicated and troublesome than that of the electric arc. It is, possibly, used to some extent in this country, but I do not know of any one so doing.

In my estimation the most generally useful radiant is acetylene, "a chunk of sunlight brought down to the work table," as some one has aptly remarked. Its brilliance, steadiness, actinic qualities and cheapness all recom- 
mend it to the photo-micrographer. In the latter quality it rivals coal oil. A pound of calcic carbide, costing 4 cents, furnishes me with a full supply of light for a week's work. Of course steady burning would require more material, but for several hours' work per day or night, with a burner consuming $\frac{3}{10}$ of a cubic foot of gas per hour, I find, as stated, that one pound of carbide lasts a full week. The light is extremely actinic (probably fully equal to that of the lime light), though its intensity is much less, requiring considerably longer exposures than the latter-vastly shorter, however, than those necessary with a coal oil lamp. I have used it almost exclusively in my work for more than five years, and therefore am in a position to speak conclusively as to its merits and capabilities.

The Welsbach incandescent gas light is one of the very best sources of light for low and medium powers, but not well suited to high amplifications, and utterly useless in "critical" illumination, as will be shown later on. The light is brilliant, intense and much more actinic than that of the best coal oil flame. It is very easily manipulated and almost universally available, as a supply of gas may be obtained in all cities and towns 
46 THE A B C OF PHOTO-MICROGRAPHY

of any size the world over. A neat little fixture for its use in photo-micrography is supplied by the Welsbach Company, and its use is fully recommended to those whose work is principally confined to low and medium powers and the photography of tissues.

Last to be named but scarcely least in importance among radiants is the reliable, universally available coal oil lamp. It can be obtained everywhere the world over, and its yellow rays are capable of making as good negatives of most subjects as are those from any other source of light if properly utilized and given sufficient time. The somewhat feeble illumination and inordinate length of exposure required when using high powers are diffculties which cannot be fully eliminated, though they may be lessened by careful manipulation, but the finished negatives will compare favorably with those made by any other radiant. On the whole, this familiar light may be commended as being one of the most useful to the photo-micrographer, notwithstanding the rather contemptuous manner in which it is spoken of by the "authorities."

Having settled upon the radiant, our next procedure is to determine the manner in which it must be employed for the illumination of 
the object we desire to photograph. The vast majority of such specimens are transparent, requiring the rays of light to be thrown through them; this mode of illuminating being termed transmitted light. Others, again, will not permit the passage of light through their substance requiring to be shown by its reflection from their surfaces. This is known as opaque illumination. Many transparent objects are shown best both as to structure and beauty when brilliantly illuminated on a dark background, which is effected by means of a paraboloid or by printing from a positive-to be presently described. This is called dark field illumination. Others, as many crystalline subjects, sections of minerals, etc., require the use of polarized light to properly display their beauties and structural details. With others, again, as most of the diatoms, the lighting must be more or less oblique in order to fully resolve their delicate markings. It will be necessary to determine which of these classes an object belongs to before commencing to photograph it. Examples of the various methods will be found in the succeeding Chapter on Negative Making, wherein I have striven to place practical processes before my readers in such simple but at the 
48 THE A B C OF PHOTO-MICROGRAPHY

same time explicit manner as will enable them to follow to success. And I would here take occasion to say that no claim is made that they are the only ones leading to that desired end. Any others which will produce the same or better results, must be equally good. 


\section{CHAPTER V}

\section{Negative Making}

Photo-micrography is usually divided into three groups, designated low, medium and high power work. To these I have taken the liberty of adding a fourth group under the designation of photo-macrography, a slight enlargement (less than ten diameters), of macroscopic objects. The amplification of the first, or low power group, ranges from ten to one hundred diameters; that of medium power, between one and five hundred, and the term high power, is applied to all enlargements greater than the last amount. The group of photo-macrographs comprises all subjects that do not require to be magnified more than ten diameters, which is readily reached by a good photographic lens and a suitable camera, without the employment of a microscope at all. The wings of butterflies, many large insects, leaves, small flowers and a host of similar objects, needing but slight enlargements to make striking and instructive pic. tures, may be named as indicating some of 
50 THE A B C OF PHOTO-MICROGRAPHY

the classes of subjects included in this group." Low powers are exemplified by photographs of insect eggs, and parts of their anatomy, sections of stems, seeds, woods, leaves, minerals, etc. Animal tissues, both normal and diseased, are usually photographed under medium powers, which really embrace a large portion of the most important work in photomicrography. High powers are necessary for germs, bacteria, cell structure, diatoms, bloodand pus-corpuscles, etc. I have endeavored in the present chapter to carry my readers through the various processes involved in making negatives in each group named; also to give them practical examples in illumination by polarized and transmitted light or on a dark field, of transparent objects, and by reflected light of opaque ones.

Low powers, transmitted light. It is more than probable that the beginner's first attempt at photo-micrography will be made with one of the various students' microscopes now in such general use. Supposing this to be the case, we will utilize such an outfit in my first demonstration. The microscope which happens to be available at the moment is one of Spencer's stands, furnished with two object-glasses, $\frac{2}{3}$ and $\frac{1}{8}$, two eyepieces of the usual Huyghe- 
nian form, and an Abbè chromatic sub-stage condenser. The object chosen is a thin, transverse section of an echinus spine-Echinometra lucuntur - long esteemed by microscopists as a very perfect test for flatness of field in an objective in addition to its beauty. The microscope having been inclined to a horizontal position, with the slide placed on its stage and secured by the clips, we turn the mirror aside in order to leave the under surface of the stage quite free and unobstructed. The radiant - in this case a Welsbach burner, so mounted as to bring its centre in a line with the optical axis of the microscope - is placed about six inches from the stage. Upon looking through the eyepiece and bringing the object into focus, we find the illumination to be somewhat uneven, and not altogether satisfactory, caused by the presence of the Abbè condenser, which is not well adapted to the low power ( $\frac{2}{3}$ inch) we are attempting to use. Removing this from its setting and closing the stage iris diaphragm somewhat, the illumination will be found quite evenly distributed over the whole field-soft, yet brilliant. But we also discover that only a fraction of the object is comprised within the field of view. Manifestly it is impossible to photograph it 
52 THE A B C OF PHOTO-MICROGRAPHY

as a whole, with this arrangement. What is to be done? The section is clearly small enough to be wholly embraced by the objective. It must be the higher magnification and narrower field of the ocular that cause the present trouble. What is to be done? There is no lower power objective with the outfit. We must make use of what we have or abandon the attempt. We are not going to do that, however, until all efforts fail. Perish the thought! We will discard the eyepiece and allow the objective alone to project the image. This was the almost universal practice in former days, and the one used exclusively by Dr. J. J. Woodward, whose work, as a whole, has never been excelled. It will not answer with apochromats, which require the addition of a compensating or projecting ocular to complete their corrections; but the case is different with achromats, which, properly corrected, will give a sharper and flatter field, when used alone for projection, than in combination with the ordinary Huyghenian eyepiece. Spencer's aplanatic oculars, however, work perfectly with them, and should be used by every one. But to return. In order to see the object, after removal of eyepiece, the camera must be brought into action with tube of microscope 
inserted into its front opening and the entrance of all extraneous light excluded by wrapping a piece of some dark fabric about the junction, or in any other manner one may decide upon; in this case a focusing cloth of cotton-velvet is used. We now find that the whole of our specimen is included within the circle of light seen on the focusing screen. The illuminated disc, however, is somewhat contracted and shows a very bright spot of light on one portion of its surface which.interferes with the definition of the image and threatens to spoil the negative unless removed. This is readily done when its origin is found to be reflection from the too bright interior surface of the tube or compound body of microscope. A tube of velvet or dead black paper inserted within the body effectually cures this "flare spot" trouble, but unfortunately contracts the already too small diameter of the tube, a defect held in common by most of the modern students' form of microscopes. In the Spencer stand we are using, this defect has been largely remedied by the employment of an outer body of unusually large diameter, from which the sliding tube may be entirely removed, leaving one of a very excellent size for photographing an image projected by 


\section{THE A B C OF PHOTO-MICROGRAPHY}

the objective alone. This tube having been thoughtfully blackened on the interior by the makers, there is no necessity for lining it with one of black paper or velvet. A useful hint is thus conveyed to other makers, which it is to be hoped they will not hesitate to improve.

If the microscope, camera and radiant are set up so that the optical axis runs straight through the center of each, as they should be and as they are in this case, the circle of light on the focusing screen will be the same, though the image may not be in its center. This must be effected by moving the specimen on stage very gently and 'carefully, since the :slightest motion is greatly magnified on the screen. Here a well-made mechanical stage becomes most convenient and important, but not having one at present we must use our fingers as delicately as possible. This is not difficult with low powers, but requires considerable practice and experience when the amplification is high. The projected image is now in the center of a well-lighted field, with the camera extension sufficiently short to permit a ready manipulation of the micrometer focusing screw whilst examining it upon the screen. It will be found difficult to distinguish details sharply or clearly, owing to the ground-glass being too 
coarse, and this indistinctness increases with the magnification. It is simply impossible to focus delicate structures possessing much detail upon so rough a surface. Recourse must be had to something else and several present themselves to our seeking. One is to cement a thin microscopic cover glass with Canada balsam to the ground surface of the screen which clears up that amount of space, permitting very accurate focusing within its limits by means of a focusing glass. If this be placed - as is usually done - in the center of the screen, only that portion of the object visible through this disc can be focused, and very often this will not answer at all. A remedy may be found in the employment of several glasses cemented to different portions of the screen, but this is often as bad or worse than the disease: it is but a makeshift at best and we will seek some other means of overcoming the difficulty. If a sheet of thin plateglass or a gelatine dry plate treated in the manner suggested by myself many years ago, be substituted for the ground-glass, either will make a screen, the surface of which is suitable for the most accurate focusing with highest powers, though differing from each other and from the ground-glass in many par- 


\section{THE A B C OF PHOTO-MICROGRAPHY}

ticulars. These may be mounted in duplicate frames of the regular screen, or the ground glass of the latter can be fitted so as to be removable and replaced by the others; the former plan being the preferable one. To make the gelatine surface-screen a dry plate of suitable size should be exposed for a briet period to white light and developed until slightly grayed over, when it is to be fixed in the ordinary way and thoroughly washed. It may be well to treat two plates in this manner, one of which is to be placed on a rack and dried. The other should be bleached in the mercurial solution used for intensification, well washed and dried. We have thus two screens with very fine surfaces, one of which will show the image, but rather faintly, to the naked eye, the other requiring the aid of a focusing-glass, as does the plate-glass also. Provided with these three screens in addition to the ordinary one of ground-glass the photomicrographer is prepared to successfully meet all focusing problems. In using the gelatine screens that surface is, of course, presented towards the projected image and the focusingglass is applied to the back as with the one of ground-glass. This is mounted in such manner as to permit being focused through the 
screen upon the gelatine surface of its opposite side and securely fixed in that position. These lenses may be procured of various forms and prices, the cheapest being the wellknown three-legged microscope costing fifty cents.

Prior to completing the final focusing, you will notice that I have placed a carrier holding a color screen of yellowish green between the radiant and stage, in such manner as to prevent any light other than that passing through it from reaching the object. I then close the iris diaphragm sufficiently to exclude the flood of light entering by its full aperture in volume sufficient to drown much of the finest details of the object. It is a very nice point to determine the precise amount of illumination necessary for a given subject; to avoid insufficiency on the one hand and harmful excess on the other. Practice and experience alone can teach this matter of almost prime importance. And observe carefully when using a color screen that the focusing must be done through it. It will not answer to place it in position after the focusing has been completed.

Having at last carried my readers through the preliminary processes of making a nega- 
$5^{8}$ THE A B C OF PHOTO-MICROGRAPHY

tive with a low power and without an eyepiece by transmitted light, we may proceed to the final and very important stages of exposure and development. The holder, in which the plate chosen for this negative (a Forbes orthochromatic S.) has already been put in the dark-room, is attached to the camera in place of the focusing screen, and an opaque card inserted between the radiant and stage, to cut off all light from the object. Now comes the crucial question, which must be answered: "How long shall the exposure be?" Although the plate allows a very considerable latitude in this important direction, it has its limits. As a rule it is better to risk overrather than under-exposure, since the former may be rectified to a considerable extent in development, whilst the latter is remediless. From previous acquaintance with the sensitiveness of this brand of plates and the brilliancy of illumination on focusing screen, I am led to the conclusion that the length of exposure, if made without the color screen, should be three seconds, and with it some ten seconds, as its employment usually trebles the time required when the screen is not used. Accordingly the slide is gently withdrawn from the holder, and after a moment's pause to allow subsidence of 
all vibrations, the card screening light is lifted and its rays allowed to fall upon the object for that period of time, when the card is replaced, the dark slide returned to the holder, and we are ready for the development. Proceed with me now to the dark-room, where everything necessary for this final act in the birth of our negative has been prepared beforehand. The lamp is burning brightly in the large, wellventilated lantern (Carbutt's), the door of which is standing open, and there is no evidence to the olfactory nerves of the presence of any such evil-smelling thing as coal oil in the little apartment. The developer, eikohydro, stands ready mixed in a beaker; the acid fixing bath is equally prepared to do its duty when called upon. Closing the lantern door, we still find the room sufficiently illuminated to enable us to see what we are doing, although the light is screened through one sheet each of ruby and dark orange glass and of post-paper, which renders it safe for manipulating the plate with proper care, such as screening it from the direct rays and covering the tray containing it with cardboard. I take the plate from its holder, place in the tray and cover with the developer in a single bold sweep, my back to the light. Then the card- 
board cover is laid over it and the development is started. This generally begins within a minute, proceeding slowly, but regularly, until finished. We glance at the plate occasionally, holding it up to the light and looking through it for a moment without fear of fogging, since the danger of this decreases very rapidly as development advances. This must be carried to a greater extent than with most classes of photographic work, as plucky negatives, with good contrasts, are almost always necessary. With hydroquinon as the developer, or a component of it, as we are now using, the plate should appear well darkened on the back, as there is always a considerable loss of density in the fixing bath when this reagent is used. Whilst talking, the development has proceeded without halt and now appears to be complete. I, therefore, pour the solution off, and, having no running water in the room, wash the plate very thoroughly in a pail freshly drawn, then place it in the fixing bath for clearing, which I allow ample time for doing completely. It is a great mistake to remove a negative from the fixing bath too soon. It will not do to trust to its apparent fixation; make sure of it by giving it plenty of time, if you desire permanence. At. 
last, feeling sure of this important work being accomplished, let us take it from the bath, rinse in water and examine. "A fine negative," you exclaim, and "made by an objective of very perfect construction," is added by all. It is the negative from which the frontispiece to this book was reproduced, and I think does credit to all concerned in its making-the optician, the plate-maker and (modestly) to the photographer. It must now be thoroughly washed to eliminate every trace of hypo from the film. An hour or two in running water, when the usually dirty Philadelphia fluid which passes by that name is at all fit for use, will suffice for this purpose; otherwise numerous changes of filtered water during many hours are necessary to remove the last traces of this necessary but treacherous salt. Then swabbing off under the tap with a tuft of cottonwool, a final rinse in filtered water and placing in a rack for spontaneous drying will complete our negative. The latter process may be accelerated by standing the rack in a current of warm, dry air, free from dust. I would not advise my readers to adopt the following directions, gravely given in a recent English work on photo-micrography by an eminent authority. 
"We have had so much trouble caused by inequalities in the film produced by irregularities in the drying that some time ago we gave much attention to the subject, and seeing that now hardly any trouble in that direction arises, we venture to simply state how it may be avoided. The negative is placed, glass side downward, on a cloth and a fine handkerchief is gently and neatly laid over the gelatine side. It is smoothly and firmly pressed with the hand for two or three seconds, which allows the fabric of the handkerchief to absorb all the superficial moisture. On raising the handkerchief it will be found that the gelatine shows distinct marks of the fabric. This is not of the slightest consequence, for it absolutely and entirely dries out of all existence. The back must now be carefully washed,-one source of trouble arises entirely from drops of moisture accumulating there. . . A A ring of slightly melted gelatine will be the result, which it is needless to say spoils the picture. This is especially the case when the negative is dried on a hot-water tank," etc., etc.

One cannot refrain from smiling at the thought of a negative treated in the above manner by the majority of our energetic young students.

When an eyepiece is used in making a negative with low powers, most of the operations are the same as those just described. In accordance, however, with my plan of giving practical illustrations in a variety of cases that may confront my readers, I will now ask them to assist in a little more low power work. For 
this purpose I have chosen a slide of carcinoma which may be of interest to all, and certainly will be to the medical men among them as an illustration of diseased tissues. A low power, less than 100 diameters, shows its details very well. I have, therefore, selected a $\frac{2}{3}$-inch objective, which, with the Spencer I-inch aplanatic ocular, gives just the desired amplification with a moderate bellows extension. We will use acetylene this time from a $\frac{3}{10}$-foot burner as the radiant instead of the Welsbach incandescent mantle, and you will notice I have attached an achromatic condenser to the substage of microscope. The specimen is placed on the stage and the radiant (mounted on a low movable stand like the Welsbach) is made to occupy the same position as the latter in our first experiment. Looking into the eyepiece, the object is now brought to a focus, the radiant being moved about until the field is evenly illuminated, when the condenser is racked forward or back until an image of the flame is seen projected perpendicularly across the field of view. If it is not in the center the stand carrying the burner must be moved about until it is so. We now have both object and radiant in focus together, really "critical" illumination which, however, 
64 THE A B C OF PHOTO-MICROGRAPHY

cannot be utilized with this objective of low aperture; the flame appearing as a brilliant line of light running across the field of view from top to bottom with comparatively dark spaces on either side. There are two remedies for this trouble, one in racking the condenser backward or forward until an even illumination of the field is obtained, the other in removing the radiant to some fifteen inches from the microscope and interposing a bull'seye condenser with convex surface turned from the light in such manner as to render the rays fairly parallel. Either plan is very good and satisfactory. We choose the former on this occasion and find the lighting of the field to be all we could desire. The subsequent manipulations are now about the same as those gone through with in making our first negative. The color-screen-yellowish green as before-is placed in position, light and object centered on ground-glass screen, sharp definition obtained with gelatine screen and focusing glass, plate holder attached loaded once more with a Forbes orthrochromatic S, and we are ready for the exposure. How long shall it be? The plate is of same sensitiveness as the other but the light is more highly actinic than the Welsbach. On the other hand, the object is stained 
red - a highly non-actinic color - the amplification is some three times greater than before and the rays of light have to pass through an ocular which always diminishes their intensity in a large degree. Clearly we must allow them considerably more time in which to do their work, say three times. So we give 30 seconds exposure, and upon treatment with the previously used developer find we have an excellent negative from which the reproduction (Fig. 7) has been made.

For the benefit of some entomological friends who will probably be among my readers, we will make one more negative with a low power; choosing, this time, that ever favorite subject, "the blow-fly's tongue," which presents in its suctorial tubes one of the best tests for a half to one inch objective that I know of. We will use the same optical arrangement as that in the last example, excepting the objective, for which I have substituted one of same power $-\frac{2}{3}-$ by Ross. The plate is a Wuestner orthochromatic; the screen dark yellowish-green pot-glass, the radiant acetylene. Exposure, 30 seconds; developer, hydroquinone. You see the reproduction in Fig. 8. Observe how beautifully the tubes or false trachea are delineated. 
Medium Powers by Transmitted Light.-There is but little material difference in the manipulations between photo-micrography with low or medium amplifications. Under one hundred diameters-which is generally termed low power work-a substage condenser may frequently be dispensed with advantageously. But in using medium powers-one hundred to five hundred diameters-it should always be employed, not only to shorten exposures, but to insure the best rendition of the object. With high powers its use is absolutely necessary. It is also requisite to provide some means for moving the fine adjustment screw when the camera is extended so far that it cannot be reached by the hand during examination of object upon the focusing screen. This may be done by means of a rod and pulley-wheel, as described on page 25 and shown in Figures 4,5 and 6 . If this is not available, a series of screw-eyes may be arranged on both sides of the camera platform, through which a fine cord (as a fishing line) can be strung, passing around a groove in the periphery of the micrometer screw and kept taut by means of a small weight attached to each end hanging from rear of the camera platform. A very slight pull upon this cord 
from either side will suffice to move the adjustment screw in the most delicate manner. It is not worth while to repeat the processes already shown, but may not be amiss to follow the making of the two negatives I have chosen for illustrations of medium power work.

In order that my friends, the diatomaniacs, may not be neglected, I have selected one of the beautiful discoid forms, Aulacodiscus Oreganus, for our first attempt at somewhat higher magnification than the earlier ones. This diatom is almost perfectly flat in the center of its disc, but the margin comprises a series of processes considerably elevated, which make it quite impossible to get the whole surface into one perfect focus with an objective of even moderate power. We therefore have to compromise on the focusing, in order to obtain a passable whole, and Ross' students' $\frac{1}{6}$-inch seeming to combine a low angle with excellent resolving powers, I have chosen it as the objective. A coal oil lamp, in the absence of something better, must suffice for the radiant, and as you will see, I am using the edge of flame in connection with a bull's-eye condenser, shown in Figures 4, 5 and 6. An Abbè chromatic condenser, with iris diaphragm, is fitted to the 
substage, and the ocular is a Huyghenian $1 \frac{1}{2}$-inch. This is not an ideal photo-micrographic combination, but quite equal, no doubt, to those with which many workers will have to be content. Let us see what we can do with it. The operations of centering light and object and of focusing, being precisely the same as those already described, it is unnecessary to repeat them. The plate is an ordinary landscape one of moderate speed. A cobalt blue screen renders the illumination fairly monochromatic in that actinic color, and, of course, does not necessitate prolonged exposure over that requisite for the ordinary yellow rays of the lamp. Still it must be confessed that the lighting, as seen on the screen, is not very brilliant, and a somewhat lengthy exposure is deemed necessary. We decide upon five minutes, and it is given. Fortunately it is evening; there are no passing vehicles, and not a tremor is perceptible throughout all that while. Now comes the development in eiko-hydro, and we have a negative which I think we need not be ashamed of, in view of the circumstances under which it was made. A reproduction will be seen in Fig. 9, the amplification being 3 I 5 diameters.

A second negative might as well be made 
whilst we are working with medium powers, and my medical friends having assisted in producing one from diseased tissue under a low power (Fig. 7), I will now endeavor to photograph a normal one, requiring considerably greater amplification, as a further example. The slide is labeled "Human voluntary muscle injected." Under a magnification of 200 diameters or more the striations are beautifully shown, but it is too great to display the injected arteries in a very satisfactory manner. We must make the best of the situation, however, as it is the striations of the muscular fiber we are after. The optical arrangement comprises an $\frac{1}{8}$-inch of moderate angle by Beck's; Ross' substage condenser, with medium cone of light, and Spencer's aplanatic ocular, I-inch. The radiant is acetylene, the plate a Carbutt's slow orthochromatic, with a screen of yellow pot glass. An exposure of three minutes is deemed necessary; the developer is hydroquinon. A fine negative is the result, reproduced in Fig. I0, magnified 200 diameters. All of the manipulations are the same as those already described under low power work.

High Powers by Transmitted Light.-For this class of work but little changes are required 
7O THE A B C OF PHOTO-MICROGRAPHY

in any of the procedures from those already shown. The lighting must be even more carefully looked after and the focusing is much more delicate and exacting. But it may be truthfully said that one who masters the art of making a good photo-micrograph with low or medium powers can do as well with the highest amplifications if he has the necessary appliances and uses them carefully. A substage condenser is among these, and homogeneous oil immersion lenses for the greatest amplifications. A serious loss of light from any radiant less powerful than the electric arc is unavoidable, which must be compensated for as far as possible by increased care and exposures. The modern oil immersion objectives are a boon, indeed, since they utilize about all the light that enters them. If we take a student's $\frac{1}{12}$ oil immersion, and carefully study its lighting of an object on the screen at say +1000, then replace it with the best obtainable dry $\frac{1}{6}$, under the same amplification, (obtained by increasing the camera's length or by higher eyepiecing), we will find the illumination by the former to be greatly superior to that of the $\frac{1}{6}$, notwithstanding the much greater actual aperture of the latter lens, there being no loss of light from either refraction 
or reflection with the homogenous objective.

High powers are chiefly useful in bacteriological work; for the resolution of diatoms and other test objects; in photographing blood; the pus corpuscles and all subjects requiring great amplifications. But higher powers than are absolutely necessary should not be used simply to exhibit a specimen made big as possible. Well and clearly shown under a moderate magnification it would be infinitely more instructive and pleasing. Could we see everything in nature without a microscope we certainly would not need to use one. Let us make a couple of negatives of this class, however, and see what we can do.

The first subject I have chosen is a karyokinetic figure in a leucocyte or white blood corpuscle, a rather rare specimen, by the way. Radiant and condenser are first centered with a low power, and it will be well to find our object, at the same time bringing it and the flame into focus together, the latter appearing as a brilliant vertical line of light in the field of view. Then removing this lens and putting a drop of cedar oil on the front of a $\frac{1}{12}$ hom. objective (a Powell and Lealand Apochromat of I.40 N.A.), we attach latter to microscope 
and carefully bringing it into focus upon the object find that the brilliant line of light, as seen under the lower power, has now broadened out, covering the whole field of view, giving us "critical" illumination, i.e., radiant and object in focus together. The substage condenser is the same achromatic one we have employed before and we use it with nearly full aperture; this objective being equal to almost any cone of light that may be offered to it. The same aplanatic ocular is also in place, so that our optical arrangements are unchanged, save in the objective and larger stop of condenser. The plate chosen-orthochromatic of course - is a Forbes slow L. The specimen shows several shades of red in the staining from a deep one to delicate pinkish. It is evident that sufficient exposure to obtain details in the dark karyokinetic figure must inevitably obliterate the more lightly stained corpuscles unless restrained in some manner. This we do with an acid-green screen placed in the holder as shown in Figs. 4, 5, 6, and having found from former experience that a yellowish tinge would help by modifying the blue-green of this screen, we add to it a second one of picric acid, the holder being constructed to carry several in combination when necessary. 
The remaining proceedings are those already detailed, the focusing being completed through both screens. The length of bellows extension and double screens, have so lessened brilliance of the acetylene flame that in connection with the slow plate a somewhat long exposure is manifestly necessary. Eight minutes are accordingly given, the plate being developed with eiko-hydro. Result, a fine negative at +825 . Shown in Fig. II.

Another example of high power work, in which the amplification is pushed closely to practical limits with either of the radiants we have been using, may probably be given with profit to some of my audience. I have chosen the well-known test diatom, Pleurosigma angulatum as the object and will endeavor to photograph it, "while you wait," at 3,000 diameters. We could obtain better results by making the negative at $\mathrm{I}, 000$ diameters and enlarging from this, for it is a curious fact that the best work on this diatom can be done at about the latter magnification. But since many have expressed a desire to see a negative made direct at a great amplification we will endeavor to gratify them. Really there is but little difference between the requirements for this and the preceding example. The optical 
arrangements throughout are identical, the increase in magnification being made solely by camera extension to about five feet, decreasing the illumination, but not to so great an extent as might be supposed. Observe that in this instance, as with all others in which an eyepiece is used, the camera is detached from microscope and slid back in order that centering and arrangement of object and illumination may be done directly on the microscope itself in the same way as ordinary examinations are made with that instrument. The camera is then attached and lighting, focusing, etc., completed upon the screen. For the present exposure I will use a rapid landscape plate - not orthochromatic - and the cobalt blue screen. An exposure of ninety seconds, with development by hydroquinon, gives us the negative from which Fig. I 2 was produced at $+3,000$.

Dark Field Illumination.-There are many transparent subjects which may be brilliantly illuminated by pencils of light passing through them at an obliquity too great to enter the objective directly, so that they appear somewhat as opaque objects upon a black ground. This is termed "dark field illumination," and will frequently exhibit details not visible by 
ordinary transmitted light, in addition to greatly increasing their beauty. It is usually effected by means of a paraboloid of glass carried by the sub-stage, which reflects to its focus the rays which fall upon its internal surface. It is useful with objectives of moderate angle and power only. I have not succeeded very well with any above $\frac{4}{10}$ inch, but others seem to have done better. The exposure in photographing is greatly lengthened as compared with that required for the same object illuminated by direct transmitted light. No change is required in the optical arrangement we have used in medium power work, excepting substitution of a paraboloid for the substage condenser then employed. By this means the negative of Fig. I3 was produced. It is a group of the anchors and plates of Synapta (a small marine animal), in the center of which may be seen a wheel of Chirodota violacea, belonging to the same order of holothuridæ. These are calcareous, without color, and not conspicuously brilliant objects when viewed by ordinary transmitted light; but, seen brightly illuminated upon a black ground, they are exceedingly beautiful, as the print well shows. In making this negative the objective was a Beck first-class $\frac{2}{3}$, without eye- 
piece. Radiant, flat side of coal oil flame; no condenser of any kind; a rapid landscape plate, without color screen. Exposure, eight minutes; developer, pyrogalol; amplification, 60 diameters.

My friend, Dr. A. C. Mercer, of Syracuse, N. Y., has suggested a method of making prints giving the effects of direct dark field illumination from any negative by ordinary transmitted light, if the subject be suited to this treatment. Details which are brought out by the oblique lighting of the paraboloid cannot, of course, be shown by this method, but it is most useful in very many instances and unlimited as to the amount of permissible amplification. Fig. I4 is a beautiful example of this method of obtaining dark field effects. The specimen, one of the beautiful discoid diatoms, Heliopelta, was first photographed by transmitted light under an amplification of 225 diameters. From the negative thus made a positive was printed by contact on a glass plate of slow emulsion, from which in turn the paper print shown in the reproduction was made. It speaks well for the process, which is particularly valuable to those who have no paraboloid for direct work, as is the usual case with the more modern micro- 
scopes. It may be interesting to some if I briefly note the procedures in making the original negative: Objective, a first-class $\frac{4}{10}$ of moderate aperture, by Beck's; ocular, Spencer's aplanatic, I-inch; Ross' achromatic substage condenser; plate, medium landscape; screen, cobalt blue; radiant, acetylene; exposure, $2 \frac{1}{2}$ minutes; developer, eiko-hydro.

Opaque Illumination by Reflected Light.-As already noted, the great majority of microscopical subjects are viewed by transmitted light, being naturally transparent or rendered so by artificial means; but a vast number are opaque; the surfaces only can be seen as illuminated by light reflected therefrom. Usually these require very low or medium powers for their rendition; in fact the illumination of an opaque object under high amplification is impossible, excepting with certain classes of subjects and by means of special illuminating devices. In metallography it is a most important adjunct in studying the characters of many metals and alloys, their polished surfaces being examined under magnifications from 100 diameters to more than $\mathrm{I}, 000$. In high power opaque work the objective is made to be the illuminator as well, either by means of a prism or a disc of thin glass placed within its mount. 
But I can do no more than mention the possibility of using high powers with opaque objects at this time and place. We are dealing only with the ordinary cases of every-day work. Such are the examples shown in Figs. I 5 and 16. The former is from a strewn slide of diatoms, mounted dry on a dead-black background, especially for examination by reflected light, and it certainly is a very beautiful object under the microscope-a beauty well repeated in the photograph. Attention is directed to a curious optical effect presented by this picture. Viewed with the page in ordinary position, many of the discs look like shallow saucers containing other diatoms of smaller sizes. Reverse the page and they all appear convex, with the smaller forms pressed into their bulging surfaces. This is caused by the illuminating pencil of light being projected obliquely across, thereby casting slight shadows of their delicate margins. Fig. 16, having been made with diffused daylight falling direct upon the object, is nearly free from shadows, and shows no change when thus reversed. The two negatives were made under the following conditions. Fig. 15: Objective, student's $\frac{2}{3}$; ocular, aplanatic I inch; radiant, acetylene, the rays thrown obliquely across surface of ob- 
ject by a bull's-eye condenser; plate, rapid landscape; exposure, 30 seconds; developer, eiko-hydro; magnified 53 diameters. Fig. 16: Objective, Beck's first-class $\mathrm{I} / 2$-inch; ocular, none; radiant, diffused daylight falling upon object, the camera being used in upright position; plate, rapid landscape; exposure, ten minutes, this apparently excessive time being rendered necessary by the color of object bright yellow on green background-and the dimness of illumination; developer, same as preceding; amplification, 30 diameters. EEcidium grossularia; cluster cups.

Polarized Light. It is a matter of regretto me, at least - that this method of illumination has fallen into such general neglect, and that its beautiful effects and valuable aid in the delineation of very many structures are utterly unknown to the majority of students at this day. A generation since, every microscope was supplied with polarizing apparatus almost as carefully as it was with object glasses. Now probably not one student's stand in a thousand can boast of one. None the less, the beauties it reveals may be opened by no other key, and I confidently predict that this formerly indispensable adjunct to a complete microscopical outfit will again become 
popular as of old. I cannot, however, pass it by totally unnoticed, though my remarks must be limited in space. For photographic purposes especially (though this holds good in all other cases) both prisms - polarizer and analyzer-should be mounted to revolve freely in their settings, and both should be of largest possible dimensions. The lower prism in my own apparatus measures $16 \mathrm{~mm}$. across its shortest diameter, admitting an immense amount of light. The analyzer must be carried between the objective and compound body of the microscope, and not above the ocular, as was formerly a common practice, since it limits the field of view very seriously. If the construction of substage permit, the polarizing prism and condenser should be carried together, the latter in front, of course. The field of view should be completely darkened by rotation of both prisms to the proper point before placing the object upon the stage, and a selenite should not be used, excepting in certain necessary cases. The exposures must be considerably lengthened, as with dark field and opaque illuminations. Two illustrations of this method in lighting are given. The first (Fig. 17) shows the large starch grains of canna root. These, mounted 
in Canada balsam, are practically invisible under plain transmitted light, but, submitted to the magic rays of the polariscope, present the beautiful picture seen in the print, showing the characteristic black cross of the starches most superbly. The negative was made in this manner: Objective, a Beck $\frac{4}{10}$ of moderate aperture; ocular, none; condenser, none; revolving diaphragm, medium-sized opening; radiant, coal oil lamp, flat side of flame; plate, rapid landscape; exposure, $2 \frac{1}{2}$ minutes; developer, pyrogallol; amplification, x ro diameters.

The beautiful effects of polarization in the illumination of crystalline substances are shown in Fig. 18, the subject being the flower-like crystals of amygdalin. These are almost invisible under ordinary transmitted light, but, submitted to that from the polariscope, are seen in glowing colors upon a black ground. The objective used in making negative was a Beck first-class $\frac{2}{3}$, without eyepiece or condenser. Radiant, coal oil, flat side of flame; plate, a medium landscape; exposure, 9 minutes; developer, pyrogalol; amplification, 70 diameters. These two negatives were made nearly twenty years ago, and are in perfect condition at present. 
Photo-micrographing Bacteria. Bacteriology is so distinctive and important a field of microscopical research that I have thought it well to give examples and some brief directions in the photographic aspect of it in a paragraph devoted exclusively to the subject. It is usually deemed a rather difficult one, but with proper staining of the specimen and a good oil immersion lens, it becomes one of the easiest operations in high power photo-micrography. The best stainings for this purpose, in my experience, are carbol fuchsine, haem-alum, gentian violet and Weigert's and Gram's methods. Methyl blue is fairly good but should be used sparingly. Amplifications of I,000 diameters are almost universally adopted in the scientific world as being sufficiently high to show very clearly even the minutest forms, and at the same time quite within the easy reach of a student's microscope and $\frac{1}{12}$ oil immersion objective. A substage condenser is indispensable. The Abbè chromatic form will answer but an achromatic is vastly superior, as by its means "critical" illumination and resolution are made practicable. No changes in the optical arrangements from those already described as being necessary with high powers need be made, and it only remains for me to. 
detail the making of each of the four negatives reproduced in Figs. 19, 20, 2I, 22, to complete my remarks on bacterial photomicrography.

Bacillus tuberculosis in sputum. Fig. 19. Objective, Bausch and Lomb's $\frac{1}{12}$ oil immersion, student's series; ocular, No. 4 Huyghenian, of the same make; condenser, Abbè chromatic, also of same series; radiant, acetylene, $\frac{8}{10}$ foot burner; plate, Carbutt orthochromatic, 23 ; screen, yellow glass; exposure, 7 minutes; developer, eiko-hydro; amplification, I,000 diameters.

Bacillus anthracis, spores. Fig. 20. Objective, Spencer's $\frac{1}{12}$ hom. immersion, student's series; ocular, aplanatic I inch; condenser, Ross' $\frac{4}{10}$ achromatic, full cone; radiant, acetylene, $\frac{3}{10}$ foot burner; plate, Forbes' orthochromatic S; screens two, picric acid and napthol yellow; exposure 3 minutes, less than half that required for previous one (Fig. I9), due to greater sensitiveness of plate, better lighting by an achromatic condenser and the aplanatic ocular; developer the same, eiko-hydro; amplification, I,000 diameters.

Streptococcus pyogenes. Fig. 2I. Objective, Powell and Leland $\frac{1}{12}$ hom. apochromat N. A. I.40; ocular, condenser, plate and screens same. 
84 THE A B C OF PHOTO-MICROGRAPHY

as in preceding example (Fig. 20); radiant, acetylene $\frac{1}{8}$ foot burner; exposure, I minute; developer and amplification the same. Observe again another great reduction in length of exposure, due entirely to the lens and its very wide aperture.

Bacillus Trommel-Schlaägel. Fig. 22. In this final example the optical arrangements were precisely those used with the two preceding ones (Figs. 20 and 2I). One screen only,picric acid,-was employed, an acetylene $\frac{1}{8}$ foot burner was the radiant and the plate was slower, being a Forbes' orthochromatic L, in consequence of which, and the denser staining of the subject, exposure was doubled,2 minutes, - development and amplification being the same.

Having carried my readers through the processes of Negative Making from widely differing subjects and illumination; under low, medium and high magnifications, it remains only to describe very briefly a method of doing the same with still lower powers-less than ten diameters. Macrograpbs such pictures would really be, and I have ventured to coin a word in this connection and call the process Photo-Macrography. Before doing so, however, I deem this a fitting place in which to give 
voice to a few thoughts which have arisen as these pages grew into being.

My earnest desire is to disclaim any intention to impress upon my readers an idea that the processes I have endeavored to make clear are the only practical ones, and must be strictly followed in order to insure successful results, which I honestly believe is too generally the case with most English writers on the subject. On the contrary, I recognize the fact that every true worker must and will have his own methods leading to the same results as those obtained by others through totally different ones, for there are many ways of accomplishing a given end. Some will doubtless regard the whole stuff as being more or less prolix, and possibly this may be true, but those who "know all about it" can skip such portions, which are intended for the real knownothings desirous of getting a start in the rudiments. I am in receipt of many communications from correspondents urging me to go down to the roots of the matter and "give all the little points that the other fellows have left out." One writes: "It will be well to suppose ignorance on the subject and give the methods as you practice them, using scientific terms only when necessary, and then clearly 
explained. B- is too much so and many, excepting true workers, can't grasp all the minutiæ. I don't care to read thirty pages for a few points." This, from one who is a "true worker" himself, seems to cover the point I would make,- that I have endeavored to explain the various processes as I follow them as clearly as possible without making any claim for their being the best or the only ones to be pursued. One thing I do know, if any "true worker" will take a single one or all of the specimens which I have enumerated and follow the processes as given in detail, he will be able to make at least as good a photomicrograph of each one as is herewith reproduced. When he has arrived at that stage of the work he will be ready to throw his mentor overboard and take to sea in his own boat. A word or two of advice-begin with the low powers and work upward, looking forward all the time and not backward. Aim high. Never allow yourself to be entirely satisfied with your own work. Always endeavor to be your own severest critic.

Photo-macrography. Worcester defines Macroscopic or Macroscopical as " noting an object which, although comparatively minute, is visible to the naked eye or to the eye assisted by 
a pocket lens,"-usually an inch or more in focus and magnifying less than ten diameters. A delineation or picture of an object thus enlarged would be a macrograph, and if produced by the aid of photography, why should it not be termed a photo-macrograph? At all events I have chosen to coin that word and to define it as a slightly enlarged picture or delineation of a macroscopical object produced by means of a lens and sensitized photographic plate. A few reproductions of such-pictures, with details of methods employed in making them, must bring to a close this already long chapter.

Photo-macrography is clearly beyond the range of the student's microscope as usually furnished. The initial magnification of its lowest power $\left(\frac{2}{3}\right)$, being about 15 diameters, renders it impossible. Nothing higher than 2-inch or 3-inch will answer for this purpose, and very few of these stands have sufficient length of rack to permit focusing with them. Some, as Spencer's, have a larger compound body and draw-tube fitted with the society screw, so that the objective may be carried within the main tube and thus focused. Such stands answer measurably well, though still restricted for practical use by the smallness of 
the tube limiting the projection of image embraced in the field of the objective. Fortunately, however, this class of work is well within the scope of a camera alone, any of which, provided with a rectilinear lens of short focus and sufficient bellows extension, may be utilized in its prosecution, if also furnished with a ground glass focusing screen. The only difficulty amounting to anything will be found in the very short bellows, so usual with American cameras, which cannot be extended sufficiently to reproduce an object at full natural size, to say nothing of enlarging it. If one possesses the E., R. \& C. camera (Fig. 3), this trouble will not worry him. The cone bellows front may be removed, and the object, if transparent, fitted in a carrier, so that all light entering the camera must pass through it. The lens is to be attached to a board in middle section, through the door shown in illustration, and the camera turned toward the source of light, which may be reflected from the sky or a cardboard placed at proper angle by day. If night work is necessary, the flat side of a coal oil burner, a Welsbach incandescent mantle or acetylene flame with rays made fairly parallel by means of a bull's-eye condenser, are all good and satisfac- 
tory. radiants, the main point consisting in securing even illumination. This accomplished, the section of camera carrying the lens is pushed forward nearly to the front and fastened. Then the rear section is to be moved forward or backward until the object is seen in focus on the ground-glass screen. If smaller than is desired, the lens must be moved a little nearer to the object and the rear section of camera farther from it; if too large these movements must be reversed and the operations continued until an image of required dimensions is projected on the screen and the final sharp focusing effected by gently moving the screen section backward or forward, as becomes necessary. The object glass or lens is not to be moved for this purpose, as with a microscope. It is effected entirely by the focusing screen. Rectilinear lenses of 3 to 5 inches focus, as usually furnished with the smaller cameras, are the best for photomacrography in general, but those of longer foci may be used if the bellows have sufficient extension. The focusing should be done with

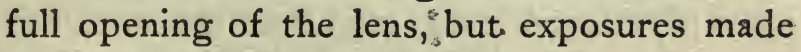
with stops of $f / 22$ or $f / 32$.

Should we not have a camera embracing the features of the E. R. \& C., some method 
must be found for utilizing whatever may be at our service in that line, usually some form of hand or portable box with tripod. It must be fitted with a focusing screen, and the length of bellows extension cannot be too great. Procure a smooth, flat board about four feet in length by nine inches wide, and nail or screw a strip of wood (say an inch wide by half an inch thick) along both edges of the upper surface for its entire length. A second board, three feet long, three-quarters of an inch thick, and of suitable width to slide smoothly between the guiding strips, must also be provided. To one end of the fixed or platform board another piece of same width and a foot or more long must be attached at a right angle, so as to stand perpendicularly when the platform rests on a table top. In this board an opening (usually square), the center of which shall exactly coincide with that of the camera when in position on the platform, must be cut and two or more spring clips similar to those on stage of microscope attached, for holding in place a glass plate, cardboard, etc., over the opening. Now, if our camera be one of the long focus folding or portable varieties so generally made at the present time, with bellows twenty or 
more inches in length and a lens of not over five inches focus, we shall have quite plain sailing. Suppose the object to be the wing of a butterfly from one to two inches in length, mounted on a glass slip with Canada balsam, rendering it quite transparent. A piece of thick cardboard with an opening in its center slightly larger than the object is attached to the front board of the platform by means of the spring clips already named, and the object slide secured to it by same means. If daylight is to be our radiant, the platform carrying camera must now be placed upon a table before a window, with its front facing the light; and the window should be darkened in such manner that none can enter save that which passes through the object or specimen. If this is not practicable, another means of preventing extraneous light from entering the lens must be devised, and will be explained presently. The camera is now to be attached to the sliding board and advanced until the lens is within a few inches of the object, which must be moved about on its cardboard support until seen squarely in center of focusing screen. If not amplified sufficiently, the lens must be carried closer to it and the bellows extended further away, the amplification being 
limited solely by their length. If it be found too great, the operations are to be reversedthe lens removed farther from the subject and the bellows shortened. The desired magnification having been attained, final focusing is done by moving the screen back or forth, and for such low powers the ground glass is sufficiently fine to do so with the greatest accuracy. If our room has not been darkened, it will be found that a large amount of light entering the window falls upon the lens without first passing through the object. This must be cut off by a cloth or some other covering placed over the space between the two. A stop or diaphragm of about $f / 22$ must then be inserted and cardboard or other device placed in front of the object or between object and lens, as may be found most convenient, to cut off entrance of light whilst the slide is being drawn from the holder. If the lens is provided with a time shutter so much the better, but cap exposures are not advisable, for fear of disarranging something. The length of exposure can only be ascertained by practice and experiment, but something may be learned about it by carefully studying the explanations as to the making of the four negatives herewith reproduced. Should artificial illumination be 
resorted to, the radiant must be placed upon the table in front of camera and behind the object, at such a height that its center shall coincide with that of the lens. The rays may be condensed upon the object by means of a bull's-eye condenser or diffused by placing a sheet of ground glass between the light source and object. The proper length of exposures must be learned by practice, but they will be somewhat longer than those required for diffused daylight illumination.

Should our camera be one of the usual short bellows form it will be of little or no use in making enlargements or photo-macrographs without certain modifications. To start with, an upright board should be attached to the front end of sliding platform, with a circular opening at precisely the same height as that in camera front. The lens flange of latter - or better a duplicate onemust be fastened to this board to carry the lens instead of camera. If the front of camera is removable, so as to admit all of the rays projected by the lens, the manipulation will be very simple, for we have the same conditions as in the last example: a lens and focusing screen moving independently. The object may be centered and brought to desired 
94 THE A B C OF PHOTO-MICROGRAPHY

dimensions as in that case, the camera secured to platform and final sharp focusing effected. Then the space between lens board and camera front is to be covered to exclude undesirable light, when the operations may be concluded as before.

A recent number of British Journal of Photography - that of May Io, I90I-contains an imperfect description and worse illustrations of a portable camera for enlarging which would seem to be admirably adapted also to photo-macrography. These convey the idea, however, and it seems to be so practical and worthy of adoption that I subjoin both description and illustrations as given in that journal. I have not seen the instrument, but from the well-established reputation of its makers, have no doubt of its efficiency.

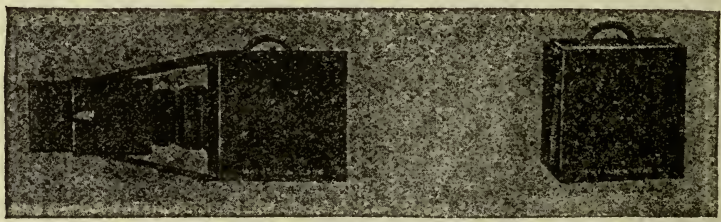

Watson's Enlarging Apparatus

"In the enlarging system shown by the appended illustrations, Messrs. Watson have combined simplicity with portability. The 
body of the instrument is made of mahogany, and the central extension portion takes the form of a camera bellows. By one or two easily controlled movements the enlarger, when not required for use, may be made to collapse, and it is then packed up within itself as shown in the second illustration. The quarter-plate and five by four sizes admit of the negative (glass or film) being enlarged up to $8 \frac{1}{2}$ by $6 \frac{1}{2}$ and ro by 8 , and the half-plate up to 12 by ro. A lens is supplied with the instrument, or the photographer's own lens can be adapted and focused. For daylight work, to a moderate degree of amplification, this portable enlarger, which has been submitted to our inspection, should meet the needs of a very large body of amateur photographers."

Should the front of our camera be fixed, the instrument will be of no use in photo-macrography. We must contrive a portable bellows or a series of boxes sliding within each other and fitted with a focusing screen at one end which may be replaced by a plate-holder, and with these make an arrangement for receiving and utilizing the image-bearing rays projected by the lens.

Four illustrations of pboto-macrograpbs of as many widely differing subjects are given. The 
96 THE A B C OF PHOTO-MICROGRAPHY

following descriptions will show the method pursued in making each one and may serve as guides in similar cases. They were all made with the E. R. \& C. camera (Fig. 3) by light reflected from a western sky.

Fig. 23. Corisa undulata, or Water Boatman. This is a large insect of too great size to be comprised within the field of any ordinary microscope objective, but easily shown in that of a photographic lens, which in the present case is one of Beck's rapid rectilinears of 7 inches focus, the stop being $f / 22$. Plate, Forbes' orthochromatic L; screens two, picric acid and acid-green; exposure, 80 seconds; developer, eiko-hydro; amplification, $3 \frac{1}{2}$ diameters.

Fig. 24. Transverse section, stem of Serjania, a tropical climbing plant. This specimen was quite within the capacity of a 3 -inch microscope objective, but was taken with a photographic lens to show the capability of the latter in delineating microscopic details of the cell structure. Lens was Beck's 5-inch rectilinear of same series as that used in the preceding example, with same stop, $f / 22$; Forbes' orthochromatic plate, L; napthol yellow screen, exposure, 5 minutes; amplification, 5 diameters. 
In Fig. 25 a female mosquito, Anopheles, is shown. The lens was the same as the last, with stop $f / 32$. Exposure, 4 seconds; plate, rapid landscape; no screen; developer, eikohydro; amplification, 3 diameters.

Fig. 26. Human scalp - flat section, cutting hairs transversely. Lens, Ross' concentric 4 inches focus; stop, f/22; plate, Forbes' orthochromatic S; screen, picric acid; exposure, 2 minutes; developer, eiko-hydro; amplification, 7 diameters. 


\section{CHAPTER VI}

\section{Printing Methods-Lantern Slides}

I fear the title of this chapter may be somewhat misleading, since it is by no means my intention to enter upon a description of the many printing processes open to the photomicrographer. There is not available space in this book for the full explanation of a tithe of them, and the student is referred to the many works on photographic matters for information on the subject in general; but there are some inklings, born of experience, which I think it well to jot down. It may be broadly stated that any known printing process will yield good prints from a photomicrographic negative, although there is a very decided choice among them if one looks for the best work. The old albumenized or plain salted papers, gelatine or chloride emulsion P. O. P., of which there is an endless variety, carbon tissue, platinum and bromide of silver papers, will all give good results if properly used. But my own preference is decidedly for the Velox glossy paper, which I 
have used almost exclusively since its introduction, a number of years ago. A shining surface is detestable in a landscape print and numerous other subjects, but it is perfectly adapted to the delineation of a microscopic object, when it possesses the peculiar properties which have made Velox altogether the best printing medium for this class of work that I have ever seen. The most delicate details are rendered with the fidelity of a glass transparency; they are not sunk into the paper, but borne entirely upon its surface. The printing may be done by lamp- or gaslight, with even greater regularity and certainty than by day. The development is simple and sure; there is no toning to be done. Pure whites, glossy blacks, lovely half-tones, are always obtainable, and the prints are almost without doubt permanent, whilst the paper itself keeps indefinitely previous to being printed upon. All of the operations may be pursued in subdued daylight or by ordinary lamp-light. No dark-room is necessary. The paper itself is so heavy as really to require no mounting. Of more than 4,000 prints made three years ago for a portion of the High schools of New York city, not one was mounted on cardboard, yet they have 
been in continuous use by classes of students during all the succeeding sessions and are in good condition at the present time. Finally, it is no more costly than any of the ordinary papers that are inferior to it for our purpose. Its price is somewhat higher than these, but this is more than offset by the cost of gold used in toning the latter-that is, where gold is used-unfortunately too often omitted, to the entire ruin of the prints in point of permanency. The directions for printing and developing, which accompany each package, are so simple and efficient as to require no additions here. They cannot be improved upon, and the formula for metol-quinol developer seems to be perfect. Pure blacks and whites, with soft gray half-tones, may be depended upon from good negatives by its use. Some subjects are decidedly improved by printing in browns, sepias or reds. All of these tones may be obtained by using the same developer greatly diluted, to which a few grains of ammonia carbonate should be added. Long printing and still longer development are required in these cases. I am not prepared to give more extended directions for these at present, not having done enough work by this printing method to render 
PRINTING METHODS-LANTEXN SLIDES IOOI

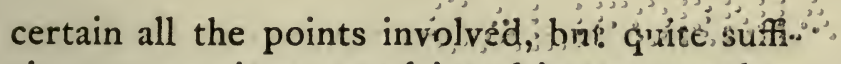
cient to convince me of its ultimate complete success, as well as desirability.

Nothing is perfect-in this world, at leastand Glossy Velox has its imperfections in common with all things mundane. The only one of any consequence that I have noticed is its liability, nay, certainty, of developing streaks or spots in the white margins around the prints as usually made with a mask. In the thousands of prints I have handled in all the stages from printing to finishing, I have not seen one entirely free from these. The makers say that they are caused by friction in the calendering machines, but can be readily removed by rubbing gently with a tuft of cotton wool moistened with alcohol. Whatever the cause, most decidedly this remedy will not answer at all. It is utterly worthless. They further say the marks may be prevented by the addition of a drop of a ro per cent solution of potassium cyanide to each ounce of developer. Useless again; it will not prevent the marks. They may, however, be instantly removed by the expenditure of a moment's work on each print, after development, fixing and a slight washing. Prepare a weak solution of Farmer's reducer, as follows: 
IO. THE \& C OF. PHOTO - MICROGRAPHY

$$
\begin{aligned}
& \text { Hyo } \because \because \therefore \text {. . . . . I oz. } \\
& \text { Water . . . . . . . } 4 \text { ozs. } \\
& \text { Ferricyanide potass. C. P. . . . . } 10 \mathrm{grs} \text {. }
\end{aligned}
$$

Take each print separately from the water, and, holding it in one hand, with the other go over it very carefully with a moderately large, round camel's hair brush filled with the reducing solution, taking care not to get this over the margin of the print during the operation. A very little practice will render one expert in this, and the marks will disappear like magic. Running water should be allowed to wash over the face of print frequently, in order to prevent any action of the reaucer upon the print itself, should some accidentally get upon it. Final washing and drying, as usual, must follow.

Since the above paragraph was written, I have had an opportunity of using another brand of paper, possessing all of the good features of Velox, with the additional one of an entire absence of the surface markings, which are such a disagreeable feature of the latter, the sole drawback to its use indeed that I have found. This is the S-C-P or "Slow Contact Paper" of Wellington \& Ward, England. It has the same perfect surface as the Velox, the same sensitiveness and is de- 
veloped with the same developer-MetolQuinol. In rather an extended use of it during the past month or two, I have not seen a single instance of the markings so common with Velox, and as it is coated on a much heavier stock, the prints are even better without mounting than are those of the latter make. I am not sure if it can be obtained in this country, but think it likely that Wm. C. Cullen, 6I William street, New York, who makes a specialty of foreign photographic articles, may be able to supply it. I am sure it is worth trying, at least.

Photo-micrographs, as a rule, look better and are more pleasing when printed under a mask with circular opening of suitable size for the object, leaving a white margin about the picture, which then is of the same shape as the field seen in the microscope itself. These masks may be made with the dark orangeyellow "post-office" paper to be had everywhere, and which is perfectly safe for the slow emulsions used in sensitizing all printing papers. The openings are readily cut by means of a "form" and a revolving wheel cutter. There has recently been introduced, at a trifling cost, a set of forms of various shapes and sizes, together with a cutter, which 
IO4 THE A B C OP PHOTO-MICROGRAPHY

may be had from all photographic supply houses. This is a veritable boon to the printer and lantern-slide maker.

Photo-micrographic prints on glossy surfaced paper are vastly improved by "squeegeeing" on a ferrotype plate, but the process is so great a bugaboo to many that they fail to follow it, and thus lose the best features of such a print; but if properly done in all its stages, nothing can be easier or more absolutely certain of success than this sometime dreaded method of finishing a print. In the first place, the ferrotype plate itself is one of the most important factors, if it be desired to have it give continued and uniform good service. In selecting it get the best, with perfect face and double thick, in order to prevent wrinkling (so common with thin plates), and have each sheet cut in half crosswise, giving two plates $7 \times$ Io inches. Each of these will hold at one time four prints $3^{1} \times 4^{1}$, or two $4 \times 5$, the most common sizes used in photo-micrography. One print each $5 \times 7$ or $6 \frac{1}{2} \times 8 \frac{1}{2}$ may be placed upon them if a larger camera be used. We now face two problems, however, each of much greater importance than the choice of the plate itself. One is to bring the surfaces of print and plate into 
perfect contact without the thinnest stratum of air between them; the other to devise some means of effectually and certainly preventing the print from sticking to the plate when dry $-a$ fatal incident in the life of the former always, and not infrequently so to the latter. All gelatine emulsions coated on paper are liable at times, especially in hot weather, to softening whilst wet, usually in spots, rarely all over the entire surface. Even Velox is not entirely free from it, though more nearly so than any other paper I have ever used. In this condition it is like the most tenacious glue, insoluble in water cold or hot, and sticks with such pertinacity to the ferrotype plate as to become inseparable from it except by destruction of the paper and practical ruin of the plate for squeegeeing purposes. I have now a plate to which two prints stuck in this manner several years ago, and thus far they have resisted every attempt at removal. I keep it as a terrible example and for experimental purposes. Fortunately I long ago discovered a preventive remedy for this defect, and the perfect contact of plate and print is very easily and certainly effected.

When the prints have been fully washed and freed from all traces of hypo, they should 
I06 THE A B C OF PHOTO-MICROGRAPHY

be transferred to a tray containing a solution of water and formaldehyde (in the proportions of one drachm of the latter to four ounces of the former), in which they are to remain until needed. A tray of sufficient dimensions to contain one of the plates (say $8 \times 10$, though $10 \times 12$ is better) is then to be filled with water and placed conveniently near the other. Then, holding the plate under the tap, with water running gently over its surface, wash the latter with a tuft of fine absorbent cotton, taking great care not to scratch it, and transfer the plate to tray (polished side upward), making sure it is plentifully covered by the water and that no airbells have formed on its surface. It should have been stated that it will be well to place the prints in the formaldehyde bath, face upward, turning them over in a few minutes, at the same time carefully noting whether any air-bells have formed upon them; if so, they must be removed and the prints turned over, face down. All being now ready, and supposing our prints to be $4 \times 5$ inches in size, I take by the corners, one in each hand, and, raising them from the bath by a sliding motion, transfer them in the same manner to the other tray, quite certain that they have carried 
no air with them, and that nothing but water intervenes between their surfaces and that of the plate. Observe that, having pushed each into position, all beneath the water, I grasp the plate and prints by thumb and fingers of each hand, and raise out of the water again by a sliding motion, allowing the surplus moisture to run off at the bottom, whilst the prints adhere quite closely to the wet plate. Now carefully wipe the prints and both sides of plate with a soft sponge, taking care not to move the former, as they are not yet very firmly attached to the plate, more or less water still intervening between their surfaces, but after passing a flat rubber squeegee several times over them they may be handled almost with impunity. The final act is to lay the plate upon a table, prints upward, and place over them a smooth, absorbent linen towel, passing the squeegee somewhat vigorously over its surface several times, until all moisture is apparently abstracted. Then remove them to a dry place-if possible in a gentle current of air-to dry spontaneously, when they will probably peel off the plate of their own accord; at farthest, a slight, steady pull by one corner will dislodge them. On no account must this be attempted until they 
are "bone dry," and it must always be done by one steady pull; a succession of them will leave a series of disfiguring creases across the print. The ferrotype plates should be carefully laid away from dust in a drawer or box face to face, with a sheet of tissue paper between. When taken out for use they should always be carefully washed with a tuft of cotton wool, as already described. It will not do any harm to wipe them occasionally with a soft cloth and a little coal-oil, followed by a perfectly dry cloth, always quite soft, to avoid danger of scratching the polished surface.

Blue prints, when carefully made on suitable paper, are very satisfactory for many classes of objects, pleasing the artistic eye and rendering delicate details with astonishing fidelity. The ordinary commercial papers, however, are totally unsuited to our work; their surfaces are not smooth enough, nor are the whites at all pure. Every photo-micrographer who elects to use this method of printing should prepare his own paper, hence I am led to give a few simple directions for so doing. The best paper for the purpose with which I am acquainted is Rives'. It is pure linen, of medium weight, heavily sized 
and perfectly white. It may be procured of any photo-stock dealer. The chemicals are but two in number, both very cheap, and should be chemically pure. They are potassium ferricyanide (red prussiate of potash) and ammonia citrate of iron. To make the sensitizing solution, dissolve just before using, 64 grains of the red prussiate in $I$ ounce of water, and roo grains of the iron citrate in a like quantity, keeping them separate to the last moment, when they are to be filtered together through a wad of wet cotton wool placed in the bottom of a small funnel. The paper, having been previously pinned by its four corners to a smooth board or table-top, is now to be gone over with a fine sponge dipped into the filtered solution, in regular, broad strokes, first from left to right, always in one direction, until its surface is completely coated; then at right angles to the first coating, ending at the upper right hand end. If properly done the surface will be smooth and even, without lines or marks of any kind. A little practice will make perfect, as in other things. The sheet must then be hung up in a warm place to dry, which it will do very quickly. All of these operations must be done by lamp- or very subdued day- 
IIO THE A B C OF PHOTO-MICROGRAPHY

light, and the paper, after sensitizing, must not be exposed to the latter except in printing. It is much less sensitive than a silver coating, but the whites will lose in purity by a very short exposure to daylight. Printing should be done by direct sunlight and continued until the details are well shown in a dirty bronze color. The prints should then be placed, face down, in a tray of water for a few moments, then washed through several changes and finally dried between sheets of smooth blotting-board under gentle pressure. A picture thus made is absolutely permanent, and, with its brilliant blue tint on a snowwhite ground, "a thing of beauty and a joy forever."

Finally, as to printing methods on paper, I would advise the use of a deep printing frame with glass front and of ample size, say $6 \frac{1}{2} \times 8 \frac{1}{2}$ (my own favorite) - not too large, easy to handle, "just right." A spoiled negative from which the film has been removed will answer for the front, but a sheet of thin plate glass is much better, as it is perfectly flat. The breaking of a negative from unequal pressure in such a frame is well-nigh impossible; all sizes, from quarter to full plate, may be printed in it, and in making 
lantern-slides by contact printing any portion of the negative can be utilized, which is not the case with frames of small sizes. A single frame can thus be made to do the work of a number - a manifest advantage.

It seems almost superfluous to say aught as to the making of lantern slides at this late day, when so many thousands of amateurs have become more or less proficient in the art formerly in the hands of professionals alone; but the excellent dry plates of thin glass, so readily obtainable everywhere, with equally thin covers, ready-cut masks and gummed binding strips, have made the production of a lantern slide so easy that every one undertakes it at times, and with very indifferent success in the majority of cases, mostly preventable. I cannot pretend to enumerate the causes of these failures or their cure. Every one is familiar with the wretched caricatures too frequently shown upon the screen. There is no need for their being, especially in photo-micrographs. Secure a good negative first; after that proper attention to a few simple details will insure the making of a good lantern slide from it. Nothing can exceed in beauty and interest a thoroughly good lantern picture shown 


\section{II2 THE A B C OF PHOTO-MICROGRAPHY}

upon the screen by an equally good light. It should stand without loss the searching rays of the electric arc, and may truly be termed good if it does so.

Excellent plates for this purpose are now furnished by all the leading makers of negative plates. I have used them all and can testify to their uniformly good qualities. They vary considerably in sensitiveness and in the tones produced by given developers. I have found it most satisfactory on the whole to use the particular one recommended by the makers, who seem, one and all, to have worked out the best methods in each case. I have already elsewhere spoken of the entire satisfaction with which I have used exclusively for over a year past the Forbes negative plates, to which must be added those for lantern-slides, which I have also employed during the same period of time with such uniformly good results as to leave no desire to change. They are quick, give brilliant pictures, have no tendency to fog or frill, allow great latitude of exposure, are very easy of manipulation and cheap. What more could one desire?

Two methods of making lantern-slides are open to the photo-micrographic in common 
with all other classes of negatives-by contact printing or by reduction with a lens. For the latter method a camera like the E. R. \& C. (Fig. 3) is most convenient, though work may be done with the improvised apparatus already described for making negatives. This is by far the best way to secure the most satisfactory lantern-slides; and when the negative must be reproduced in whole but is of too large size for their limits, is the only method by which it can be accomplished. It is not necessary to repeat the manipulations already detailed for negative-making, these being precisely the same, excepting that the image is enlarged in the one case and reduced in size in the other.

Contact prints are made in the same manner as those upon paper, but masking out of portions of the negative may be omitted. If the latter has been made with a view to this method of printing it on a lantern-slide, there is nothing further to do than to put the film surfaces of both plates together and expose in a printing-frame to lamp- or gaslight. If only a certain portion of a larger negative be needed, it should be carefully placed in contact with the center of lanternplate before exposure. Do not make this 


\section{II4 THE A B C OF PHOTO-MICROGRAPHY}

latter too long. A short, but, of course, sufficient exposure, with comparatively long development, will give clearer high lights and more transparency in the shadows than the reverse; but be careful to avoid under-exposure, as no amount of forcing or other manipulations will ever give satisfactory results if the light has not acted its part upon the sensitive emulsion. Experience and practice alone will give proficiency in this somewhat difficult and always delicate work. You must be prepared for and expect some failures, since you are certain to meet with them; but be not discouraged; success is sure to attend upon patient, persistent effort. The spoiled plates need not be wholly wasted. After keeping them long enough as "frightful examples and warnings," the films may be cleaned off by hot water and the plates be used as cover-glasses for other slides.

All lantern slides should be varnished, but not before making sure they are worth preserving and require no further doctoring, as they may do in the way of local intensification or reduction, toning, etc. I do not deem it necessary to give directions here, since they are so fully detailed in the books accessible to all at this time. A thin, clear varnish, 
drying hard quickly without heat, should be used. If coloring of the picture is decided upon it must, of course, be done before varnishing. Many subjects are greatly improved by judicious application of transparent colors, but great care must be exercised in the operation. In The Photo-Miniature, Vol. I, No. 9, "Lantern Slides," may be found very clear and explicit details of all necessary operations.

The finishing of a lantern slide is a very important factor in the beauty of its appearance. Slovenly-cut masks, dirty backgrounds, pictures upside down and other defects - all preventable-detract largely from its other good features. A uniformity of mounting, in so far as possible, is greatly to be desired. As a rule each maker of slides seems to have either his own pet plans or no plans at all, for frequently no two of his mounts are alike, with results most embarrassing to the unfortunate who manipulates the lantern, to say the least. At the risk of appearing, perhaps, somewhat egotistical, I venture to give my own method of finishing, which seems simple and practical, and which I have followed for many years in mounting slides of photomicrographs:

After varnishing and drying, the mask, hav- 


\section{II6 THE A B C OF PHOTO-MICROGRAPHY}

ing circular opening if possible, from $2 \frac{1}{2}$ to $23 / 4$ inches in diameter, is laid upon the slide and covered with the previously cleaned thin glass of same size. Should there be more than one to finish, all are treated in the same manner before proceeding farther. A gummed binding-strip - to be had of any dealer-is now to be taken by one end between the thumb and forefinger and drawn through a tray of water, gummed side uppermost. When lifted from the tray the excess of water should be removed by drawing it between the thumb and finger of the other hand with a gentle pressure, after which the back may be dried by drawing it over a soft towel. It is then to be laid upon any dry, hard surface; the slide and cover-glass, held between the thumb and finger, are pressed by one edge along its center, to which it will adhere, and may be raised from the table. Now bend it carefully around the corner and repeat until all four sides are attached to the center of the strip, with the ends overlapping a little at one end of the slide. Then carefully press the paper along each side firmly to the glass, turning the corners neatly and rubbing all down smoothly with finger and thumb. This may not be a success at the 
first trial, but, as in all of our other operations, a little patient work will make perfect. It would be well to practice with a dummy slide until the "knack" is acquired. Now come the finishing touches. Lay the slide flat upon the table, cover side up, and with the top of the picture as you wish it to appear upon the screen also at top of slide as it lies before you. In other words, it should be in exactly the position you desire it to occupy on the screen. Then gum a circle or square of white paper to the lower left-hand corner, as shown in Fig. 27. Now turn the slide over from top to bottom (not from right to left), and gum the label on left-hand side, as shown in Fig. 28, which will bring it over the spot on face of slide. If then the operator, when putting a slide into the carrier, does so with this spot label always on top and facing the screen, the picture must be projected right side up and just as you have designed it to be shown.

The picture on a lantern-slide must fill either the entire space of cut-out in the mask or only a portion thereof with a margin of clear glass or slightly tinted, as the negative may be more or less dense. The appearance of such a slide as the latter, is greatly marred 
II 8 THE A B C OF PHOTO-MICROGRAPHY

by a dirty or imperfect background highly magnified on the screen, and the utmost care should be taken to avoid this, not only in making both negative and positive, but also in the preparation of the object to be photographed. The mounting should be absolutely clean and free from specks of any foreign substance. No subsequent carefulness in the photographic manipulations can entirely compensate for defects in a faulty microscopic preparation.

Two illustrations, representing the front and back of a lantern slide prepared in accordance with the foregoing directions, are given. They are of the standard American size $-3 \frac{1}{4} \times 4$ inches. Fig. 27 is a transverse section of a compound ovary, magnified 20 diameters, and occupies the center of the cutout, with clear glass about it. Fig. 28, the compound eyes of a water-beetle (Dytiscus Marginalis), +75 , fills the entire circle. Each of these facets or eyes being a convex lens, shows an image of the radiant used in making the negative. Both slides were printed by contact, as with a paper print. 


\section{CHAPTER VII}

\section{General Notes}

In my note-book are a number of suggestions which may, perchance, be of interest to some of my readers, but could not well be incorporated with any of the preceding chapters. Taken at random from its pages, I present them in collected form, with the hope that they may be useful to a few, at least, which is my excuse for adding them at all.

Note-Book. I would urge upon all who intend giving serious attention to photomicrography the great importance of keeping liberal notes of each negative they make, in some clear and simple form.- These should include date of exposure, objective, ocular, condenser, plate, screen, radiant, length of exposure, developer, amplification, etc. It would add still further to the value of such notes if the stain used in making preparations were given also. The note-book should be of ample size and may be ruled to suit the ideas of each worker, or left blank if he prefers. A form shown on the next page is good. 
I20 THE A B C OF PHOTO-MICROGRAPHY

\begin{tabular}{|c|c|c|c|c|c|c|}
\hline 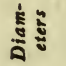 & 8 & q & $\stackrel{\text { ̊ }}{ }$ & $\stackrel{\circ}{\circ}$ & $\stackrel{8}{8}$ & 8 \\
\hline ذั & 客竞 & $\begin{array}{l}\text { E. } \\
\text { : }\end{array}$ & 宰害 & 它飑 & 竧离 & 客蓄 \\
\hline 产 & 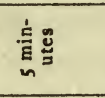 & 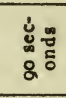 & 离总 & 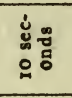 & 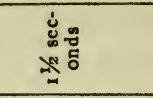 & $2 x$ \\
\hline$\stackrel{\Xi}{a ̆ ~}$ & 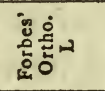 & 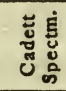 & 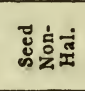 & 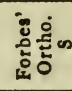 & 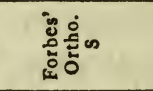 & 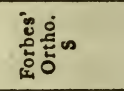 \\
\hline हू & 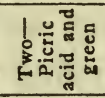 & 言 & $\begin{array}{l}: \\
\\
\end{array}$ & 产 & 1. & 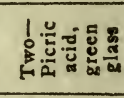 \\
\hline $\begin{array}{c}\text { हूँ } \\
\text { चूँ } \\
\end{array}$ & 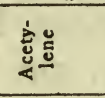 & 容苛 & $\begin{array}{l}\overline{0} \\
\text { ö } \\
\text { i }\end{array}$ & 产我을 & 苞 & 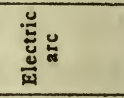 \\
\hline ปัँ & 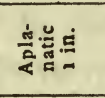 & : & 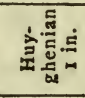 & 产 & 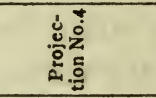 & 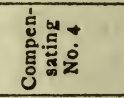 \\
\hline हूँ & & 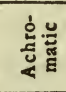 & 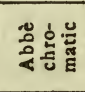 & 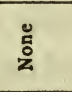 & 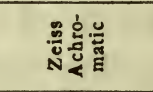 & 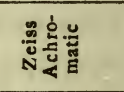 \\
\hline 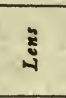 & 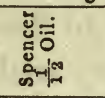 & $\begin{array}{l}m \\
\text { घँ } \\
m\end{array}$ & $\not 0$ & 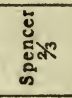 & $\begin{array}{l}0 \\
\stackrel{D}{0} \\
\text { N } \\
\end{array}$ & 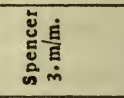 \\
\hline 乡ั & 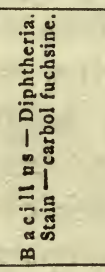 & 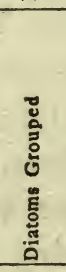 & 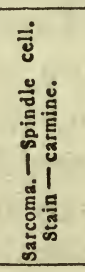 & 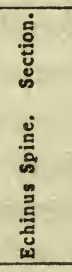 & 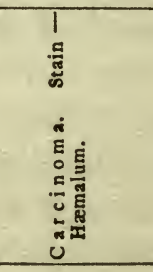 & 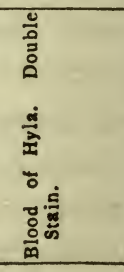 \\
\hline ฐั้ ฉั & $\sum^{n}$ & $\stackrel{0}{0}$ & $\begin{array}{l}\bar{E} \\
\vdots \\
\end{array}$ & $\begin{array}{l}n \\
\vdots \\
\vdots\end{array}$ & $\frac{\pi}{8}$ & בั \\
\hline$\stackrel{8}{2}$ & $\tilde{8}$ & 8 & 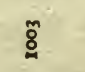 & 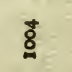 & $\tilde{g}$ & : \\
\hline
\end{tabular}


The purposes such a list will serve are numerous and varied. One of the most important of these is the information it imparts as to plate, illumination, exposure, etc., which have produced satisfactory negatives as guidance in future cases of similar character, until experience shall have given the worker intuitive knowledge, as it were, of the best methods of handling every class of subject.

Numbering Negatives. Systematic work is urged throughout, and from the very beginning. One most important point is the num. bering of every negative in a permanent and legible manner. This should be done before exposure, to guard against forgetfulness and possible confusion afterward. There may be various plans adopted. My own, which has stood the test of practical use during many long years, is simple in the extreme. The only tools required are a good lead-pencil of medium hardness only (indeed it is better to incline somewhat to the soft side), with a fairly blunt point, and a sheet of cardboard sufficiently large to cover the plate. When about to place the latter in holder, lay it, face upward, in front of the ruby lantern, covered by the card, excepting a narrow strip of its lower edge, to protect it from the light. 
Then write the number in strong, well-formed figures in the left-hand corner, using considerable pressure, but not enough to break the pencil point or scratch the film. After development these figures will remain perfectly legible and permanent. The corresponding number, with particulars, entered in the notebook at the same time, completes the record.

Storing Negatives. As the number of our negatives increases, the necessity of storing them in some systematic manner which will keep them in safety and at the same time facilitate the prompt finding of any one as needed, becomes more and more apparent, if we have not started to do so at the outset of our work. It is, therefore, wise to begin this important item with the very first negative made. Two methods are suggested, both of which have been found good and practical. In the first, the negatives are to be placed in empty plate-boxes of same size, with a sheet of paper between each pair, and the numbers written on the end of box, these in turn being piled on shelves in a dry room, with the numbered ends in front. They are thus kept free from dust or other injury, and any one can be readily found after reference to the note-book record of its number. A serious objection to 
this plan is the facility it affords for scratching the gelatine film. Very frequently the plate wanted proves to be the bottom one in the box, necessitating the removal and replacing of all the others in obtaining it. A careless movement might seriously mar the perfection of a valuable negative in a moment. This danger, however, can be greatly lessened by coating the film with a hard varnish.

The second method which I would suggest as being altogether preferable, is to place each negative in an envelope of stout manila paper,-sold by all stock dealers under the name of negative preservers, - with its number plainly written on the face. These are stood on end upon a shelf in numerical succession, where they are fully protected from injury, and are instantly accessible. As their number increases it will become more and more difficult to pick out a desired one from the notebook. At this point recourse to card cataloguing, as with a library, will effectually remove all trouble and greatly facilitate the finding of any desired negative.

Varnishing Negatives. In a dry climate like ours the varnishing of gelatine negatives is not at all necessary, unless very large num- 
I24 THE A B C OF PHOTO-MICROGRAPHY

of prints are to be made from any one, in which case it is recommended to do so. And if we have unfortunately to employ the services of a printer, it is well to varnish the negatives first, as a safeguard against carelessness. A hard varnish, drying without heat, should be used and must not be applied unless the film is entirely free from moisture, in fact "bonedry." Neither should it be done before a print is made and the negative found to be satisfactory in all particulars, since no alterations, such as reducing or intensifying, can be made without its removal. This may be done by immersion in alcohol, but it is much better to be sure that the negative is all right first.

Intensification. A perfect negative of course is one which needs no after-treatment when the development is finished; specimen, lens, illumination, exposure, developer, having alike done their parts in producing a harmonious whole. It is what we strive for throughout, and thanks to the present perfection of optical apparatus and dry plates, is very generally reached by all who have had some practical experience and earnestly work for it always. But there are frequent unforeseen contingencies to be met, which disappoint our expectations and require the making of another 
negative, or a "doctoring" of the defective one. The beginner must not yield to discouragement should his most careful work turn out a failure. Such contretemps will happen to the most experienced workman. We do not usually show our failures, and only the operator himself ever knows how long a list of them have been charged off to profit and loss. It is well, therefore, to be prepared for troubles and how to meet them. As it is impossible in this connection to enumerate all that may arise, I shall confine myself to two or three of the most common ones and their remedies.

Assuming that both optical and photographic appliances, including plates of course, are of good qualities, the majority of failures are due to under- or over-timing of the exposure, and to under- or over-development of the plate. The first of these I shall dismiss at once in a single sentence,-make another exposure,-for a really under-timed negative can never be successfully after-treated. An overexposed plate probably gives more frequent trouble to the novice than any other thing, but fortunately he can usually remedy it. The development commences so quickly and proceeds with such rapid strides that he is 
alarmed, fearing the entire plate will be equally blackened throughout and completely ruined. He thereupon removes it from the developing bath, washes hurriedly and places in the hypo solution quickly as possible, in order to prevent this dreaded result, only to find after fixation, that the negative is full of detail but so utterly lacking in density or contrasts as to be quite unprintable. The plate, however, is not necessarily wasted, nor need another exposure be made in most cases, as required in undertiming. Unless the negative is hopelessly over-exposed, very thin and flat, intensification will usually put it into shape for producing good prints. There are many ways of doing this, to be found in all books on photography, and I shall give but two here which I know to be good and reliable. The first has had nearly twenty years of continual use in my hands without a failure, hence I recommend it without any hesitation or reservation. I am indebted for it to an article in an old number of The British Journal of Photography's Almanac - under the heading of "Cyanide of Silver Intensifier." Every one, of course, is familiar with the old method of intensification by first bleaching with a mercurial solution 
and subsequent blacking by treatment with ammonia, sodium sulphite, or other agents. I had long used them all with very unsatisfactory results as to permanence, when I saw this formula in the aforementioned journal and tried it, with such success that I have had no wish to make any change. It always works satisfactorily and I have never had a negative change in any manner after its application. It consists of two solutions, which may be used repeatedly without apparent exhaustion. I renew them occasionally, say once or twice in a year, more from habit than necessity, as the old solutions appear to act quite as well as fresh ones, though rather more slowly. The formula is as follows, to be put in two bottles:

A

Mercury bichloride . . . . $96 \mathrm{grs}$.

Potass. bromide . . . . . . 96 grs.

Water, distilled . . . . . 12 ozs.

B

Potass. cyanide, chem. pure . . . $90 \mathrm{grs}$.

Silver nitrate . . . . . . 96 grs.

Water, distilled . . . . . I2 ozs.

Shake well and allow to settle; keep the precipitate-cyanide of silver-always at bottom 
of the bottle. It will be good for use so long as any precipitate remains.

The negative to be intensified (which must be absolutely free from hypo), after being well wetted, is immersed in A until bleached to the desired extent. If great density is required it should be whitened entirely through the back, but merely grayed over the surface if but slight intensification is desired. It must then be very freely washed for fifteen minutes in running water, or several changes if the former is not convenient. And herein lies one of the cardinal factors in the permanence of the negative-thorough washing at every stage of its making. In the quaint diction of the formula as found in the old Journal

"Three rules, which must be carefully obeyed, are necessary to insure permanence in the intensified negative. And what is the first rule? Wash thoroughly. And what is the second rule?. Wash thoroughly. And what again is the third? Wash thoroughly."

The negative is now to be immersed in Solution B until completely blackened through on the back; then again "washed thoroughly" and placed in a rack to dry spontaneously. Thus treated it will never change in any manner more than one which has not been intensified. 
Somewhat recently we have from Germany an intensifying medium, which is sold in a concentrated form under the name of "Agfa." A dilute solution having been made as per accompanying directions, the plate to be intensified is simply soaked therein until the required degree of density is reached, which may be noted as that process advances, after which washing and drying succeed each other as before. The resulting negative is of an agreeable brownish color and excellent print. ing qualities, whilst its permanence is said to be unquestionable. I have used Agfa with great satisfaction, but have seen nothing in it to tempt abandonment of the silver cyanide intensifier. Of course both methods are equally applicable to the rather frequent cases of under-development of properly ex posed plates, or those which have been over. timed as described.

Reducing Density. It not infrequently hap. pens, from some cause,- generally over-devel. opment of a fully exposed plate,-that the negative is too dense for printing. If it be otherwise right, reduction of the over-density may enable us to utilize it with good results. This is generally effected by immersion in Farmer's Solution - formula for preparing 
which is given in all books on photography,until the desired reduction is reached, when it is to be washed and dried spontaneously. My own practice is to make this reducer by "rule of thumb," as follows: About half an ounce of potass ferricyanide (red prussiate of potash) is dissolved in four ounces of water, and put in a well-stoppered bottle, where it will keep very well in a dark place or if the bottle is covered with opaque paper, the solution spoiling if exposed to light in a short time: this is kept for stock. To make the reducer, I dissolve I ounce of sodium hyposulphite in 4 ounces of water, and add a small quantity of the ferricyanide solution, stirring the whole to mingle the ingredients evenly. Should its action be abnormally tardy, more of the ferricyanide may be added, but a slow, steady reduction by a somewhat weak solution gives more satisfactory results than rapid work with a strong one. This bath will not keep and should be thrown away after using.

Persulphate of ammonium is also a most excellent reducing agent, and as it seems to attack the denser portions of the negative first is especially valuable in many cases. A 2 per cent solution is about the proper 
strength for general use. Reduction commences at once, and proceeds at times somewhat rapidly, rendering a careful watching quite necessary. When the desired amount of reduction is reached, the negative must be removed at once to a bath of sodium sulphite and water - no particular strength being required,-to stop reduction, which will continue energetically in the presence of water alone; after which it is to be thoroughly washed and dried as usual.

"Agfa"-reducer is a recently introduced material, said to possess many very desirable qualities for that purpose. I have not used it, but from the many good words spoken of it, think it well to call the attention of my readers to it. The article, as sold, is highly concentrated, merely requiring to be diluted with ten parts of water for use. Complete reduction takes place in a few minutes, the length of time required being governed by the density of negative to be reduced.

Mechanical Local Reduction. Occasionally an object which does not present very marked contrasts visually as seen in the microscope, becomes an altogether different subject under the photographic eye; portions of the negative being so dense that no light can pass 


\section{I32 THE A B C OF PHOTO-MICROGRAPHY}

through them, whilst other parts may be full of detail though quite lacking in printing density. It is manifestly impossible in such cases to effect sufficient reduction in the overly dense portions by chemical methods, without obliterating details in the shadows, making the last stage of the unfortunate negative worse than the first. A method of mechanical reduction, which may not be so generally known as it deserves, has answered so well in my own work that I feel inclined to include it with these notes for the benefit of those who may not be familiar with it. The requisite materials are few and inexpensive: a little alcohol or methylated spirits, a finger from an old kid glove, and patience. The kid is to be simply wetted with the spirits (its inner surface is the better), stretched over the forefinger and the dense spot gently rubbed with a rotary motion, until the desired amount of reduction is obtained. The process is a slow one, demanding the exercise of care and patience. In stubborn places, the wetting with alcohol may have to be repeated several times. No portion of the negative will be affected but the spot that is rubbed. Should this be too small for the finger to manipulate properly, the 
piece of kid may be stretched over some suitable article, the blunt end of a pencil for instance, or better, the small rubber eraser attached to pencils, which may be procured for a few cents. If carefully done, this method of mechanical reduction will be found exceedingly useful and satisfactory in cases where no other could be used.

Potassium Bromide. Although the bromides of potassium or ammonium are so generally recommended and used as restrainers, my own experience has not been favorable to them. Slow development, with rather weak, or even dilute solutions, has always given better results in every way-details, density, evenness. With Eiko-Hydro developer, the addition of about one-fourth volume of an old and used solution to the fresh mixture is very satisfactory. Ample exposures and somewhat weak solutions give slow development, rarely failing to produce better results than short exposures and energetic developers.

Frilling and Fixation. In the earlier days of gelatine dry plates, frilling was by no means an uncommon occurrence, the entire film quite frequently leaving the plate during the washing after development, and at times becoming completely disintegrated. Although 
134 THE A B C OF PHOTO-MICROGRAPHY.

these imperfections are now almost unknown, there are still some makes of plates, the films of which are so soft as to chip or rub off in patches all around their edges, even under the most careful handling, giving them a most unsightly appearance to say the least, and often spoiling a subject which nearly covers the plate. Several remedies are suggested. If the negative is transferred directly from the developer to a fairly strong chromealum bath, in which it should be left several minutes, the film will usually be sufficiently hardened to prevent any rubbing off at the edges. But mark carefully, the plate must be thorougbly washed previous to being placed in the fixing bath, in order to remove the alum which greatly retards action of the hypo. It must not be forgotten that complete fixation and removal of the last trace of hypo are essential to the permanence of a negative. Therefore, the washing after treatment with alum must not only be very thorough, but the negative should be allowed to remain in the fixing bath for a considerable time after the white has entirely disappeared from its back, and the final washing cannot well be too prolonged or complete. I desire to urge this most earnestly upon all my readers who 
wish perfection and permanency in their negatives. A formaldehyde bath, in the proportions of one drachm to eight ounces of water, answers the same purpose as alum and in a better manner. It is my own favorite means of hardening a film. An excellent method of preventing the film from breaking off around the edges is to rub it to the depth of about one-eighth inch with a piece of soft paraffine wax before development.

Box for Fixing Bath. If but a few negatives are made at one time, a hard-rubber or agate-ware tray will answer quite well for holding the hypo bath, as was pointed out in the chapter on negative making. The principal objections to such a receptacle are slower and less even fixation, and the increased danger of scratching or otherwise defacing the moist and tender films. A grooved box, in which the plates stand on edge, is far better in every way. But you are warned to be very careful in selecting such a box, to see that it is made of hard rubber, which will be found practically indestructible. On no account take one of papier maché. It may look better and cost less than the rubber one, but is a delusion and a snare. The sharp edges of plates when low- 
I36 THE A B C OF PHOTO-MICROGRAPHY

ered into the grooves will speedily cut through the enamel or varnish, exposing the paper fabric to action of the hypo, and then very soon its life will be ended.

Washing Box. A tray will answer for final washing of the plates, but is not recommended, especially if a number are to be done at one time. There is great danger of scratching the soft, wet films; and if the water contains any dirt in suspension, it is sure to settle upon their surfaces. Washing boxes, as now made, will carry any size of plates up to their full capacity. These stand on their edges, and the water being admitted at the bottom, flows upward until the box is filled and the overflow runs off at top. This not only washes the plates better than it can be done in a flat tray, but in less time and with greater safety from damage. If there be no supply of running water at hand, a cork may be inserted in the intake at bottom and the box filled from a pail, changing the water several times by removing the cork, emptying and refilling box, until the washing is completed.

Measuring and Recording Amplifications. I would earnestly urge upon every photo-micrographer the importance of measuring the 
amplification of all exposures in diameters and recording same in his note-book. This is a matter that is all too frequently neglected. It is quite a common thing to find an article or even a whole book illustrated by drawings, or reproductions of photo-micrographs bearing the legend "highly magnified;" - this and nothing more, save the name of the subject. Whether it be amplified ten, or a hundred, or a thousand diameters, is all one in this slipshod method of announcing that it is magnified at all. It conveys no idea whatever to one unacquainted with the original as to its actual size, or in comparison with the pictured enlargement. If every one making a photo-micrograph would at the time carefully measure its amplification in diameters and make entry of same in his note-book, it would add greatly to the practical value of his work. And it is so readily done, requiring so little time, such few and simple tools, that there is no excuse for neglecting it. A stage micrometer ruled in $\frac{1}{10 \theta}$ and $\frac{1}{1000}$ of an inch (or the metric scale if preferred); a pair of dividers and a scale divided in tenths of an inch, or in millimeters, comprise all the necessary apparatus. The methods of use are equally simple. They 


\section{I38 THE A B C OF PHOTO-MICROGRAPHY}

are probably familiar to the majority of my readers, but at the risk of repeating an ofttold tale I will give them once again. Let us suppose that we have just made a negative under a low or medium power and wish to know the number of diameters employed in the making. Before changing the microscope or camera in any manner, replace the object with a stage micrometer ruled in parts of an inch as above and focus the projected lines sharply upon the ground-glass screen, using those $\frac{1}{100}$ of an inch apart for this moderate enlargement. Now, applying one leg of the dividers to a line, we extend the point of the other until it rests upon the next adjacent line. Should the distance from point to point be found to measure, say just one inch upon the scale, it is obvious that the enlargement is one hundred diameters, each hundredth division of the micrometer having been magnified to that extent. Of course this enlargement is equal in every direction, - horizontal, vertical, diagonal, so that in popular parlance it is really ten thousand times, or the square of the diameters; - the latter term alone being used scientifically, as it is presumed my readers all know quite well. Should the divider points 
embrace but nine of the one-tenth divisions on scale, then the amplification is shown to be only ninety diameters, as five would give fifty, etc. Intermediate enlargements between the tenths must be carefully calculated. This method is, perhaps, not always accurate to a single diameter, but is sufficiently so for all practical purposes. If the enlargement is more than Ioo diameters it will be well to measure the distance between two rulings when using the $\frac{1}{100}$ scale. With high powers it will be necessary to employ the $\frac{1}{1000}$ rulings, ten spaces of which enlarged to one inch on the focusing screen are equal to one thousand diameters. It will be found very useful to ascertain the exact camera extension necessary to give, say 100, 250, 500 and 1,000 diameters with combinations of the various objectives and eye-pieces; making records of the same for future use. Then, if it be desired to photo-micrograph an object at any particular number of diameters, by referring to note-book, the combination of objective, ocular and camera extension, which will give this amplification, may be found at once, thereby saving much time and the necessity of making fresh measurements. Tissue work is usually done under 
low and medium powers, from fifty to two hundred diameters, occasionally reaching five hundred, but only in more or less rare cases. In bacterial work one thousand diameters is the generally accepted enlargement at home and abroad. It is sufficiently high to show the more minute forms very satisfactorily, is within the compass of all students' microscopes supplied with the usual $\frac{1}{12}$ oil immersion lens, and if universally adopted in published reproductions, affords a very useful standard for comparative sizes of the various forms of bacteria.

Ocular or No Ocular? The constantly increasing use of apochromatic objectives, due both to their many points of superiority over achromats and reduced cost since their early introduction, has been a large factor, I believe, in the nearly universal employment of an eyepiece for photo-micrography at the present day. Time was, and at no very distant date, when exactly the reverse might have been said. The image of an enlarged microscopic subject was projected by the object glass alone; and increased amplification was obtained by adding to the length of bellows in the camera. The late Dr. Col. J. J. Woodward, whose wonderful work has rarely been 
equaled, and never excelled in certain directions, never used an eyepiece in making his world-famous negatives. He worked within his camera, from which every ray of light was excluded that did not pass through the microscope. His lenses were perfectly corrected in themselves, and did not require completion by means of a compensating or projection ocular, as do the present-day apochromats. Had he elected to use an eyepiece, it must perforce have been one of the Huyghenian form, which alone were available in his time. Fortunately the judgment which led him to discard the ocular was not at fault, since the photographic image projected through one of this form is decidedly inferior in sharpness and brilliancy to that produced by means of a well-corrected achromatic objective alone, especially in high powers. With apochromats and compensating oculars, however, the results are reversed, very many objects being resolved with a sharpness and brilliancy quite beyond the reach of the best achromats. Doubtless, if Dr. Woodward was living and working at the present time, it would not be in the darkness of his former work-room camera, but with the modern appliances in the clear light of day. 
142 THE A B C OF PHOTO-MICROGRAPHY

And yet I am constrained to enter a plea in favor of dispensing with the ocular (cer. tainly with the Huyghenian form), in low and medium power work. You will do more and better without than with it. Look at the section of Echinus spine (frontispiece of this book), made with a cheap students' two-thirdinch objective of two systems without an eyepiece, and note its almost perfect definition and flatness of field, together with evenness of lighting. Then photograph the same subject under the same amplification, using any achromatic objective you may choose in connection with a Huyghenian eyepiece, such as accompanies the usual students' microscope. Make a print of it and compare with the reproduction. If it equals the latter I shall have nothing more to say in favor of using the objective alone. If for any reason you should prefer to employ an ocular, then by all means procure one of Spencer's Aplanats, for use with acbromatic object glasses, if you desire the best results in your work.

Blocking out Backgrounds. Although the details of a negative must not be retouched or changed in any manner, it is quite legitimate to block out the background of an object requiring to be shown as a whole, by painting 
around its margin - on the film side-with some light-excluding piginent, to the width of about a quarter of an inch. Then paste on the glass side a piece of "post paper" with an opening slightly larger than the object, which will render the negative opaque excepting the object itself, and the print can be made with a white and clear field. Figures 9, 24, and 27 are from negatives treated in this manner.

In bringing these notes to a conclusion, which is also the finis of this little book, I would say, in apology for their being perhaps somewhat drawn out, that in the writing I have kept .its title constantly in view, and earnestly endeavored to ground my readers who may have known nothing of photo-micrography, in the A B C of the science, or art, before proceeding with more advanced lessons. Those who have already learned its alphabet, or crossed its "asses-bridge," and to whom these details will appear trivial or unnecessary, may pass them by, perhaps picking out a grain of wheat here and there among the chaff. To one and all, however, I extend my earnest wishes for their success in this fascinating and important work, urging upon each the homely old advice - "If at first you don't succeed, try, try again." 



\section{DESCRIPTION OF PLATES}

\section{FRONTISPIECE}

Transverse Section of an Echinus Spine-Echinometra lucunter.

For details, see page $5 \pi$.

\section{PLATE I}

Fic. 1.-Improvised Photo-micrographic Apparatus.

See page 19.

Fig. 2.-Adjustable Photo-micrographic Camera.

See page 2r.

Fig. 3. -The Author's Photo-micrographic Camera.

See page 23.

\section{PLATE II}

Fig. 4-E. R. \& C. Camera with Microscope. Arranged for use without Eye-piece.

See page 26.

Fig. 5.-E. R. \& C. Camera, and Microscope fitted with Compound body and Ocular. The camera is run back on its sliding bed to permit adjustments of object and illumination by the microscope.

See page 26.

Fic. 6.-E. R. \& C. Camera with Microscope, arranged for High Power Work.

See page 26. 


\section{PLATE III}

Low Powers by Transmitted Light

FIG. 7.-Carcinoma of Mammary Gland.

For details, see page 62.

Fic. 8.-Suctorial Tubes in Tongue of Blow-fly.

For details, see page 65.

\section{PLATE IV \\ Medium Powers by Transmitted Light \\ FiG. 9.-Aulacodiscus Oreganus. Diatom. \\ For details, see page 67.}

Fig. Io.-Human Voluntary Muscle. Injected.

For details, see page 60.

\section{PLATE V \\ High Powers by Transmitted Light}

FiG. 11. Karyokinetic figure in a Leucocyte. Human.

For details, see page 71 .

Fic. 12.-Pleurosigma angulatum. "White dot" resolution.

For details, see page 73.

\section{PLATE VI \\ Dark-Field Illumination}

Fig. 13.-Anchors and Plates of Synapta. Grouped.

For details, see page 75.

Fig. 14.-Heliopelta euleri. (Sunshield Diatom.) Dr. Mercer's Method.

For details, see page 76 . 
PLATE VII

Opaque Objects

Fig. 15.-Strewn Diatoms. Cuxhaven.

For details, see page 78 .

FIG. I6.-Cluster Cups. (Æcidium grossularia.)

For details, see page 70.

\section{PLATE VIII}

By Polarized Light

Fic. 17.-Starch from Canna Root. (Tous le mois.)

For details, see page 80.

Fig. 18.-Amygdalin Crystals.

For details, see page 80.

\section{PLATE IX}

Bacteriological.

Fic. 19.-Bacillus tuberculosis in sputum.

FIG. 20.-Bacillus anthracis.

For details, see page 83 .

PLATE $X$

Bacteriological

FiG. 21.-Streptococcus pyogenes, aureus.

For details, see page 83.

FIG. 22.-Bacillus Trommel-Schlägel. (Spores.)

For details, see page 84. 


\section{PLATE XI \\ Photo-Macrographs}

Fig. 23.-Corisa undulata. Water Boatman.

FIG. 24:-Serjania. Transverse Section of Stem.

For details, see page 96 .

\section{PLATE XII \\ Photo-Macrographs}

FIG. 25.-Mosquito-female. (Anophele.)

FIG. 26.-Human Scalp. Flat Section. Showing Hairs cut transversely.

For details, see page 97.

\section{PLATE XIII}

LANTERN SLIDES

Fig. 27.-A Sample Lantern Slide. (Front view.)

FIG. 28.-A Sample Lantern Slide. (Back view.)

For details, see page II8. 


\section{PLATE III}

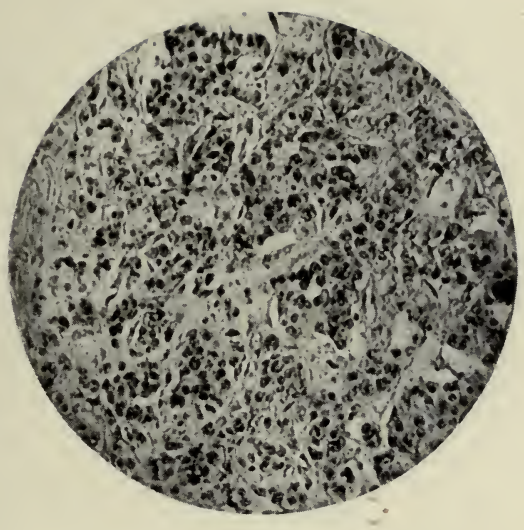

FIG. 7

Carcinoma of Mammary gland + 90

Transmitted light: Low power

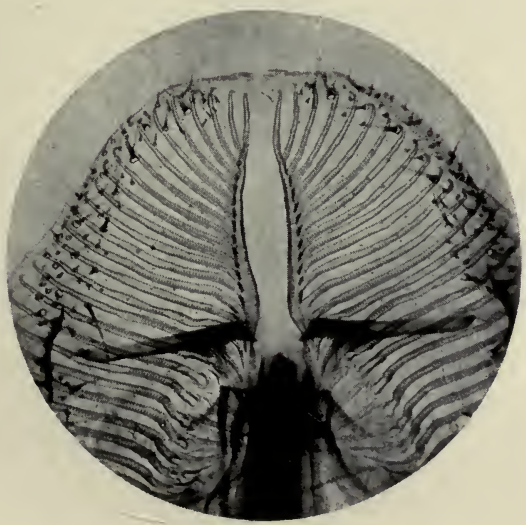

FIG. 8

Tongue of Blow-fly +50

Transmitted light: Low power 


\section{PLATE IV}

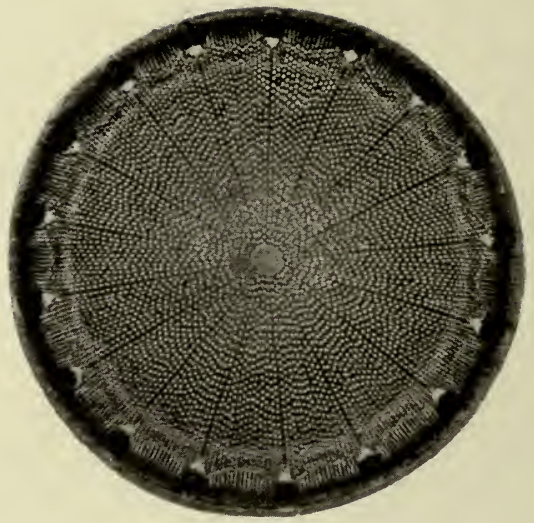

FIG. 9

Aulacodiscus Oreganus +315

Transmitted light: Medium power

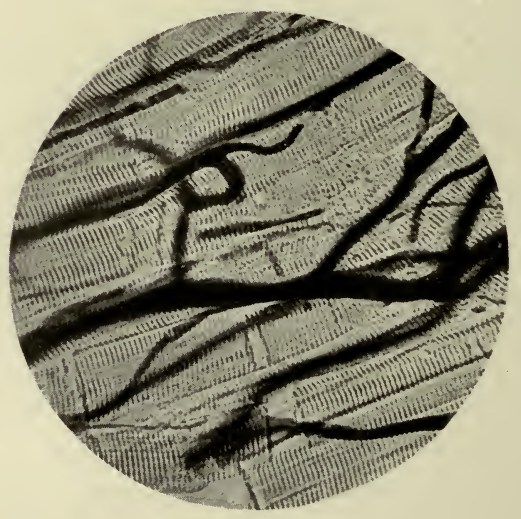

Fig. 10

Voluntary muscle, Man; injected +200

Transmitted light; Medium power 


\section{PLATE V}

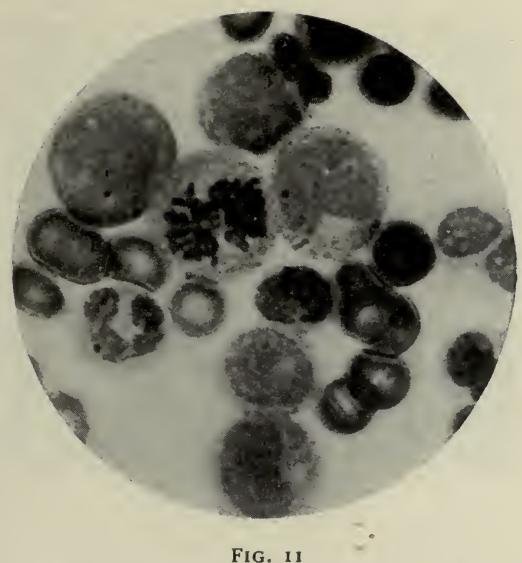

Karyokinetic figure in a Leucocyte +825

Transmitted light: High power

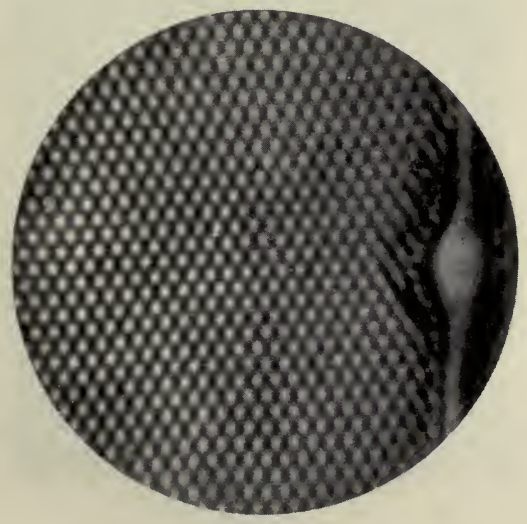

FIG. 12

Pleurosigma angulatum +3000

Transmitted light: High power 


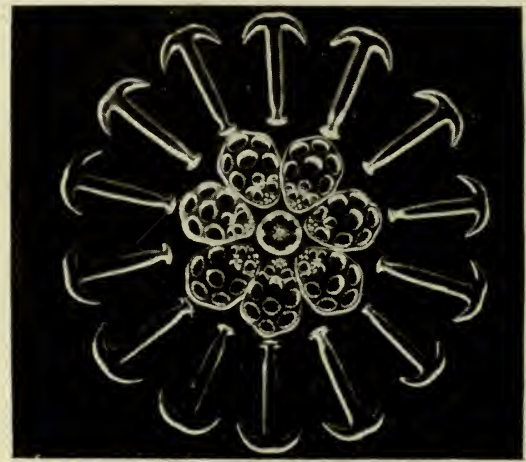

FIG. I3

Anchors and plates of Synapta +60

Dark-field illumination; Paraboloid

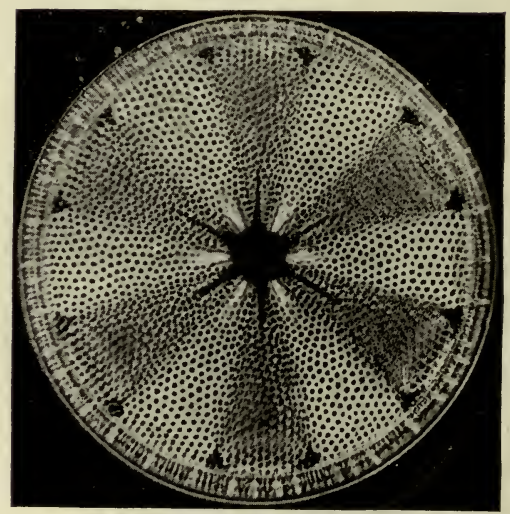

FIG. 14

Heliopelta euleri. Sunshield Diatom +225

Dark-field illumination: Mercer's rethod Printed from a Positive 


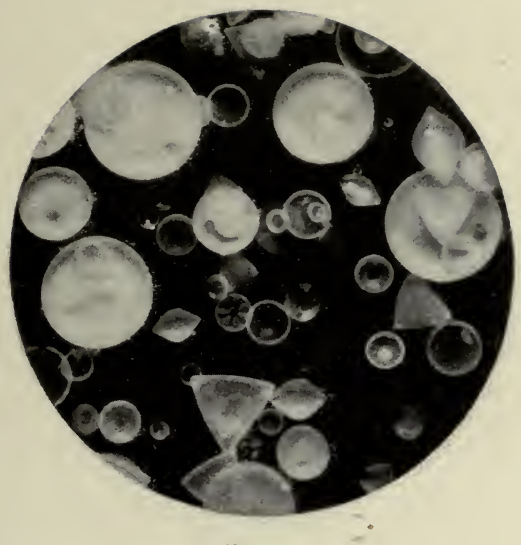

FIG. 15

Diatoms. Cuxhaven +53

Opaque; by Reflected light

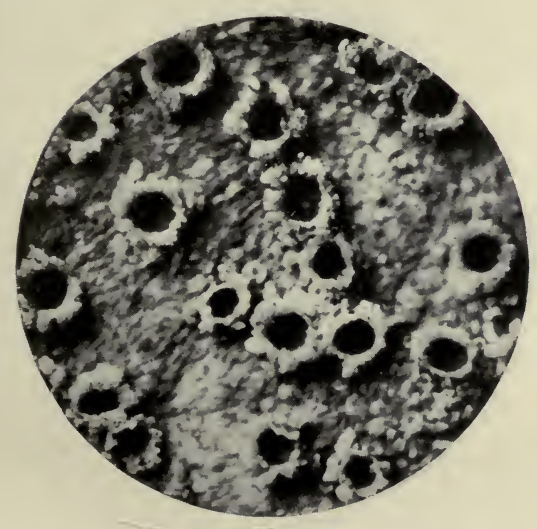

Fig. 16

Æcidium. Cluster cups +30

Opaque: by Reflected light 


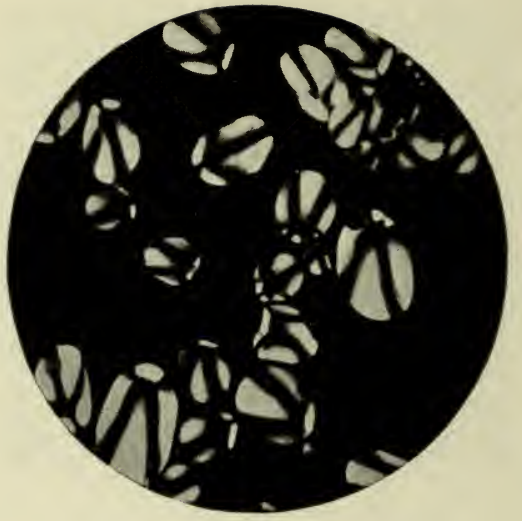

FIG. 17

Canna-root starch. (Tous le mois) + 110 Polarized light

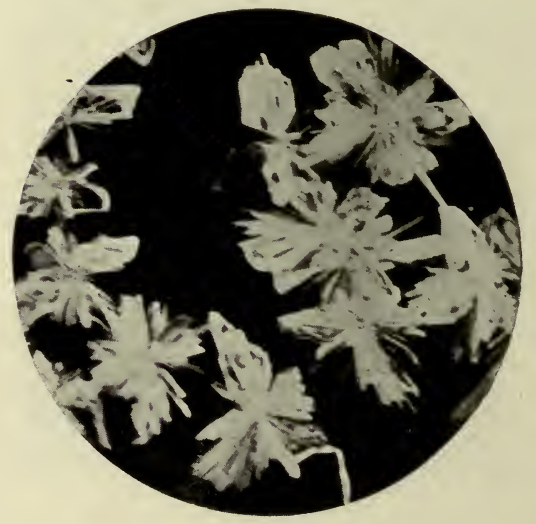

F1G. 18

Amygdalin crystals +70

Polarized light 


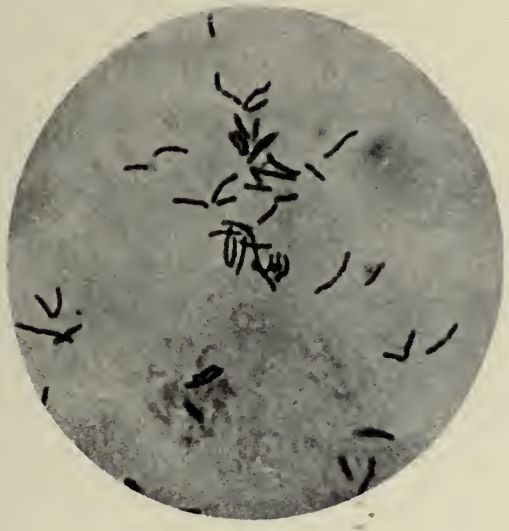

FIG. 19

Bacillus tuberculosis in sputum +1000 Bacteriological

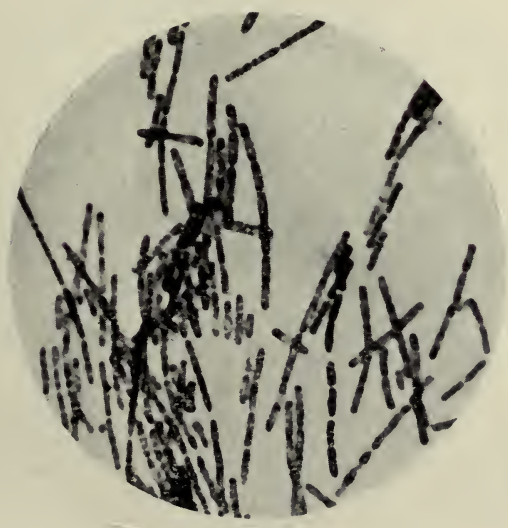

FIG. 20

Bacillus anthracis. Spores +1000 Bacteriological 
PLATE $X$
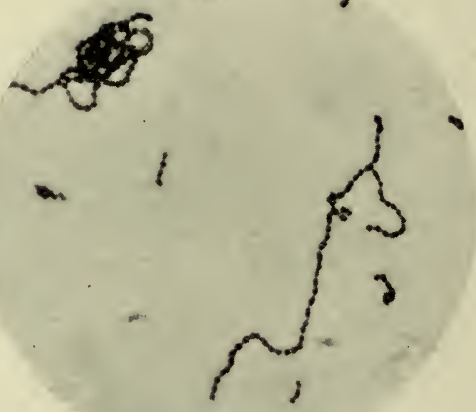

FIG. 2 I

Streptococcus pyogenes +1000

Bacteriological

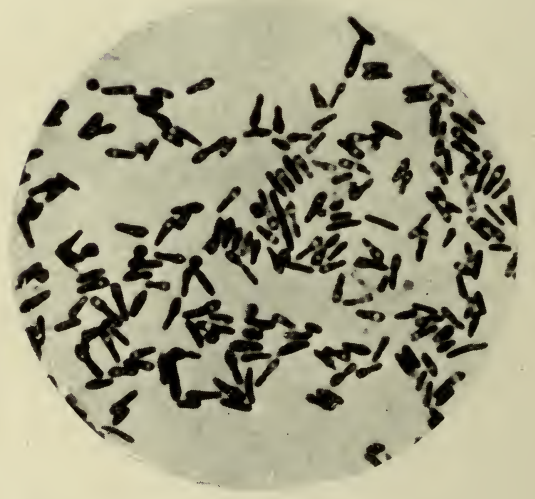

FIG. 22

Bacillus Trommel-Schlägel, spores +1000 Bacteriological 


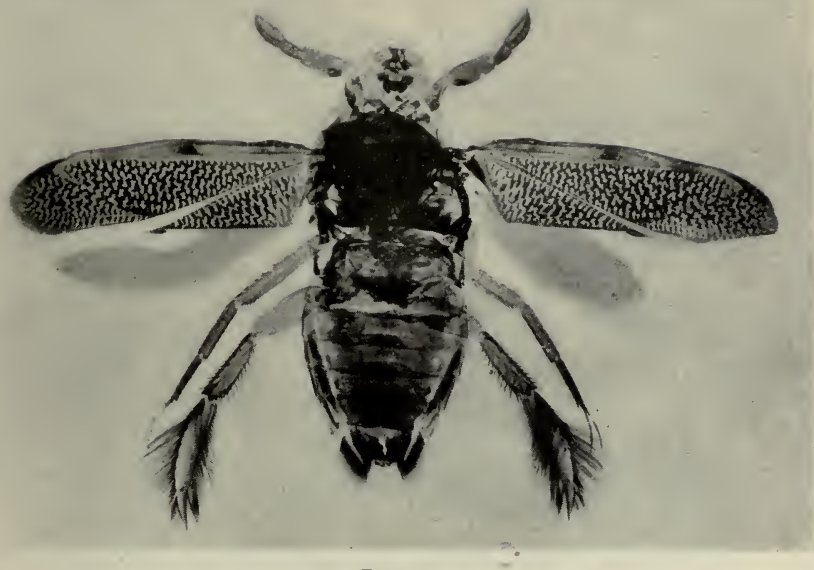

FIG. 23

Corisa undulata or Water Boatman $+3 \frac{1}{2}$

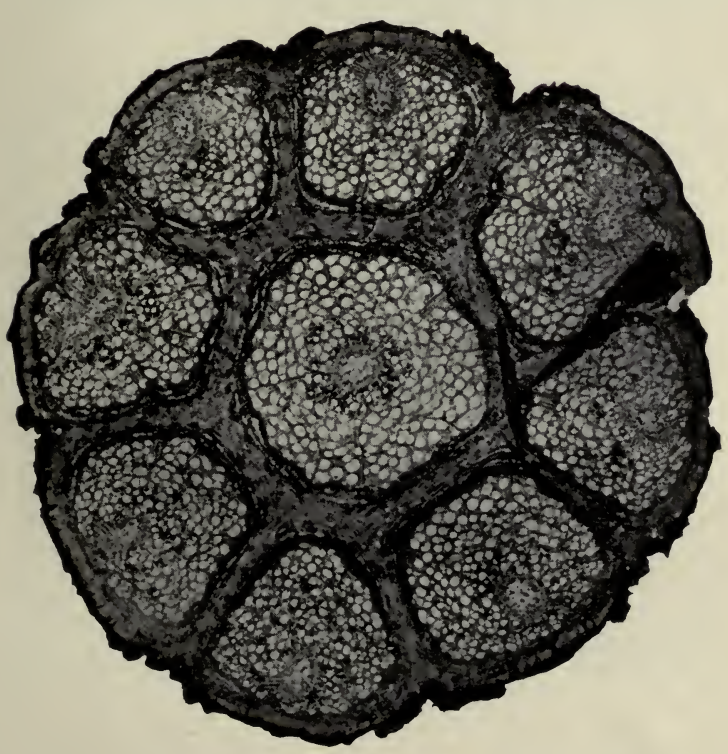

FIG. 24

Serjania. Trans-section stem +5 


\section{PLATE XII}

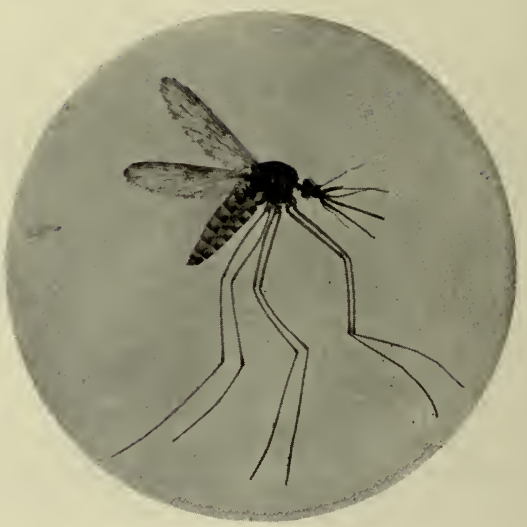

FIG. 25

Mosquito, Anophele + 3. Female

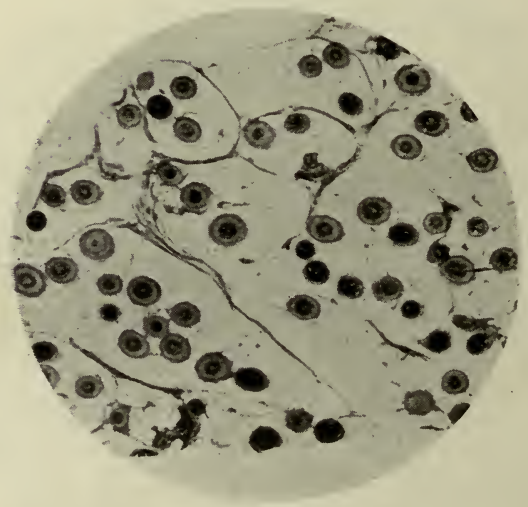

FIG. 26

Human scalp. Flat section +7 . Hairs cut transversely 


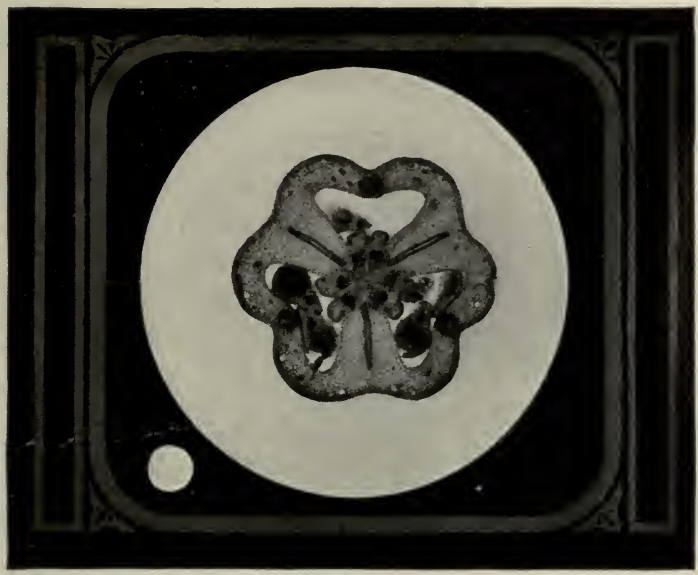

FIG. 27. Lantern slide. Front

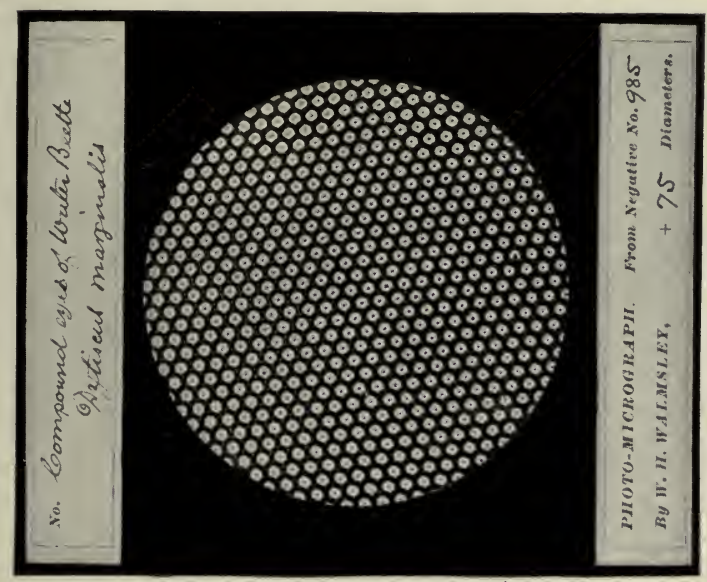

FIG. 28. Lantern slide. Back 



\section{INDEX}

PAGE

Abbè's Substage Condensers ........ 13, 67, 120 Acetylene Gas as Radiant........... 44 Achromatic Condenser ................... 69

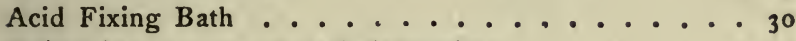
Adjustable Camera, Bausch \& Lomb's ........ 2 I Agate Ware Developing Trays ........ 30 "Agfa" Intensifier ................ 129 "Agfa" Reducer ................ 131 A Home-made Camera ........... . 90 An English Method of Drying Negatives ...... 62 An Optical Illusion . . . . . . . . 78 Aplanatic Oculars, Spencer's ........ 12, 52 Atwood's Camera-Microscope .......... 8 Backing Plates ............. 37 Bacteria, Photo-micrographing . . . . . . 82 Bausch \& Lomb's Adjustable Camera . . . . . . 2 I Bausch \& Lomb's Microscopes ............ 10 Beck's Objectives ............... 15 Binding Lantern Slides ............ 116 Blacking Interior of Microscope Body ........ 53 Black Paper Backing for Dry Plates ....... $3^{8}$ Blocking Out Negatives ............ 142 Blue Prints ................ rog Box for Fixing Bath ........... 135 Box for Washing Plates ........... 136 Bromide of Potassium as a Restrainer . . . . . . 133 Bull's-Eye Condenser ............. $1_{3}$ Camera, Bausch \& Lomb's Adjustable ........ 2 2 I Camera, Leitz' Upright ............ 22 
Camera, Walmsley's E. R. \& C. . . . . . . . 23

Camera and Photographic Appliances, The ..... I8

Camera-Microscope, Atwood's......... 8

Carbutt's Dark-room Lantern . . . . . . 28, 59

Carbutt's Orthochromatic Dry Plates ..... 36,69

Care of Dark-room Lantern . . . . . . . . 29

Celluloid Developing Trays.......... 30

Centering Radiant and Condenser ....... 63 .

Coal-oil Lamp as the Radiant . . . . . . . 46, 67

Color-correct Dry Plates ........ 35, 69

Coloring Lantern Slides........... II 5

Color-Screens for Orthochromatic Plates . . . . 57,68

Color-Screen Holder .......... 72

Condenser, Bull's Eye ............ I3

Condenser, Substage ............. I3

Continental form of Microscopes ......... ro

Correcting Objectives for Photo-micrography . . . . . 14

Cramer's Orthochromatic Plates ........ 36

"Critical" Illumination ............ 63,72

Cyanide of Silver Intensifier ......... 127

Dark-field Illumination . . . . . . . . 47, 74

Dark-field Photography. Mercer's Method . . . . 76

Dark-room, The ............ 27

Darlot Focusing-glass ............ I4

Davy, Humphrey: His early Photo-micrographs .... 3

Deep Printing-frame ........... I Io

Definition of Micro-photograph ........ I, 2

Definition of Photo-macrograph ....... 87

Definition of Photo-micrograph ......... 2

Density, Loss of, in Fixing-bath ........ 60

Density Reducers ............. 129

Description of Illustrative Plates ......... 145

Developers ................ 31, 33

Developing Lanterns .......... 28, 59

Developing Trays............ 30

Developing a Negative ........ 59 
Diatoms, Photographing . . . . . . . . . 67

Diffused Daylight as Radiant . . . . . . . 42

Donnè, Dr. Early Photo-micrographs by . . . . . 4

Drying Negatives .............. 61

Drying Squeegee Prints ........... I07

Earliest published Photo-micrographs ...... 4

Eikonogen ................... 32

Eiko-Hydro Developing Powders ......... 33

Electric Arc as the Radiant .......... . 43

Electric Incandescent Light for Dark-room . . . . 27

Enlarging, Reducing, and Copying Camera . . 23, 88, I 13

Exposure, Length of ........ . 58, 64

Farmer's Reducer. Formula . . . . . . . . I02

Ferrotype Plates for Squeegeeing Prints ....... . 104

Ferrotype, Care of ........... 108

Fiber Water Pail ............. 3

Fine Adjustment of Focus . . . . . . 25, 66

Finishing Lantern Slides.......... I15

Fixing after Development ......... 60, 134

Fixing-bath Formula . . . . . . . 30

"Flare Spot"................ 53

Focusing-glass ............. . 13, 57

Focusing-screens ........... 55

Folding Drying-ruck ............ $3^{I}$

Forbes' Lantern Plates ............. II2

Forbes' Orthochromatic Plates ...... 36, 64, 72

Form of Note-book ............. I20

Forms for Cutting out Masks . . . . . . . . ro3

Formula for Backing Plates ......... 37

Frilling ............... 133

General Notes ............. II9

Graduates .............. . . 30

Hand-feed Electric Arc Lamp . . . . . . . 43

Hard Rubber Developing Trays ........ . 30

Hard Rubbar Fixing-box ........... 135

Heliostat .............. 42 
High Powers, Subjects for .......... 50

High Powers with Transmitted Light ... . . . . 69

Holder for Color Screen ........... 72

Home-made Camera ........... . 90

Homogeneous Objectives, Illuminating Power of . . . 70

Huyghenian Eye-pieces ......... 50

Hydroquinon ............. 32

Illumination ............... 42

Improvised Photo-micrographic Apparatus . . . . . . 19

Intensification ............. 124

Intensifier, Cyanide of Silver ..........127

Iris Diaphragm . . . . . . . . . 57

Isochromatic Plates ......... 35

Karyokinesis ............... . 71

Labeling Lantern Slides ............ . II7

Lantern, The Dark-room .......... 28

Lantern Plates ............... I12

Lantern Slides ............... III

Langenheim's Micro-photographs ........... 2

Leitz's Microscopes . . . . . . . . . . . . 10

Leitz's Upright Camera . . . . . . . . . . 22

Length of Exposure ....... 58, 65, 68, 73

Leucocytes . . . . . . . . . . . 71

Lime-light as the Radiant . . . . . . . . 44

Local Reduction of Density ........... . 13I

Low Powers, Subjects for .......... 50

Low Powers with Transmitted Light ....... 50

Lumière's "Color-correct" Plates . . . . . . . . $3^{6}$

Maddox, Dr. R. L.............. 5

Magnesium as the Radiant ........... 43

Masking Prints.............. ro3

Measuring Amplifications ......... 136

Mechanical Local Reduction of Density ....... . 131

Mechanical Stage............ 54

Medium Powers, Subjects for .......... 50

Medium Powers with Transmitted Light ....... 66 
Mercer, Dr. A. Clifford ......... 2, 76

Metallic Surfaces, Photo-micrographing . . . . . 77 Methods of Evenly Illuminating the Field . . . . . 64 Metol ................ 34 Micro-photographs ........... 2 Microscope and Optical Apparatus, The ..... 8 Microscopes, Bausch \& Lomb's .......... 10 Microscopes, Leitz's . . . . . . . . . . xo Microscopes, Spencer Lens Company's .... Ix, 14, 50 Microscopes, The "Continental" form ....... . ro Microscopes, Zeiss' ............. ro Negative Drying Racks ........... 31 Negative Making . . . . . . . . . 49 Non-halation Plates.......... 37 Note-book . . . . . . . . . . . . II9 Numbering Negatives .............. 12I Oblique Illumination ............ 47 Ocular or no Ocular ? ........... 140 Oil Immersion Objectives ......... 70 Old Developer, Use of ........... 34 Opaque Objects by Reflected Light . . . . . . 47,77 Orthochromatic Plates........... 35 Oxy-hydrogen Light ............. 44 Paper Backing for Plates ........... $3^{8}$ Paraboloid for Dark-field Illumination ....... I6 Persulphate of Ammonium Reducer......... 330 Photo-macrography ............ 3, 49, 86, 87 Photo-micrography, Definition of ......... 2 Photo-micrography in Metallography ....... 77 Photo-micrographs as Educational Aids .... . 6, 99 Photo-micrographing Bacteria ......... 82 Photo-micrographing without an Ocular ....... $5^{\text {I }}$ Plate-holders ............... 24 Polarizing Apparatus........... 16,80 Polarized Light . . . . . . . . . 47,79 Potassium Bromide as Restrainer .......... 333 
Powell and Lealand's Apochromat $\frac{1}{12}$ Hom. . . . . . . $7 x$

Printing-frames . . . . . . . . . . r ro

Printing Methods............. 98

Projection Oculars ............. . 12

Pyrogallol . ............. 32

Rack for Drying Negatives ........... $3^{1}$

Reade, Rev. J. B. Early Photo-micrographs of . . . . 4

Recording Amplifications .......... . 136

Reducer, "Agfa"............... . I3

Reducer, Farmer's .......... I01, 130

Reducer, Persulphate Ammonium ........ I30

Restraining Development ........... I33

Revolving-Disc Paper-Cutter .......... I03

Rives' Photographic Paper . . . . . . . . 108

Ross' Achromatic Condenser . . . . . . . . 69

Rubber Squeegee .............. I07

Seymour's Device for Instantaneous Exposures . . . . . 18

Screens for Focusing . . . . . . . . . 55

Spencer Lens Company's Microscopes . . . II, I4, 50, 53, 87

Squeegeeing Prints ............ I06

Stage Micrometer . . . . . . . . . . 137

Staining Bacteria ........... 82

Storing Negatives and Plates ....... 35, 122

Substage Condenser . . . . . . . . 66, 69

Sunlight as the Radiant. . . . . . . . 42

The Acetylene Light as Radiant . . . . . . . . 44

The Coal-oil Lamp as Radiant . . . . . . . 46

The "Continental" form of Microscope ....... Io

The Dark-room ... . . . . . . . . . 27

The Electric-arc as Radiant . . . . . . . . . 43

The Lime-light as Radiant . . . . . . . . . 44

The Radiant and Illumination . . . . . . . . . 42

The Wellsbach Incandescent Mantle as Radiant . . . 45

The Three-legged Focusing Microscope .... . . 13, 57

Utilizing Spoiled Lantern Plates .......... II4

Varnishing Lantern Slides . . . . . . . . . . II4 
Varnishing Negatives . . . . . . . . . 123

Velox Developing Papers......... 98, rо I

Walmsley's E. R. \& C. Camera ...... 23, 88, Ir 3

Walmsley's Gelatine Focusing-screen ....... 55

Washing-box for Negatives ........ 136

Washing the Negative ............ 6r

Watson's Enlarging Apparatus . . . . . . . . 94

Wedgewood's early Photo-micrographs ....... 3

Wellington and Ward's S. C. P. Papers. . . . . . 102

Welsbach Incandescent Mantle as Radiant . . . . 20, 45

Wenham's Method of Correcting Objectives ...... I 5

Woodward, Dr. J. J. .......... . 5, 52

Wuestner Orthochromatic Plates ........ 65

Zeiss' Microscopes ............. ro 



\section{PHOTOGRAPHIC SUPPLIES}

FOR

MICROGRAPHIC WORK

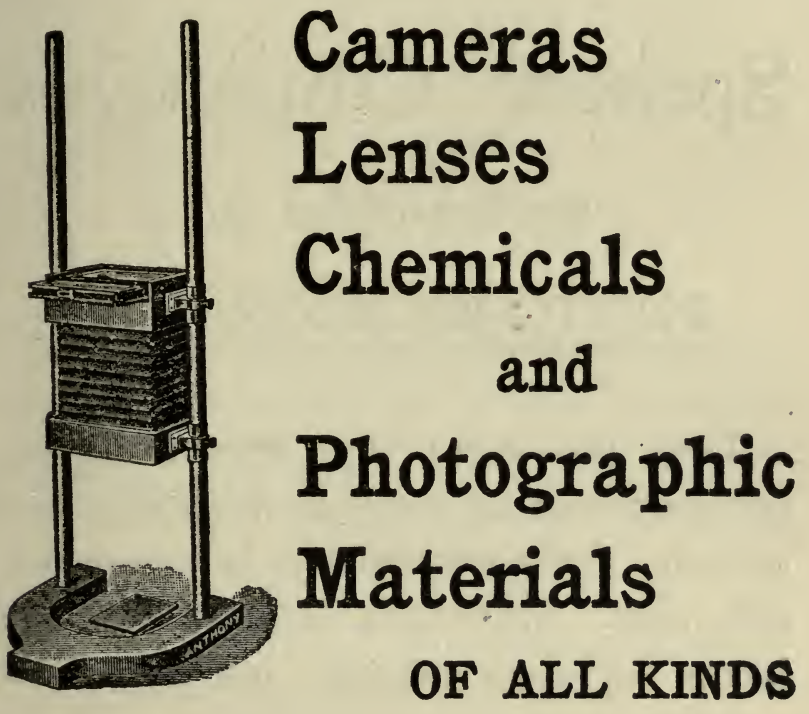

Send for free Illustrated Catalogue

THE ANTHONY \& SCOVILL CO. 122-124 Fifth Avenue - - NEW YORK ESTABLISHED 1842 


\section{SPENCER}

MICROSCOPES

AND

Spencer Objectives are unexcelled for

\section{PHOTO-MICROGRAPHY}

Large Body-tube; Draw-tube of standard size, permitting an exchange of oculars when desired. Finest workmanship in construction and finish. SPENCER OBJEGTIVES are famous for sharp definition and general excellence.

SEND FOR CATALOGUE

SPENCER LENS COMPANY BUFFALO, NEW YORK 


\title{
THREE IMPORTANT BOOKंS FOR THE STUDENT OF PHOTOGRAPHY
}

\section{Photography as a Fine Art}

\author{
By Charles H. Caffin
}

What can be done with the camera is here shown, not by theorizing, but by actual examples of the work of some of the greatest American photographers. Mr. Caffin's idea is to show what is worth striving for, and how the masters of the camera attain it. The hundred pictures are in themselves an inspiration, showing the work of Alfred Stieglitz, Gertrude Käsebier, James T. Keiley, Frank Eugene, W. B. Dyer, Clarence H, White, Eduard Steichen, etc.

\section{The Insect Book}

BY DR. L. O. HOWARD

Chief of Division of Entomology, U. 3. Departnent of Agriculture 16 colored plates, 32 full-page half-tones and 300 text cuts illustrating hundreds of species.

A popular description of North American insects, giving full life histories

THE INDEPENDENT says: "One noteworthy feature of 'The Insect Book' is its frequent direct indication of fields wherein special study is likely to be well rewarded." Other books in the New Nature Library are: The Butterfly Book, The Mushroom Book, Nature's Garden, Bird Homes, Birds That Hunt and are Hunted, and Bird Neighbors.

Price, net, 83.00

\section{Camera Shots at Big Game}

\section{By MR. and MRS. A. G. WALLIHAN}

THEODORE ROOSEVELT has written an appreciative introduction to this striking collection of wild animal photographs-a collection absolutely unique, comprising pictures at close range of mountain lions, deer, bear, elk, and nearly all the wild animals of our great West, taken in their native haunts by the authors, during the last ten years.

Over 100 large octavo pages, with 50 photogravures and half-tones. Price, net, $\$ 10.00$

For net books sent by mail, add 10 per cent of list price for postage

\section{DOUBLEDAY, PAGE \& COMPANY}

34 Union Square EAST :: New York City



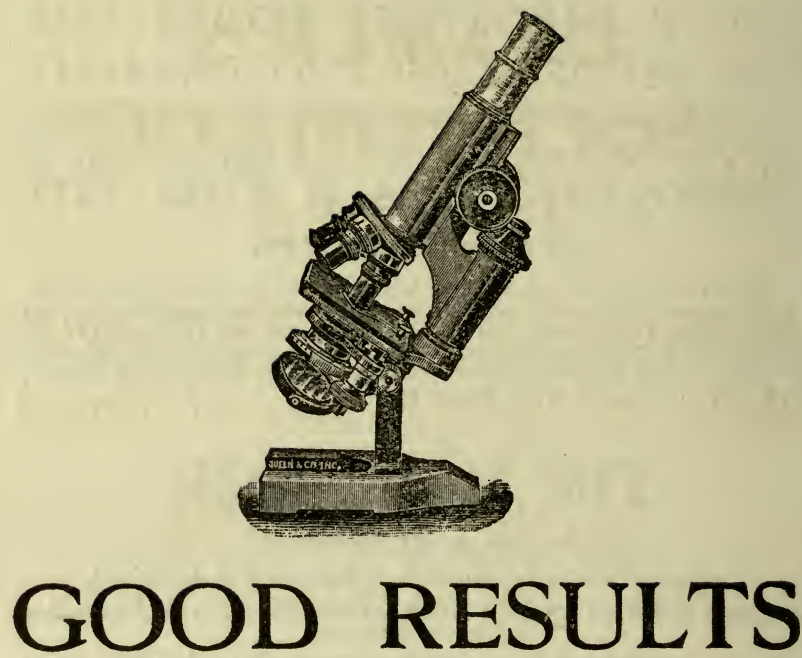

can only be obtained in Photo-Micrographic work when perfectly accurate apparatus is used. The

\section{Queen Microscopes}

are intelligently designed and accurately made and adjusted in every way. Objects specially prepared for Photo-Micrography.

\section{CATALOGUES SENT ON APPLICATION}

BM Microscopes, Lenses, Photo-Micrographic Apparatus, etc. HH Projection Microscope, Polariscope, elc.

\section{QUEEN \& CO.}

Optical and Scientific Instrument Works 1010 Chestnut Street, PHILADELPHIA 59 Fitth Avenue, NEW YORK 


\title{
CRAMER'S \\ ISOCHROMATIC \\ PLATES
}

Are the most sensitive plates in the market

Made in Three Grades of Speed

\section{SLOW, MEDIUM \\ AND INSTANTANEOUS}

For Sale by all

Dealers in Photographic Supplies

\section{CRAMER DRY PLATE CO.} ST. LOUIS, MO.

\author{
OFFICES IN \\ NEW YORK, 32 East 10th Street \\ CHICAGO, Room 705 Cable Building \\ SAN FRANCISCO, Room 38, 819 Market Street
}

USE MALLINCKRODT'S SODIUM SULPHITE ANHYDROUS ABSOLUTELY PURE FOR PHOTOGRAPHIC PURPOSES 


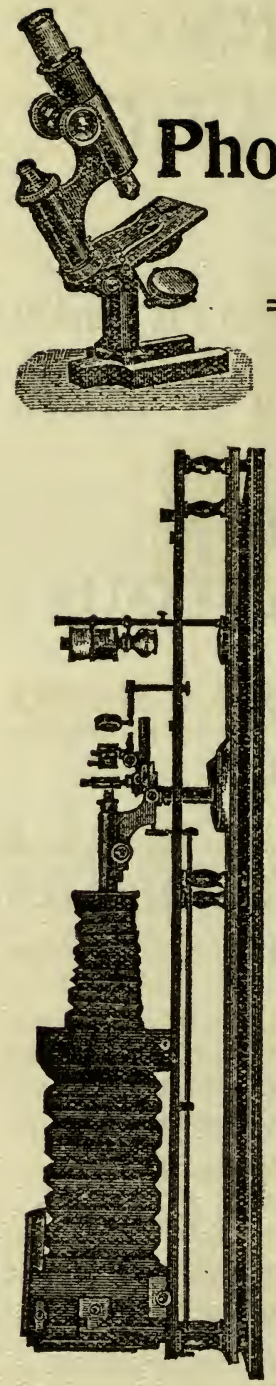

\section{ROSS}

MICROSCOPES

New "Standard" Model. Specially suitable for use with Photo-Micrographic Cameras.

\section{MICR0-OBJECTIVES}

Corrected for Photography.

\section{CAMERAS}

Specially adapted and fitted with every necessary movement for Photograph. ing Microscope Slides.

\section{ROSS-ZEISS “PLANAR" LENSES}

For Photo-Micrographic Enlarging and Reducing.

PRICE = LISTS FREE

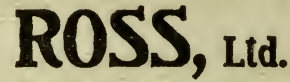

Manufacturing Opticians

111 New Bond St., London, W., England 


\section{EDWARD PENNOCK}

\section{IMPORTER OF OPTICAL INSTRUMENTS}

3699 Woodland Ave., Philadelphia, Pa.

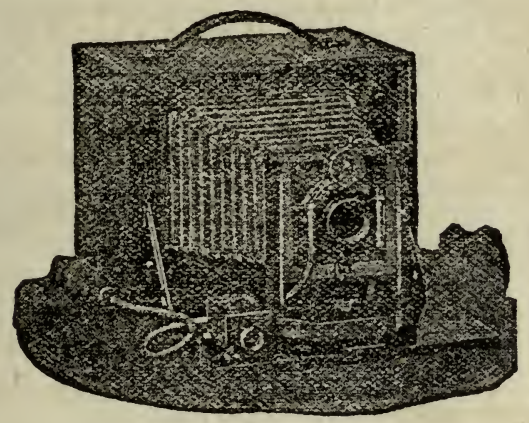

\section{Fine Microscopes and Cameras}

\section{OF BEST MAKES}

Aid in Selection Given when Desired. Statement of Your Wants Solicited

I always have bargains in SECOND-HAND MICROSCOPES and CAMERAS. Send for Special Bulletin. At present I have a few 1901 KORONAS, with best GUNDLACH SYMMETRICAL LENSES and latest Model D Shutter, at extremely low prices.

\section{A SIMPLE PHOTO-MICRO CAMERA, $\$ 9.00$}

FORBES ORTHOCHROMATIC PLATES of following sizes kept in stock: $3^{1 / 4} \times 4^{1 / 4}, 30 c$.; $4 \times 5,45^{\mathrm{C}}$; $5 \times 7,75^{\mathrm{c}}$., in either $\mathrm{S}$ brand (very rapid) or $\mathrm{L}$ brand (medium speed). 
Photo-Micrographic records are best kept by the " $\mathrm{Y}$ and $\mathrm{E}$ " card system

\begin{tabular}{|c|c|}
\hline 1275 & subject: Tissue: human retina \\
\hline$\frac{\text { class }}{\text { lens }}$ & $\begin{array}{l}\text { Normal } \\
\text { Zeiss } 1 / 2 \text { in apochromat }\end{array}$ \\
\hline magniff & $\begin{array}{l}\text { Project_ocular 6: jeiss achrom. } \\
+1000\end{array}$ \\
\hline $\begin{array}{l}\text { stained } \\
\text { series }\end{array}$ & Luegroed: Foessle's method. \\
\hline Rem. & Thick section. \\
\hline & $\begin{array}{l}\text { light. contrasts } \\
\text { increased, qreen glass }\end{array}$ \\
\hline & \\
\hline
\end{tabular}

We make up cards and cabinets to suit just your special requirements

YAWMAN \& ERBE MFG. CO., ROCHESTER, N. Y. N. Y,: 360 Broadway. [Chicago, 138 Wabash. Boston, 92 Franklin

\section{PHOTOGRAPHIC BOOKS}

We carry the largest and most complete stock of photographic literature in America. Any book dealing with photography and its applications can be obtained promptly if not in stock when order is received. Descriptive catalogue of 200 of the best photographic books free on application

\section{TENNANT and WARD}

287 Fourth Avenue

New York City 


\section{In order to make photo-}

micrographs free from halation use our

\section{ORTHONON

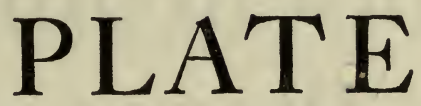

It is the best all-around plate on the market. SEND FOR BOOKLET STANDARD DRY PLATE CO. (Home Office) LEWISTON, MAINE DEPOTS IN $\left\{\begin{array}{l}\text { CHICAGO : NEW YORK } \\ \text { PHILADELPHIA : MONTREAL }\end{array}\right.$ 


\section{FOR THE BEST RESULTS IN PHOTO-MICROGRAPHY}

Experts use

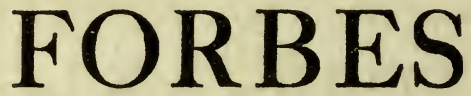

Orthochromatic Plates

S brand-very rapid

$\mathrm{L}$ brand-medium rapidity

In securing color values and for general excellence these plates are admittedly unsurpassed. For full particulars apply to your dealer or

FORBES DRY PLATE WORKS

ROCHESTER, N. Y. 
The most complete work on the subject-1899

\section{PHOTO-MICROGRAPHY}

\section{A Manual for Beginners and Experts}

\section{By Edmund J. SpITta}

With forty-one half-tone reproductions from original negatives and sixty-three text illustrations.

163 pages, $81 / 2 \times 11$ inches. Cloth. Price, $\$ 5.00$.

CONTENTS

Introduction; I, Illuminants; II, Low-power Work; III, Medium-power Photo-Micrography-Camera and Accessories; IV, Microscopes, Lenses and Eye Pieces used in Medium and High-power Work; V, The Substage and Auxiliary Condensers, and other matters of importance; VI, Medium-power Work; VII, High-power or Critical Photo-Micrography; Appendices (9) and Index.

\section{Practical Photo-Micrography}

\section{By ANDREW PRINGLE}

160 pages, with index and many diagrams. \$2.50.

This work, published in 1893 , followed the author's larger and more pretentious treatise, now out of print. It is not illustrated with examples of photo-micrography.

\section{CONTENTS}

I, General Appliances; II, Microscope and its Parts; III, Photo-Micrographic Apparatus; IV, Objectives and Oculars; V, The Condenser and Its Fittings; VI, Illumination; VII, General Routine; VIII, Photographic Plates: Exposure; IX, Color Treatment of Various Objects; X, Black Backgrounds, Reflectors; XI, Development and Fixing; XII, Reduction, Intensification; XIII, Printing on Gelatino-Chloride Paper; XIV, Bromide Paper; XV, Enlarging on Bromide Paper; XVI, Lantern Slides; XVII, Microscopical Technique and Preparations; Appendix.

NoTE. - The two books here listed are written from the Bnglish view-point.

\section{TENNANT \& WARD}

Publishers of Photographic Books : Catalogae on Application 287 Fourth Avenue, New York 


\section{THE PHOTO-MINIATURE}

series of little monographs on photography offers the most interesting and complete library available for photographic reference. Published monthly, at $\$ 2.50$ per year. Every number complete in itself. 43 numbers published. Always obtainable. Separate numbers, 25 cents each, postpaid.

1. MODERN LENSES (14th thousand)

2. THE POSE IN PORTRAITURE (14th thousand)

3. HAND-CAMERA WORK (12th thousand)

4. PHOTOGRAPHY OUTDOORS (13th thousand)

5. STEREOSCOPIC PHOTOGRAPHY (8th thousand)

6. ORTHOCHROMATIC PHOTOGRAPHY (11th thousand)

7. PLATINOTYPE PROCESSES (11th thousand)

8. PHOTOGRAPHY AT HOME (11th thousand)

9. LANTERN SLIDES (9th thousand)

10. THE "BLUE PRINT" "ETC. (7th thousand)

11. DEVELOPERS AND DEVELOPMENT (14th thousand)

12. RETOUCHING NEGATIVES AND PRINTS (14th thousand)

13. PHOTOGRAPHING FLOWERS AND TREES (8th thousand)

14. STREET PHOTOGRAPHY (8th thousand)

15. INTENSIFICATION AND REDUCTION (7th thousand)

16. BROMIDE PRINTING AND ENLARGING (11th thousand)

17. THE CARBON PROCESS (8th thousand)

18. CHEMICAL NOTIONS, ETC. (7th thousand)

19. PHOTOGRAPHING CHILDREN (8th thousand)

20. TRIMMING, MOUNTING AND FRAMING (8th thousand)

21. ALBUMEN AND PLAIN PAPER PRINTING

22. GUM-BICHROMATE PRINTING

23. PHOTOGRAPHIC MANIPULATIONS (8th thousand)

24. PHOTOGRAPHING CLOUDS (8th thousand)

25. LANDSCAPE PHOTOGRAPHY (8th thousand)

26. TELEPHOTOGRAPHY

27. PINHOLE PHOTOGRAPHY

28. SEASHORE PHOTOGRAPHY

29. FLASHLIGHT PHOTOGRAPHY (8th thousand)

30. PHOTOGRAPHING INTERIORS

31. PHOTOGRAPHING AT NIGHT

32. DEFECTS IN NEGATIVES

33. THE DARK-ROOM

34. DEVELOPMENT WITH PYRO, METOL AND ORTOL

35. ENLARGING NEGATIVES

36. LENS FACTS AND HELPS

37. FILM PHOTOGRAPHY

38. COLOR PHOTOGRAPHY

39. PHOTOGRAPHING ANIMALS

40. PLATINOTYPE MODIFICATIONS

41. COPYING METHODS

42. GENRE PHOTOGRAPHY

43. PHOTOGRAPHIC CHEMICALS OTHERS TO FOLLOW. Descriptive List on Application

TENNANT \& WARD

287 Fourth Avenue : : New York City 


THIS BOOK IS DUE ON THE LAST DATE STAMPED BELOW

RENEWED BOOKS ARE SUBJECT TO IMMEDIATE RECALL.

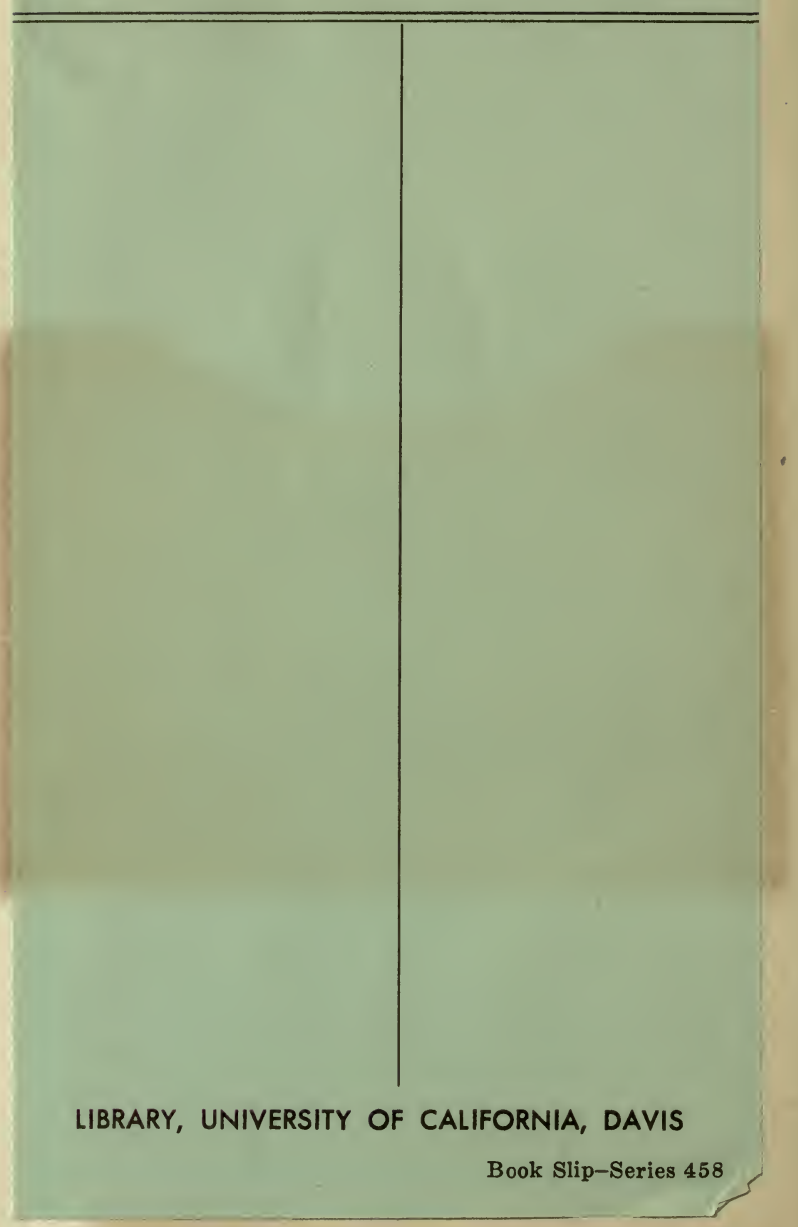




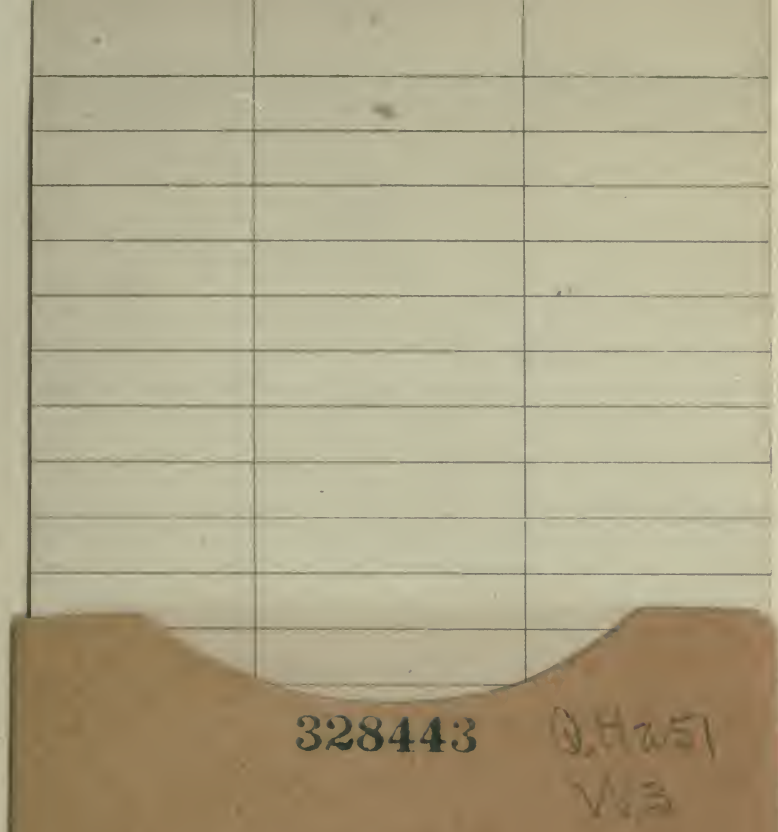

UNIVERSITY OF CALIFORNIA LIBRARY 
